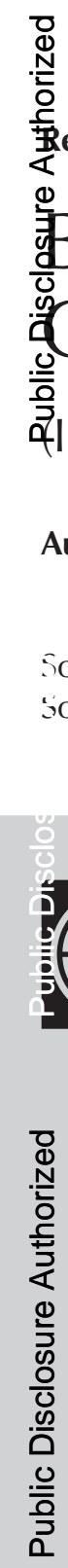

South Asia Environment and Social Development Unit south Asia Region 


\section{CURRENCY EQUIVALENTS}

US $\$ 1.00=$ Tk. 69.36 (Bangladesh Taka, August 2006)

\section{GOVERNMENT'S FISCAL YEAR}

July 1 - June 30

\section{ACRONYMS AND AbBREVIATIONS}

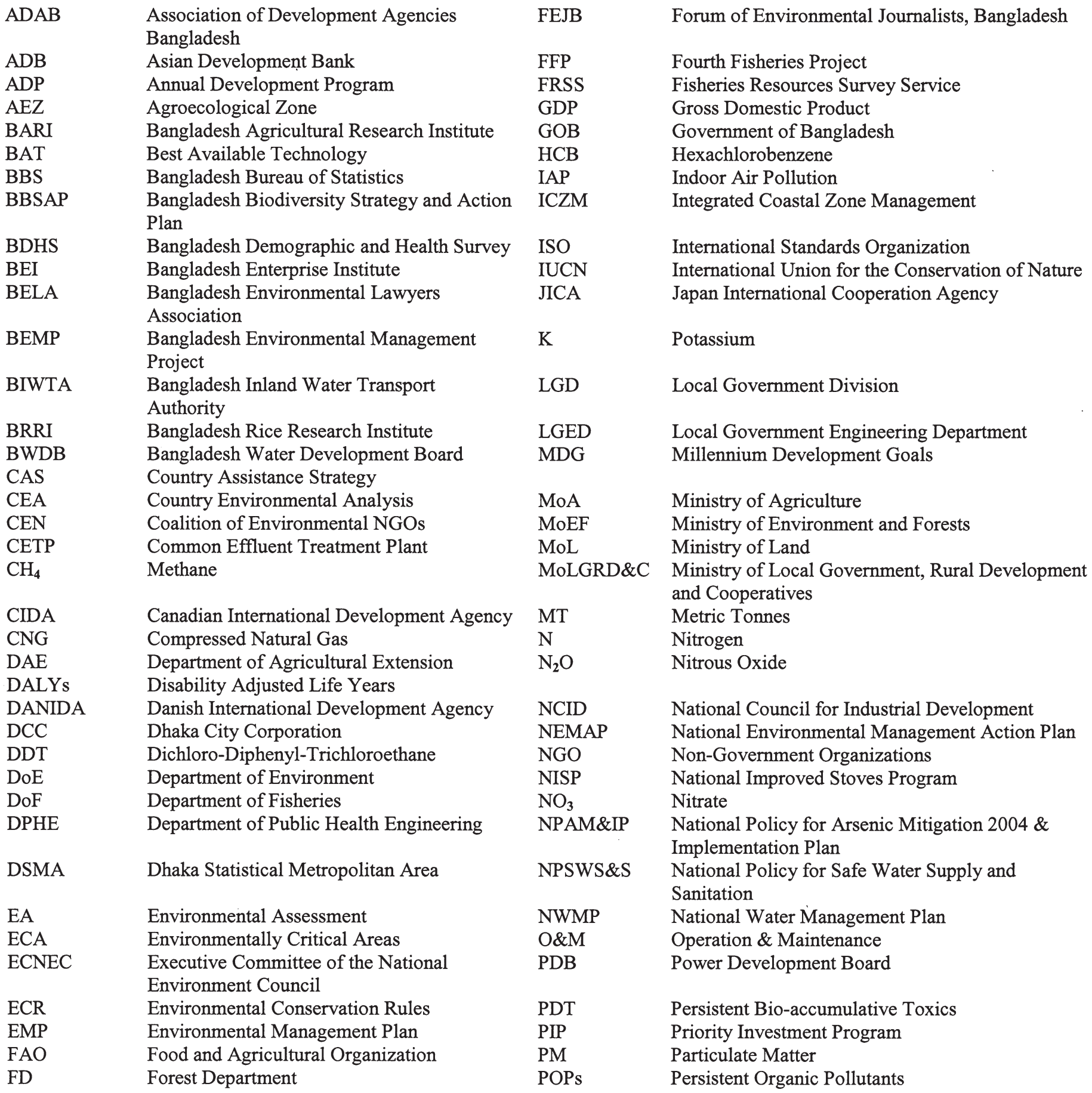




\section{TABLE OF CONTENTS}

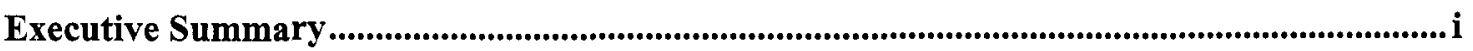

I. Environmental Management: a Key to Growth and Poverty Reduction ............................ i

II. Selecting Environmental Challenges for Analysis .........................................................ii

III. Environmental Priorities for Additional Action .............................................................. ii

IV. Environmental Risks to Health: a Major Contributor to the Burden of Disease ...............iii

V. Protecting Environmental Quality in Dhaka.................................................................

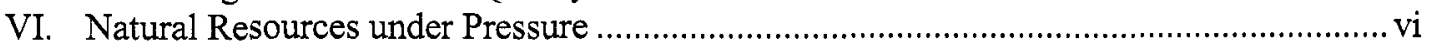

VII. Environmental Governance: An Over-Arching Agenda...............................................vii

VIII. Conclusion: Key Actions and World Bank Support ..................................................viii

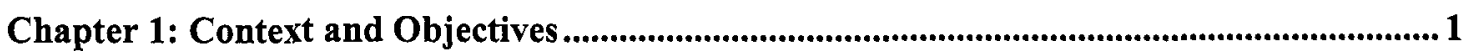

I. Environmental Challenges to Poverty Reduction.................................................... 1

II. The Response of the Government of Bangladesh and Development Partners ................... 3

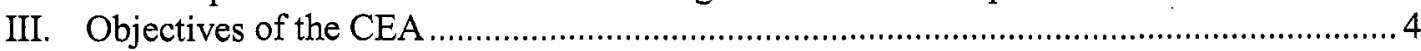

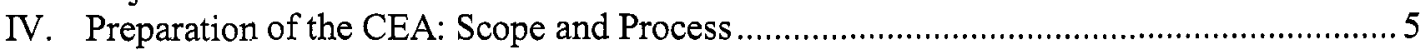

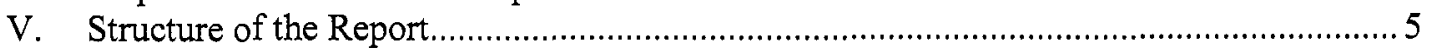

Chapter 2: Environmental Health........................................................................................................ 7

I. Environmental Health: Risk Factors and Costs .......................................................

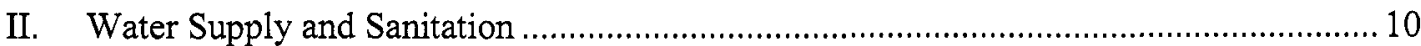

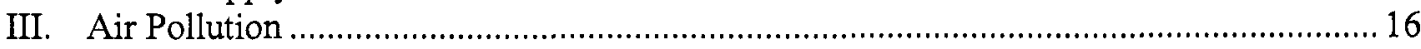

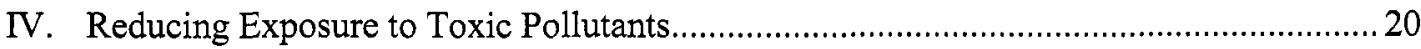

V. Environmental Health: Recommendations and Areas for World Bank Support ..............24

Chapter 3: Management of Water Quality in Dhaka .............................................................27

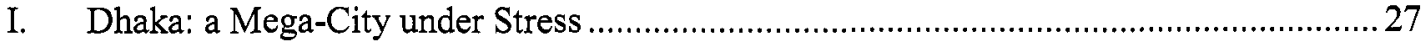

II. A Triple Threat: Contamination of the Air, Land and Water ......................................27

III. The Economic and Social Costs of Water Degradation.................................................28

IV. Policy and Institutional Factors Affecting Water Quality ............................................... 32

V. Responses to Water Quality Issues in the Dhaka Area ................................................... 34

V. Water Quality in Dhaka: Recommendations and Areas for World Bank Support ............ 39

Chapter 4: Management of Capture Fisheries.....................................................................4 41

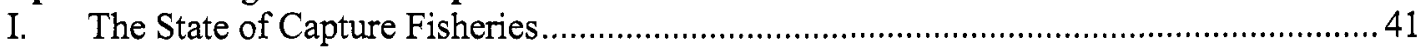

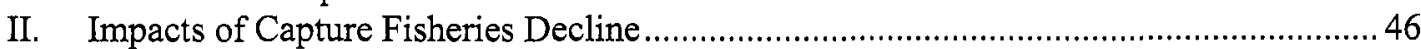

III. Policies and Institutions for Capture Fisheries Management …….................................. 48

IV. Capture Fisheries: Recommendations and Areas for World Bank Support......................50

Chapter 5: Sustaining Soil Quality...............................................................................................5 53

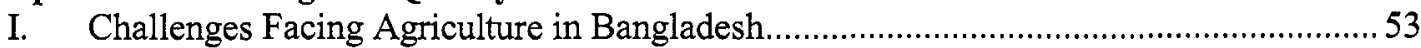

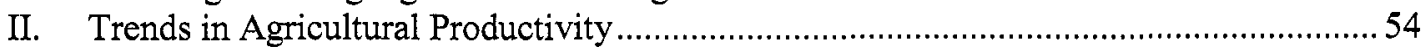

III. Evidence of Declining Soil Productivity and Soil Quality ..........................................57

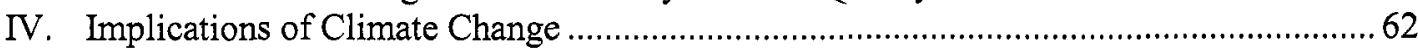

V. Sustaining Soil Quality: Recommendations and Areas for World Bank Support .............64 


\begin{tabular}{|c|c|c|c|}
\hline SRDI & Soil Research and Development Institute & UP & Union Parishads \\
\hline STEDs & Septic Tank Effluent Disposal Systems & WARPO & Water Resource Planning Organization \\
\hline PCB & Poly-Chlorinated Biphenyls & WASA & Water Supply and Sewerage Authority \\
\hline UDCC & $\begin{array}{l}\text { Upazila Development Coordination } \\
\text { Committee }\end{array}$ & WATSAN & Water Supply and Sanitation \\
\hline UNICEF & United Nations Children's Education Fund & WHO & World Health Organization \\
\hline UNO & Upazila Nirbahi Officer & WSSD & World Summit on Sustainable Development \\
\hline
\end{tabular}

\begin{tabular}{lll}
\hline Vice President & $:$ & Praful Patel, SARVP \\
Country Director & $:$ & Christine I. Wallich, SACBD \\
Sector Director & $:$ & Jeffrey S. Racki (Acting), SASES \\
Sector Manager & $:$ & Jeffrey S. Racki, SASES \\
Task Leader & $:$ & Paul Jonathan Martin, SASES
\end{tabular}




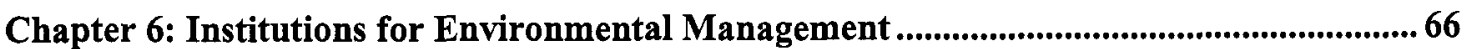

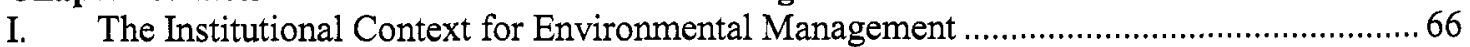

II. The Ministry of Environment and Forest: Custodian of the Environment .........................67

III. Environmental Management at Sub-National Levels ..................................................... 73

IV. Environmental Management in Other Sectors: Incentives and Coordination..................... 75

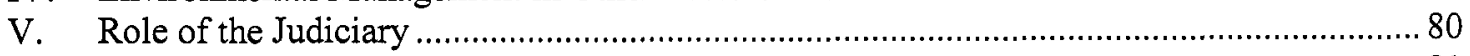

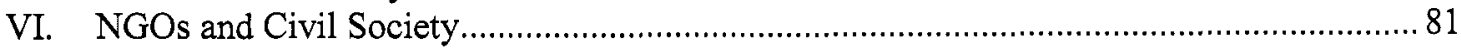

VII. Strengthening Institutions for Environmental Management: Recommendations and Areas for World Bank Support.......................................................................................... 81

Chapter 7: Environmental Constraints to Growth - Priorities for Additional Action........... 88

I. Environmental Risks to Health: the Need to Better Address Air Quality...........................89

II. Protecting Environmental Quality in Dhaka: a Focus on Water Quality ............................. 90

III. Natural Resources under Pressure: Protecting Capture Fisheries ....................................... 90

IV. Environmental Governance: an Over-Arching Concern ....................................................91

V. Priorities for Additional Action and World Bank Support ............................................... 92

\section{Appendices}

I. Dhaka Environment Programme: Prioritized Portfolio of Water Quality Solutions............. 94

II Organogram of the Department of Environment ...................................................................... 96

III. World Bank Country Assistance Strategy for Bangladesh FY06-09: Selected Products and

Key Environmental Management Outcomes .................................................................................... 97

\section{List of Boxes}

2.1 A Comparative Assessment of IAP in Bangladesh and India ...................................... 17

2.2 The Successfully Promotion of Improved Stoves in China............................................. 18

2.3 Persistent Bio-accumulative Toxics - Lead and Mercury Emissions in Bangladesh ......... 20

2.4 The Stockholm Convention on Persistent Organic Pollutants.......................................... 21

3.1 Responsibilities of Government Institutions Regarding Dhaka Air Quality ...................... 33

4.1 Saving the Hilsa - Showing It Can be Done.................................................................. 43

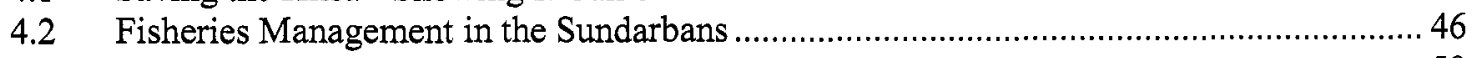

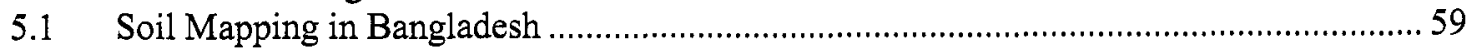

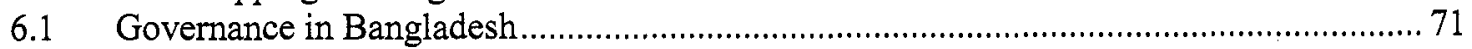

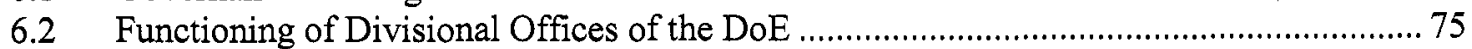

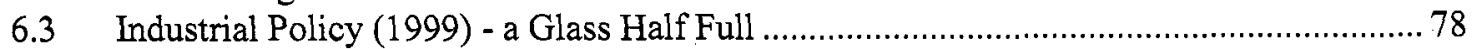

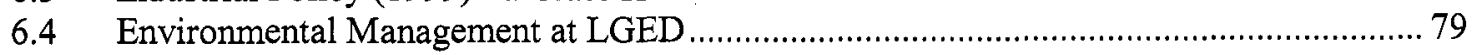

6.5 Catalyzing Cross-Sectoral Action - the Case of Diesel Emissions .................................. 80

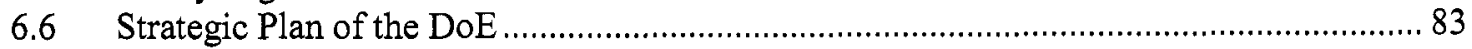

\section{List of Figures}

1 The Economic Costs of Environmental Degradation............................................................. V

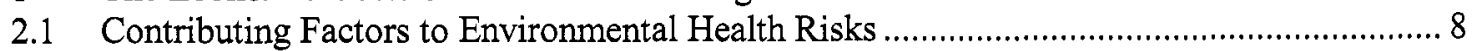

3.1 Pollution Hotspots in the Dhaka River and Canal System in the Dry Season ..................... 30

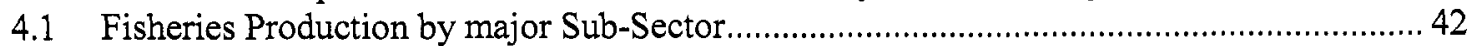

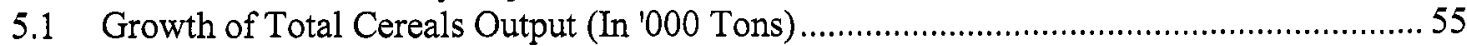

5.2 Production of Major Cereals in Bangladesh (1960-2004) ..............................................56

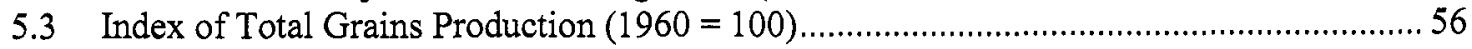

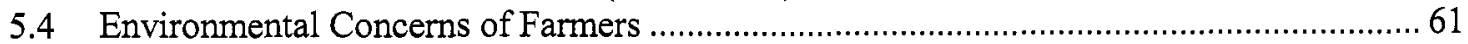

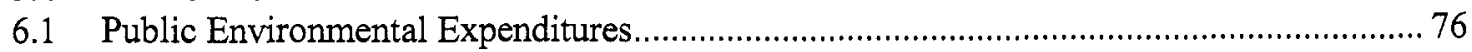

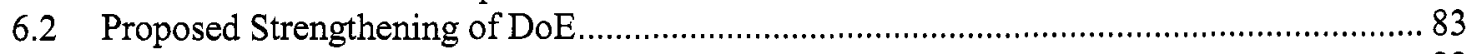

7.1 The Costs of Environmental Degradation.............................................................. 88 


\section{List of Tables}

2.1 Bangladesh: Share of Disability Adjusted Life years (DALYs) Lost by Cause and Environmental Contribution ....

2.2 Potential Reductions in Mortality and Morbidity, and Economic Savings by Reducing Exposure to Environmental Health Risks .... 9

3.1 Water Quality in the River and Canal System around Dhaka, 2003-2004........................... 31

3.2 River Committee Proposals for Water Resource Management in Dhaka ............................. 35

4.1 Estimated Physical and Financial Loss due to Declining Production.................................48

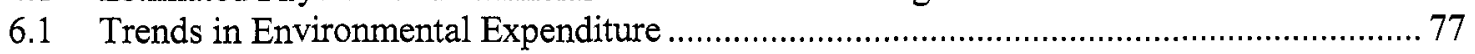

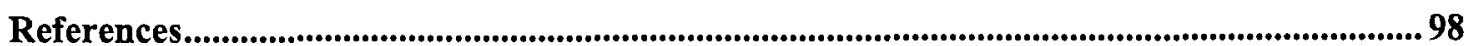

Volume II - Technical Annex:

Health Impacts of Air and Water Pollution in Bangladesh 


\section{ACKNOWLEDGEMENTS}

We would like to thank the staff of the Ministry of Environment and Forest for their guidance and support in the preparation of this report.

This report is the product of a team managed by Paul Martin and including Poonam Pillai, Sameer Akbar, Priti Kumar, William Collis, M. Khaliquzzaman, Bilqis Hoque, John Carter, Enamul Haque, John Gaunt, Anwarul Islam and Mainul Huq. Helpful advice and contributions were received from a number of colleagues across the World Bank including Richard Damania, Adriana Damianova, Susmita Dasgupta, Kseniya Lvovsky, David Meerbach, Khawaja Minnatullah, Mohinder Mudahar, Stefano Pagiola, S.A.M. Rafiquzzaman, Suphachol Suphachalasai and Ronald Zweig. Valuable guidance was provided by the peer reviewers, Carter Brandon, Anil Markandya and Ernesto Sanchez-Triana. Assistance with document preparation was provided by Vinod Ghosh.

The report was prepared under the overall guidance of Jeffrey Racki, Acting Director, South Asia Environment and Social Development Department, and Christine Wallich, Country Director for Bangladesh. 



\section{Executive Summary}

\section{Environmental Management: a Key to Growth and Poverty Reduction}

1. Bangladesh has achieved steady economic growth of almost $5 \%$ annually over the last decade, and while half the population still lives in poverty, this represents an improvement from $59 \%$ in 1990 . Bangladesh has also demonstrated significant success in achieving the human development targets of the Millennium Development Goals (MDGs). In making further progress towards poverty reduction and human development goals, however, environmental challenges to natural resource productivity and human health will become increasingly important.

2. Although the total burden of disease in Bangladesh is comparable to other South-East Asian countries with high mortality rates, the share attributable to respiratory infections and diarrhoeal disease, both associated with poor environmental conditions, is significantly higher. Environmental health risks are also increasing rapidly as a result of industrial growth, which is the fastest in South Asia, and urbanization, which is occurring at double the rate of India and Pakistan. Almost all future population growth, forecast to be some 100 million over the next fifty years, is expected to occur in urban areas, underlining the growing importance of addressing urban and industrial contamination.

3. With population density among the highest in the world, pressure on natural resources in Bangladesh is necessarily high. Two-thirds of the land area is under crops, the highest proportion in South Asia. Cropping intensity is also the highest in the region, having increased by $25 \%$ over the last thirty years, and surveys provide evidence that agricultural inputs are imbalanced and nutrient mining is occurring. The share of land area under forest cover is the second lowest in the region, with natural forest cover halving since the 1960's, and most natural forests now significantly degraded. Protected areas cover the smallest share of any country in South Asia, and pressure on wetlands and aquatic life is a particular concern. As detailed in the Country Water Resources Assistance Strategy, ${ }^{1}$ water quality and quantity are key determinants of outcomes in many sectors of the Bangladeshi economy, with both under pressure from industrial, urban and agricultural growth within the country and upstream. Bangladesh is highly vulnerable to the projected impacts of climate change, which will increase the already high risk of disasters, exacerbating existing vulnerabilities both to flooding and drought, and threatening agricultural productivity in coastal areas that face increasing salinity.

4. While emphasizing that economic growth is essential to reduce poverty, Bangladesh's National Strategy for Accelerated Poverty Reduction cautions that "A careful balancing act must be orchestrated where economic growth is maximised without compromising environmental protection...". The Strategy explicitly recognizes both the dependency of the poor on natural resources, and the vulnerability of the poor to environmental health risks. This Country Environmental Analysis (CEA) reinforces the message that the linkages in the balancing act work in both directions: not only can economic growth compromise environmental protection, but environmental degradation threatens

\footnotetext{
${ }^{1}$ World Bank, 2005

${ }^{2}$ National Strategy for Accelerated Poverty Reduction, 2005, Section 5.H
} 
economic growth. Together, the environmental impacts considered in this report account for economic losses equivalent to more than $4 \%$ of GDP, and these costs are felt most severely by the poor.

\section{Selecting Environmental Challenges for Analysis}

5. This CEA is intended to assist the Government, civil society and development partners of Bangladesh in identifying and addressing critical environmental constraints to sustainable, poverty-reducing growth. The initial set of issues chosen for analysis was selected jointly by the Ministry of Environment and Forest (MoEF) and the World Bank based on their relevance to growth and poverty reduction, as well as a consideration of the value of new analysis. These criteria led to a focus on five priority issues in the CEA, as follows:

- environmental risks to human health;

- protection of water quality in Dhaka;

- management of capture fisheries;

- sustaining soil quality; and

- strengthening institutions for environmental management.

These selected topics do not constitute an exhaustive list of environmental issues in Bangladesh. Urban environmental degradation, for example, extends beyond Dhaka; but with its population expected to grow fivefold in the next fifty years, the capital is clearly a priority, and provides lessons relevant to other cities. Similarly, natural resource concerns extend beyond the selected priorities of capture fisheries and soil quality, with forest management a prominent pending issue, as is adaptation to climate change.

6. Initial analyses of the selected issues were considered during a series of consultative discussions with key stakeholders, held in Dhaka in December, 2004. Subsequently, the draft CEA was discussed in July, 2005, at a workshop in Dhaka convened by MoEF, and inaugurated by the Minister of Environment and Forest. The final version of the CEA reflects the agreements reached during the workshop, and provides recommendations for more effective environmental management in each of the five selected priority areas.

\section{Environmental Priorities for Additional Action}

7. The estimated economic losses associated with the sources of environmental degradation selected for analysis in the CEA amount to more than $4 \%$ of GDP. The relative shares of the principal sources are indicated in Figure 1, below. Within the set of issues selected for analysis, a number of concerns are being addressed through initiatives that are already underway or planned, and a few pose risks that are relatively less pressing in the near term. The following three issues emerge, however, as priorities currently receiving insufficient attention given their relative significance:

- the threat of indoor and urban air pollution to human health;

- the need to better control urban and industrial effluent in Dhaka; and,

- the continuing decline of capture fisheries. 
The economic losses associated with these three environmental challenges may together amount to more than $2.7 \%$ of GDP, in each case with the poor suffering disproportionately as a result. In addition to targeting greater effort towards these three prionity concerns, the CEA also highlights the need to strengthen the institutional framework for environmental management through improvements in environmental governance.

8. This executive summary briefly summarizes the analysis and recommendations related to all five issues selected for consideration by the CEA, but focuses on the three prionity areas for greater attention listed above, as well as the over-arching need to strengthen environmental governance.

Figure 1: The Economic Costs of Environmental Degradation

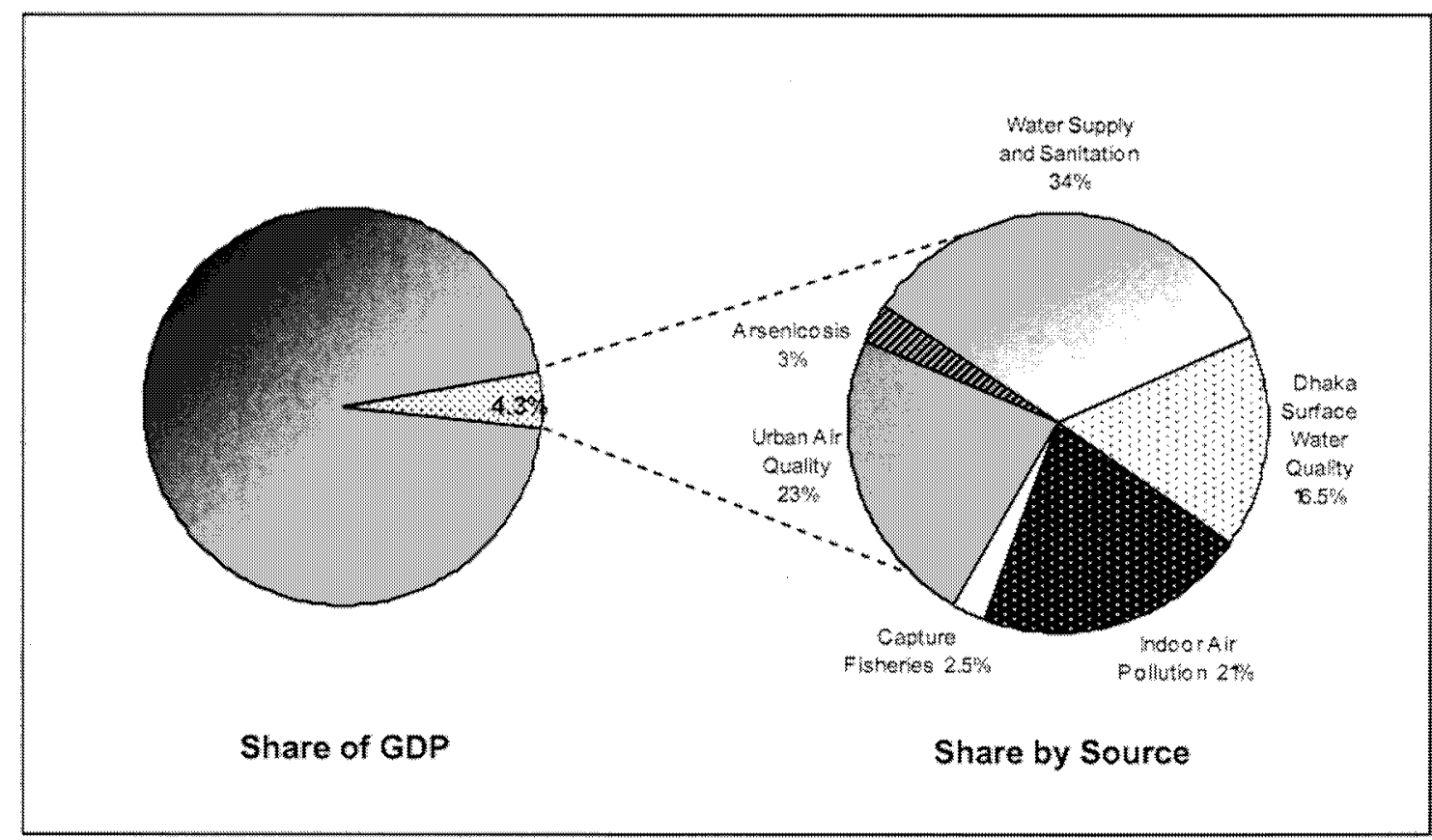

\section{Environmental Risks to Health: a Major Contributor to the Burden of Disease}

9. While the total burden of disease in Bangladesh is comparable to other low income Astan countries, the share attributable to respiratory infections and diarrhoeal disease is significantly higher. Both are associated with poor environmental conditions, highlighting the relatively greater importance of focusing attention on environmental quality in Bangladesh. This report estimates that environmental factors account for as much as $22 \%$ of the national burden of disease, principally in the form of respiratory infections and diarthoeal disease. Achievable goals for reduced exposure to envirommental health risks could result in economic savings equivalent to as much as $3.5 \%$ of GDP. This would be achieved by improving access to adequate sanitation and safe water supplies, better hygienic practices, reducing exposure to indoor and urban air pollution, and to a lesser extent by the better management of agro-industrial toxics. 


\section{Improving Air Quality}

10. Important efforts are underway to address a range of environmental health concerns in Bangladesh, in particular through the Total Sanitation Campaign and a variety of water supply initiatives. Indoor Air Pollution (IAP) remains almost entirely ignored, however, and urban air quality continues to deteriorate, despite a temporary improvement following the 2003 ban on two-stroke three-wheelers in Dhaka. This report estimates that the respiratory infections and disease caused by poor air quality, both indoor and urban, may contribute up to $10 \%$ of the total burden of disease, equivalent to the diarrhoeal disease caused by inadequate access to safe water, lack of sanitation and poor hygiene.

\section{Reducing Exposure to Indoor Air Pollution}

11. Inhaling smoke from burning biomass can have both temporary and permanent consequences for health, and recognition of the health impacts of LAP is growing worldwide. Poor households in Bangladesh depend heavily on wood, dung and other traditional fuels for cooking. As a result, the health impacts of IAP are significant, estimated to account for as much as $8 \%$ of the total burden of disease. Further evidence for concern is provided by a recent World Bank study, which detected dangerously high concentrations of particulates in indoor air for many poor households in Bangladesh. Particularly high levels of exposure to IAP were recorded for women and children under five.

12. Opportunities should be explored to integrate efforts for the mitigation of IAP into existing programs through the provision of both cleaner technologies and public information. Better ventilation and longer outdoor time for children may reduce IAP exposure, but achieving such behaviour change will require Government support for a public education effort explaining the health benefits. While support for cleaner fuel and cooking technologies may include a subsidy, at least in initial stages, the longer term goal should be to establish demand for the provision of such technologies by the private sector. The World Bank plans to provide further technical assistance to explore sustainable delivery models for the information and technology necessary to reduce exposure to IAP.

\section{Expanding Efforts to Manage Urban Air Quality}

13. Up to $10 \%$ of respiratory infections and disease in Bangladesh may be attributable to urban air pollution. While the problem is most severe in Dhaka, both because air quality is worse and more people are exposed, air pollution is a growing concern in other major cities. Measurements in Dhaka indicate that particulate matter is the most significant pollutant, and mobile sources remain the priority for emissions control. Unless there is a much stronger program of actions than at present, encompassing major secondary cities as well as Dhaka, urban air pollution will continue to worsen in line with the projected rapid rate of urbanization and rising incomes. Such actions should focus on gross diesel polluters, fuel quality, and the expansion of air quality monitoring both within the capital and to other cities. To help develop and implement such a program, the World Bank will continue to provide support for the Air Quality Management Project, and possibly a follow-up operation. 


\section{Protecting Environmental Quality in Dhaka}

14. The environment of the capital city faces the triple threat of air pollution, inadequate solid waste management, and contamination of surface water. While initiatives are underway to better manage air quality and solid waste, little has yet been done to improve water quality, identified as a priority for World Bank engagement in the Bangladesh Country Water Resources Assistance Strategy. ${ }^{3}$ The total economic cost of the poor management of water resources in Dhaka is estimated at US\$670 million annually, including impacts on human health, as well as industrial and natural resource productivity. Unless prompt action is taken, these costs will continue to rise in line with Dhaka's continuing rapid growth, which suggests that the city may double in population by 2015 , potentially making it the fourth largest city in the world. Given that economic activity in Dhaka contributes about one-fifth of the nation's GDP, environmental constraints to growth in the capital constitute a national priority.

\section{The Impacts of Deteriorating Water Quality}

15. Dhaka surface water is in very poor condition, especially in the dry season when dilution of contaminants is drastically reduced. There is only one sewage treatment plant at Pagla which is currently operating below capacity because of sewerage system failures, and few industries operate effluent treatment systems. Almost all the waste from humans, industry, and millions of farm animals, along with tonnes of pesticides and fertilizers, make their way into Dhaka's surface water untreated. As a result, many sections of the rivers and canals in the city and surrounding areas are biologically dead during the dry season, with most of this water unfit for any human use and likely to be dangerous to livestock. A particular concern in the dry season is the high level of ammonia in the raw water used by the Saidabad Water Treatment Plant, threatening the plant's ability to treat water to drinking quality standards. All Dhaka residents are impacted to some extent by deteriorating water quality, but the most vulnerable are the poor, who have few options for accessing clean water and little ability to move away from offensive locations next to polluted ponds, canals, and rivers.

\section{Improving Water Quality: a Strategic Framework and Promoting Compliance}

16. Interventions to improve the quality of surface water in Dhaka need to fit within an integrated strategy addressing water quality and supply, sanitation, and flood management, all as part of the broader urban planning framework. Poor environmental quality cannot be addressed by environmental authorities alone, but will require cross-sectoral coordination. An important element of the strategic framework will also be public provision of information to raise awareness of the causes and impacts of poor water quality, and to build support for the necessary investments and regulatory enforcement. Industrial discharges must be reduced if surface water quality is to be improved, which will require stricter enforcement of environmental clearance conditions and effluent standards. Greater regulatory and societal pressure will also stimulate demand for low cost waste minimization initiatives, which could be provided as part of a broader program of compliance promotion.

\footnotetext{
${ }^{3}$ World Bank, 2005
} 


\section{Investing in Waste Treatment}

17. Improving the quality of surface water in and around Dhaka will require significant public and private investment. The rehabilitation of the existing sewerage and drainage system is alone projected to cost about US\$100 million. Attracting private resources will require predictable and transparent enforcement, as well as the recovery of costs for urban services. In response to the Government's request, the Bank is helping prepare a project to improve water supply, sewerage, sanitation and storm water drainage services in Dhaka. A proposed separate initiative to strengthen the management of water resources will supplement these investments with support for low cost solutions targeting industrial effluent. Environmental compliance initiatives will form components of both these projects, as well planned support for private sector development.

\section{Natural Resources under Pressure}

18. With population density among the highest in the world, pressure on natural resources in Bangladesh is necessarily high. Two-thirds of the land area is under crops, the highest proportion in South Asia, and the share under forest cover is the second lowest in the region. Deforestation in the 1980's averaged 3.3\% per year, and in 1989 the Government issued a moratorium on felling in natural forests which continues to date. Official figures indicate a net rate of reforestation of about $1 \%$ annually during the 1990 's, but the major areas of natural forest remain significantly degraded. Protected areas cover the smallest share of any country in South Asia, although pressure on biodiversity is close to the regional average, with approximately $17 \%$ of mammal species and $4 \%$ of bird species under threat.

19. Agriculture accounts for some $21 \%$ of GDP, and the ability of soil to sustain agricultural production is an issue of national concern. Declines in rice yields in some areas of Bangladesh in the mid-1990s led to a decline in soil productivity being inferred. Analysis of more recent data indicates, however, that yield trends are stable or increasing, and that earlier assessments were influenced by a period in which yields were below trend. Consequently it does not appear that agricultural production is declining as a result of a reduction in soil productivity. There remain causes for concern, however, including evidence that fertilizer inputs are imbalanced and nutrient mining is occurring, which suggest that greater attention to the monitoring of soil quality is warranted.

\section{Capture Fisheries: the Threat of Collapse}

20. Bangladesh's fisheries are estimated to provide two-thirds of the country's animal protein needs, which is twice the regional average and the seventh highest in the world. Capture fisheries and associated wetlands play a particularly important role in the nutrition and welfare of the poor. There is general consensus, however, that inland and coastal capture fisheries are in decline. Threats include losses of floodplain habitat due to agriculture and urbanization, lost connections along critical fish migration pathways, significant reductions in dry season river flows, over-fishing, and rapidly increasing industrial, human and agricultural pollution. Almost $30 \%$ of all inland fish species are in some danger of extinction, and there is a fear that the inland major carps, Indian Salmon and other coastal inshore fisheries, may be in danger of collapse. The consequences of a collapse would impact every citizen, but in particular the poor. 


\section{Reversing the Decline}

21. As with all biological systems, recovery of the capture fisheries is possible if political will combines with good management. By late 2004 a remarkable recovery of Hilsa was seen, most likely as a result of Government management activities. The actions needed to reverse the decline of Bangladesh's capture fisheries are reasonably clear, and a framework for their implementation is provided by the Government's draft Inland Capture Fisheries Strategy. Within this framework, the key priorities to ensure the sustainable productivity of capture fisheries are (i) protecting dry season water flows; (ii) establishing both large and small sanctuaries; (iii) developing and implementing fisheries management regulations; (iv) adoption of an Integrated Coastal Resource Management framework; (v) enhanced monitoring of fisheries; and (vi) reduced barriers to the import of fish. The development of this strategy was supported by the World Bank through the Aquatic Biodiversity Conservation Project and the Fourth Fisheries Project, and the Bank is prepared to provide further assistance to support implementation of the strategy and to strengthen community management of fisheries. The Bank is also prepared to support the development of a strategic action plan for the management of marine and coastal resources in the Bay of Bengal, for which an ecosystem approach would be adopted to foster regional collaboration in addressing the transboundary issues.

\section{Environmental Governance: An Over-Arching Agenda}

22. Across all of the issues examined in the CEA, an over-arching theme that emerges is the need to improve environmental governance to strengthen incentives for behaviour and investments that lead to better environmental quality. The most important governance elements to support such incentives are access to environmental information, transparency and consultation for accountable decision-making, adequate institutional capacity for credible enforcement, and economic policies that promote improved environmental performance.

\section{Access to Environmental Information and Awareness of Environmental Risks}

23. The current paucity of environmental information and understanding in Bangladesh constrains decision-making at all levels. At the household level, for example, greater awareness of the risks of indoor air pollution could significantly reduce exposure through simple changes in behaviour. Nationally, the sustainable management of capture fisheries requires information on necessary dry season flows, and the monitoring of soil productivity depends on the development of appropriate indicators of soil quality. Greater access to environmental information and understanding of the impacts of degradation will also create demand for environmental investments. Public investment in the necessary infrastructure to protect water quality around Dhaka will require strong civil society support, based on an understanding of the costs of inaction. Private investment to control pollution will require public pressure for compliance, based on information regarding sources of pollution and their performance.

\section{Transparency and Consultation for Accountable Decision-Making}

24. Transparency and public consultation are essential elements of environmental decision-making, strengthening the accountability of environmental institutions and thereby building their credibility. There is considerable scope to introduce greater transparency and 
broaden consultation in environmental management in Bangladesh, not least in the core function of reviewing Environmental Assessments (EAs). At the local level, for example, the issuance of No Objection Certificates could be subject to consideration by an open meeting of the Union Parishad, and at the national level all EA information should be publicly available, with high-risk projects presented for public review.

\section{Institutional Capacity for Credible Enforcement: Strengthening the Role of the DoE}

25. As the credible threat of regulatory enforcement is central to environmental governance, so too is the establishment of the institutional capacity to deliver such enforcement. For this reason, implementation of the Department of Environment's (DoE's) Strategic Plan is essential to strengthen environmental governance in Bangladesh, as it will provide the DoE with the resources and incentives it needs to fulfil its mandate. Despite its critical and wide-reaching mandate, the DoE currently receives less than $1 \%$ of MoEF's annual budget, which itself is less than $0.5 \%$ of the Government's total revenue and development budget. In addition to a significant increase in resources, a key element of the Strategic Plan is the creation of civil service cadre positions for DoE staff, which will do much to improve the quality of applicants and strengthen incentives for staff performance. Implementation of the Strategic Plan will also allow the DoE to bring more environmental cases to court, which is essential to build the credibility of the Government's environmental intentions. Stronger environmental enforcement capacity is also necessary outside the DoE, particularly for sustainable management of natural resources. The recent success of the Department of Fisheries in protecting the hilsa, for example, serves to demonstrate the potential effectiveness of regulatory enforcement in ensuring the long-term productivity of the nation's capture fisheries.

\section{Economic Policies and Incentives for Improved Environmental Performance}

26. While information and regulatory enforcement help establish incentives for improvements in environmental quality, these are most effective when combined with supportive economic policies. For example, the reduction of duties and other barriers on the import of fish would increase supplies, and thereby reduce the intensity of the exploitation of Bangladesh's capture fisheries. An important element in the battle to curb urban air pollution will be to ensure that the sulphur content of imported diesel is reduced to $500 \mathrm{ppm}$, reflecting the economic cost of the health damage caused by lower quality fuel. Economic incentives can also be used to complement regulatory approaches to improve environmental management. In the case of industry, there is scope for this to be achieved through the promotion of waste-minimization and eco-labelling initiatives. While this would primarily attract export-orientated businesses, particularly in the garment manufacturing and aquaculture sectors, consideration could also be given to the promotion of an eco-label for the domestic market.

\section{Conclusion: Key Actions and World Bank Support}

27. The economic losses resulting from the environmental impacts considered in this report are equivalent to more than $4 \%$ of Bangladesh's GDP. Among these impacts, three sources of environmental degradation stand out as currently receiving insufficient attention given their relative significance: (i) indoor and urban air pollution, (ii) the degradation of water quality in Dhaka, and (iii) the decline of capture fisheries. The economic losses 
associated with these three concerns alone may amount to more than $2.7 \%$ of GDP. The report proposes a set of actions in each of these areas, and also identifies a series of measures that could be taken to strengthen environmental governance, which forms an overarching constraint to improved environmental management across all issues. While the report estimates the economic losses associated with the environmental impacts considered, it does not provide a benefit-cost or cost-effectiveness analysis of the proposed mitigating actions. It will be important to examine the costs of the proposed actions in more detail as an element of the follow-up work in each of the priority areas. The proposed actions are summarized below, with an indication of potential World Bank support in each area.

\section{Reducing Exposure to Air Pollution}

28. Key actions to reduce exposure to indoor and urban air pollution include:

- Integrate the mitigation of IAP into existing energy and public health programs through the provision of both cleaner technologies and public information;

- Support a public education effort on IAP explaining the health benefits of better ventilation and longer outdoor time for children;

- Promote cleaner fuel and cooking technologies, with the aim of establishing demand for private sector provision of such technologies in the longer term;

- Expand urban air quality management activities, focusing on gross diesel polluters, fuel quality, and the extension of air quality monitoring within Dhaka and to other cities.

The World Bank plans to provide technical assistance to explore sustainable delivery models for the information and technology necessary to reduce exposure to IAP. The Bank will also continue to provide support for the Air Quality Management Project, and possibly a followup operation to expand urban air quality management activities.

\section{Improving Water Quality in Dhaka}

29. Key actions to improve water quality in Dhaka include:

- Develop an integrated framework to address water quality and supply, sanitation, and flood management in Dhaka;

- Provide public information to raise awareness of the causes and impacts of poor water quality;

- Support stricter enforcement of environmental clearance conditions and effluent standards;

- Provide technical assistance for low cost waste minimization initiatives, as part of a broader program of compliance promotion; and

- Invest in water supply, sewerage, sanitation and storm water drainage services, as well as low cost solutions targeting industrial effluent.

The Bank is preparing to support investments in water supply, sewerage, sanitation and storm water drainage services in Dhaka. A proposed separate operation to strengthen the 
management of water resources would supplement these investments with support for appropriate industrial effluent treatment technologies, as well as environmental compliance initiatives. This support will draw on planned analytical work and technical assistance to identify policies for more effective management of industrial pollution and the promotion of cleaner production in the Greater Dhaka area.

\section{Reversing the Decline of Capture Fisheries}

30. Key actions to reverse the decline of capture fisheries include:

- Establish and ensure minimum dry season water flow requirements for capture fisheries.

- Establish both large and small scale sanctuaries for protection of capture fisheries.

- Develop and implement fisheries management regulations.

- Adopt an Integrated Coastal Resource Management framework.

- Enhance monitoring of capture fisheries.

- Reduce barriers to the import of fish.

The Aquatic Biodiversity Conservation Project (closed in 2005) and the Fourth Fisheries Project (closing in 2006) were supported by the World Bank, and among other achievements led to the development of the Government's draft inland capture fisheries strategy. The Bank is prepared to provide further assistance to support the implementation of this strategy and to strengthen community management of fisheries. In addition, the Bank is also prepared to support regional collaboration to develop a strategic action plan for the management of marine and coastal resources in the Bay of Bengal.

\section{Strengthening Environmental Governance}

31. Key actions to strengthen environmental governance include:

- Implement DoE's Strategic Plan.

- Create cadre positions for DoE staff.

- Make environmental assessments and information related to the environmental clearance process publicly available, including through the internet.

- Mandate public consultation on environmental assessments of high risk projects.

- Require consideration of No Objection Certificates at open meetings of Union Parishads.

- Delegate responsibility for environmental clearance of less polluting facilities to local authorities.

- Publish a national environmental scorecard annually.

- Publish the environmental performance of selected high-priority industrial facilities.

- Provide DoE with legal assistance in bringing environmental cases to court. 
Given the availability of technical assistance resources for $\mathrm{DoE}$, the most important role for the World Bank will be to help address the revenue budget implications of the Department's Strategic Plan through the Bank's dialogue with the Ministry of Finance and the ongoing program of development policy lending. The need to implement the DoE's Strategic Plan is reflected in the policy matrix for the series of Development Support Credits supported by the World Bank, and will continue to be incorporated in future development policy lending discussions. World Bank support for the strengthening of local government provides an additional avenue to increase consultation and accountability for environmental decisionmaking at this level.

32. The technical assistance, investment and budget support operations discussed above are reflected in the World Bank's Country Assistance Strategy (CAS) for the period FY0609. Appendix III provides a summary of the key products, and indicates the principal environmental management outcomes associated with each. Such initiatives will complement the investment support and technical assistance being provided by other development partners to strengthen environmental management in Bangladesh.

33. The Government's strong commitment to the MDGs is reflected in the National Strategy for Accelerated Poverty Reduction, and achievement of two of the MDGs in particular is closely dependent on improvements in environmental management. Meeting the target for reduction in child mortality under Goal 4 will require continued reductions in environmental health risks, particularly those leading to respiratory infections and diarrhea, which together account for about a quarter of under-five deaths. Meeting the targets to ensure environmental sustainability under Goal 7 will require renewed effort to strengthen environmental governance, reverse the loss of natural resources, and reverse the degradation of urban environmental quality. While the Government has made important strides towards these targets, this report highlights a number of sources of environmental degradation that merit greater emphasis. Initiatives to undertake the key actions summarized above will not only bring Bangladesh closer to achieving its targets under the MDGs, but will significantly contribute to the removal of environmental constraints to poverty-reducing growth. 



\section{Chapter 1: Context and Objectives}

\section{Environmental Challenges to Poverty Reduction}

1. Despite poor initial conditions, a widespread perception of poor governance, confrontational politics, and vulnerability to natural disasters, Bangladesh has achieved steady economic growth of 4-5\% annually over the last decade. At the same time, annual population growth has been reduced from $2.5 \%$ in the 1980 s to $1.7 \%$ since 1990 . As a result, annual per capita GDP growth has increased from $1.6 \%$ in the 1980 s to $3.7 \%$ in 2004 , although this is still below the regional average of $5.0 \%$. While half the population still lives in poverty, this represents an improvement from $59 \%$ in 1990, and with the country selfsufficient in food grains, food security has also improved, even for the very poor.

2. Bangladesh has also demonstrated significant success in achieving the human development targets of the Millennium Development Goals (MDGs). Primary school enrolment has risen to $98 \%$, with enrolment rates now slightly higher for girls than boys. By 2000 , infant and child mortality rates had been significantly reduced to 30 and 60 per thousand live births, respectively. With the second lowest infant mortality rate and third lowest child mortality rate in the South Asia Region, Bangladesh is set to meet the MDG target of a two-thirds reduction by 2015 over 1990 levels. In reaching this target, however, and in making further progress towards other poverty reduction and human development goals, over-coming environmental challenges to human health and natural resource productivity will become increasingly important.

3. The linkages between environmental degradation and poverty are explicitly recognized in Bangladesh's National Strategy for Accelerated Poverty Reduction, which emphasizes both the dependency of the poor on natural resources, and the vulnerability of the poor to environmental health risks. The Strategy highlights a number of natural resource issues as being of particular concern to the poor, including the degradation of agricultural land, and the unsustainable use of common resources such as fisheries. Among the environmental health risks to which the poor are exposed, the Strategy identifies both indoor and outdoor air pollution, drinking water contaminated bacteriologically and with naturallyoccurring arsenic, as well as a growing burden of toxic waste from urban, industrial and agricultural sources. While recognizing that economic growth is essential to reduce poverty, the Strategy cautions that "A careful balancing act must be orchestrated where economic growth is maximised without compromising environmental protection...".

\section{Environmental Health Risks: a Major Contributor to the Burden of Disease}

4. While the total burden of disease in Bangladesh is comparable to other South-East Asian countries with high mortality rates, the share attributable to respiratory infections and disease is about one third higher than the average for these countries, and the proportion caused by diarrhoeal disease is almost double the average. Since both are associated with poor environmental conditions, the relatively higher prevalence of respiratory infections and diarrhoeal disease highlights the importance of focusing attention on environmental quality in Bangladesh. In addition to these traditional environmental health risks, Bangladesh is also

\footnotetext{
${ }^{4}$ National Strategy for Accelerated Poverty Reduction, 2005, Section 5.H
} 
faced with rapidly increasing industrial and urban environmental health risks. Not only is Bangladesh experiencing the fastest industrial growth rate in South Asia, but the rate of urbanization between 1990 and 2000 was double that of India and Pakistan, and the share of the urban population living in slum conditions is the second highest in the region. Almost all future population growth, forecast to be some 100 million over the next fifty years, is expected to occur in urban areas, underlining the importance of addressing urban and industrial contamination. This report estimates that environmental health risks may account for as much as $22 \%$ of the total burden of disease in Bangladesh.

\section{Natural Resource Productivity under Threat}

5. With population density approaching one thousand people per square kilometre, among the highest in the world, and growing at $1.7 \%$ annually, pressure on natural resources in Bangladesh is necessarily high. Two-thirds of the land area is under crops, the highest proportion in South Asia, and the share under forest cover is the second lowest in the region. Protected areas cover the smallest share of any country in South Asia, at less than $0.5 \%$ of the total area compared with an average of nearly $8 \%$ for Asia as whole, although pressure on biodiversity is close to the regional average, with approximately $17 \%$ of mammal species and $4 \%$ of bird species under threat. Pressure on wetlands and aquatic life is a particular concern in Bangladesh, as booming urban and industrial growth leads to land reclamation and pollution, and fishing effort increases to meet growing demand, with fish continuing to provide more than half the animal protein in the national diet.

6. Agriculture accounts for some $23 \%$ of GDP and more than half of total employment, so the ability of soil to sustain agricultural production is an issue of national concern. Cropping intensity in Bangladesh is the highest in South Asia, having increased from below $140 \%$ to more than $175 \%$ over the last thirty years ${ }^{5}$ as the introduction of short duration cereal varieties and winter irrigation facilitated double- and triple-cropping. Pressure on agricultural land is further intensified by urbanization and infrastructure development, as a result of which the cropped area is declining at about $1 \%$ annually. To support this intensity of cultivation, rates of fertiliser application are the highest in the region; ${ }^{6}$ nevertheless, surveys and soil tests provide evidence that agricultural inputs are imbalanced and nutrient mining is occurring.

7. Bangladesh has limited natural forest cover, at about $10 \%$ of land area, down from $20 \%$ in the 1960s. Large areas of the Chittagong Hill Tracts have been degraded, the Sundarbans mangrove forest is in decline, and most parts of the plain land Sal forest are now shrub lands. The deforestation rate in the 1980's was 3.3\% per year, but in 1989 the Government issued a moratorium on felling in natural forests which continues to date. As a result of this ban and social forestry initiatives, official figures indicate a net rate of reforestation of about $1 \%$ annually during the 1990's. The moratorium also stimulated private sector timber production, which now accounts for over $80 \%$ of local timber marketed in Bangladesh, and satellite imagery suggests as much as $35 \%$ of land area has $10 \%$ or more tree cover of all types, including private plantations.

\footnotetext{
${ }^{5}$ Bangladesh Bureau of Statistics. Cropping intensity calculated as gross sown area divided by the cultivated area.

${ }^{6} \mathrm{FAO}, 2001$. Measured as kilograms of nitrogen, potash and phosphate per hectare of cropland.
} 
8. As detailed in the Country Water Resources Assistance Strategy, ${ }^{7}$ water quality and quantity are key determinants of outcomes in many sectors of the Bangladeshi economy, from industry and transport, through agriculture and fisheries, to human health. About $80 \%$ of renewable water is received from transboundary inflows, and as the lower riparian, Bangladesh is impacted by upstream diversions and abstractions that reduce water availability during the dry winter months, and by upstream discharges and runoff that degrade the quality of water entering the country. Water quality and dry season flows are further impaired by industrial growth and urbanization within Bangladesh, with particularly significant impacts on fisheries, inland water transport and drinking water supply.

\section{Vulnerability to Climate change}

9. Bangladesh is highly vulnerable to the projected impacts of climate change, as these are likely to increase the already high risk of disasters, and exacerbate existing vulnerabilities. Global warming will cause changes such as higher temperatures, sea level rise and changing rainfall patterns, as well as more abrupt effects, such as an increase in the intensity and frequency of extreme events such as floods, storm surges and cyclones. An increase of one degree centigrade in ocean temperature could increase tropical cyclone intensity by as much as $10 \%,{ }^{8}$ while temperature alterations associated with climate change are already affecting the rate of snowmelt in the Himalayas, which is expected to lead to increased flooding. It is predicted that by the year 2030 , an additional $14 \%$ of the country will become extremely vulnerable to floods, and currently vulnerable areas will experience higher levels of flooding. Indeed, significant areas may be permanently inundated. ${ }^{9}$ At the same time, some areas of the country may be at greater risk of drought and food insecurity during the dry season, and agricultural productivity in coastal areas may be compromised by increasing salinity. While climate change does not form a focus of this report, the scope and scale of Bangladesh's vulnerability to climate change demand that assessment of the associated risks and planning for adaptation remain a priority for further work, building on the recently completed National Adaptation Programme of Action. ${ }^{10}$

\section{The Response of the Government of Bangladesh and Development Partners}

10. The need to protect the quality of the environment has been recognized since the birth of Bangladesh, with the Water Pollution Control and Wildlife Preservation Acts being established in 1973, shortly followed by the Environmental Pollution Control Ordinance. It was not until 1989, however, that a separate Ministry dealing exclusively with environment was created, drawing together the Forest Department from the Ministry of Agriculture, and the Department of Environmental Pollution Control (renamed the Department of Environment) from the Local Government Division.

11. Following the creation of the Ministry of Environment and Forests (MoEF), the Government took a number of important policy steps to guide the strengthening of environmental management, starting with the development of the National Conservation Strategy in 1991, and shortly followed by the adoption of National Environment Policy in 1992, the National Forest Policy in 1994, and the National Environment Management Action

\footnotetext{
${ }^{7}$ World Bank, 2005

${ }^{8}$ World Bank, 2000

${ }^{9}$ BCAS and DoE, 2001

${ }^{10} \mathrm{MoEF}, 2005$.
} 
Plan (NEMAP) in 1995. At the same time, the need to broaden the institutional framework for environmental management was recognised, leading to the creation of the National Environment Council in 1993, which is headed by the Prime Minister and is designed to provide guidance on environmental issues to line Ministries.

12. Building on these policy and institutional foundations, an enabling legal framework was created, anchored in the Environmental Conservation Act of 1995, and elaborated in the Environmental Conservation Rules of 1997. Mechanisms for enforcement of these provisions were strengthened through the Environment Court Act of 2000, and have since been clarified through a series of amendments to the Environmental Conservation Act and Rules. Following the development of the NEMAP, the late 1990's also saw concerted efforts by development partners to prepare a series of operations designed to support the strengthening of environmental management in Bangladesh. Among the larger donorsupported initiatives implemented by MoEF were the Sustainable Environment Management Programme supported by UNDP, the Sundarbans Biodiversity Conservation Project supported by ADB, the Bangladesh Environmental Management Project Supported by CIDA, and the Air Quality Management Project supported by the World Bank. As in other areas of Bangladeshi public life, civil society has also exerted an important influence on environmental decision-making, with a range of NGOs now actively addressing both 'green' and 'brown' environmental issues.

\section{Objectives of the Country Environmental Analysis}

13. The Government of Bangladesh's commitment to the MDGs requires it to take action to address a range of environmental challenges, in particular to reduce environmental health risks and to ensure the environmental sustainability of economic growth. As described above, significant progress has been made in establishing the policy, institutional and legal framework necessary to strengthen environmental management, and a number of initiatives have been successfully implemented, such as the elimination of leaded gasoline, the phasingout of two-stroke three-wheelers from the streets of Dhaka, and the ban on thin polythene bags. More broadly, however, practice lags behind the Government's good environmental intentions.

14. The Country Environmental Analysis (CEA) is intended to support the Government in more effectively addressing the environmental challenges to poverty-reducing growth. The process of developing the CEA helped promote recognition in the National Strategy for Accelerated Poverty Reduction of the linkages between environmental degradation and poverty. Building on this recognition, the objective of the CEA is to help reduce environmental constraints to economic growth by recommending measures to (i) reduce the environmental health risks borne by the poor, and (ii) promote more sustainable management of the natural resources on which the poor depend. As well as informing Government decision-making, these recommendations are designed to guide the support provided by development partners, including the World Bank's program of technical assistance, investment operations, and development policy lending. 


\section{Preparation of the CEA: Scope and Process}

15. The CEA was jointly developed by MoEF and the World Bank, beginning with a review of environmental priorities for poverty-reducing growth. Based on this initial scoping exercise, it was agreed that the CEA should focus on the following five priority areas:

- environmental health;

- surface water quality in Dhaka;

- capture fisheries;

- soil quality; and

- institutions for environmental management.

The selection of these priority environmental concerns was based not only on their relevance to poverty reduction, but also considered the additional value of further analysis, and the scope for subsequent action. Regarding the management of forest resources, for example, a Forestry Sector Review was recently completed ${ }^{11}$, and while state-owned forests are locally important for poverty reduction, about $80 \%$ of local timber marketed in Bangladesh originates from village or private lands rather than Government forests ${ }^{12}$, a fact reflected in satellite imagery showing forest cover to be four times that of official statistics. ${ }^{13}$

16. An initial analysis of existing and proposed policies as these affect the identified environmental priorities, and an assessment of the institutional capacity for environmental management in these areas, was discussed during a series of consultative discussions with key stakeholders, held in Dhaka in December, 2004. The analysis was refined based on these discussions, and the draft CEA was discussed in July, 2005, at a workshop in Dhaka convened by MoEF, and inaugurated by the Minister of Environment and Forest. The workshop was extremely valuable in framing the final version of the CEA, which reflects the recommendations arising from the working sessions.

\section{Structure of the Report}

17. The following chapters of this report present the analysis of the policy and institutional factors affecting management of the five priority environmental concerns selected in scoping the CEA, as follows:

- Chapter 2 - Environmental Health;

- Chapter 3 - Management of Water Quality in Dhaka;

- Chapter 4 - Management of Capture Fisheries;

- Chapter 5 - Sustaining Soil Quality;

- Chapter 6 - Institutions for Environmental Management ;

- Chapter 7 - Environmental Constraints to Growth: Priorities for Additional Action.

\footnotetext{
${ }^{11}$ Bangladesh Forest Department, The Forestry Sector Review Report, 2004

${ }^{12}$ Intercooperation, Review of Wood Marketing in Bangladesh, June 2002.

${ }^{13}$ World Resources Institute, 2005. The difference between official statistics and satellite imagery of forest cover for Bangladesh is twice the average for Asia.
} 
Each chapter concludes with recommendations for action by key stakeholders to strengthen environmental management. Priority areas for future World Bank support are identified in the final chapter, based on an assessment of the constraints to growth and poverty reduction imposed by the selected sources of environmental degradation, as well as consideration of the coverage of current initiatives to strengthen environmental management. 


\section{Chapter 2: Environmental Health}

18. Since being launched in 2000, the Millennium Development Goals (MDGs) have become the most widely accepted measure of development efforts, and the Government of Bangladesh is committed to achieving the targets embodied in the Millennium Declaration by 2015. The health-related goals include the target of reducing infant and child mortality by two-thirds by 2015 from their levels in 1990. It is estimated that in Bangladesh about onefifth of the total burden of disease may be associated with environmental factors (see Table 2.1 below). Two of the top three causes of death and sickness in Bangladesh are respiratory illnesses and diarrhoeal disease, both of which are strongly associated with the quality of the environment, and both of which have particularly significant impacts on the health of children. Management of these environmental risks presents an important development challenge, further compounded by widespread exposure to naturally-occurring arsenic, the growing significance of health risks posed by the pollution resulting from rapid urban and industrial expansion, and the increasingly intensive use of chemicals in agriculture.

\section{Environmental Health: Risk Factors and Costs}

19. The estimated shares of the top five causes of death and disease in Bangladesh, plus cancers (malignant neoplasms), as measured in Disability Adjusted Life Years (DALYs) ${ }^{14}$, are shown in Table 2.1 .

\begin{tabular}{|l|c|l|l|l|}
\hline \multicolumn{5}{|c|}{ Table 2.1: Bangladesh - Share of Disability Adjusted Life Years (DALYs) Lost } \\
by Cause and Environmental Contribution
\end{tabular}

Sources: Streatfield (2001), Murray and Lopez (1996), Lokuge et al (2004), WHO (2002), World Bank staff.

(a): Disease burden due to arsenic levels $>50 \mathrm{ppb}$, estimated by Lokuge et al (2004). May include portions of the burden of disease listed under other causes.

While the total number of DALYs lost per capita is comparable to the average for countries with high rates of adult and child mortality in South-East Asia ${ }^{15}$, the share of the total burden of disease attributable to respiratory infections and disease is about one third higher than the average for these countries, and the proportion caused by diarrhoeal disease is almost double

\footnotetext{
${ }^{14}$ Estimated by Streatfield (2001), based on the Indian subcontinent pattern provided in the Global Burden of Disease study, with adjustments for Bangladesh. DALYs are calculated as the present value of the future years of disability-free life that are lost as the result of the premature deaths or cases of disability occurring in a particular year.

${ }^{15}$ WHO, 2002.
} 
the average. The Table also indicates the estimated contribution of environmental factors, both as a share of each cause and as percentage of the total burden of disease.

20. Some $16.5 \%-22 \%$ of the total burden of disease is attributable to environmental health risks associated with (i) poor indoor and urban air quality leading to higher rates of respiratory infections and disease, (ii) lack of access to safe water combined with low levels of sanitation and hygiene, resulting in elevated rates of diarrhoeal disease, (iii) chronic exposure to toxic contaminants from agricultural and industrial sources, increasing the risks of certain cancers, and (iv) exposure to elevated levels of naturally-occurring arsenic in drinking water, contributing to a range of conditions, including a variety of cancers, heart disease, diabetes and non-malignant respiratory disease. The estimated contribution of these factors to the burden of disease imposed by environmental health risks is summarized in Figure 2.1 below.

Figure 2.1: Contributing Factors to Environmental Health Risks

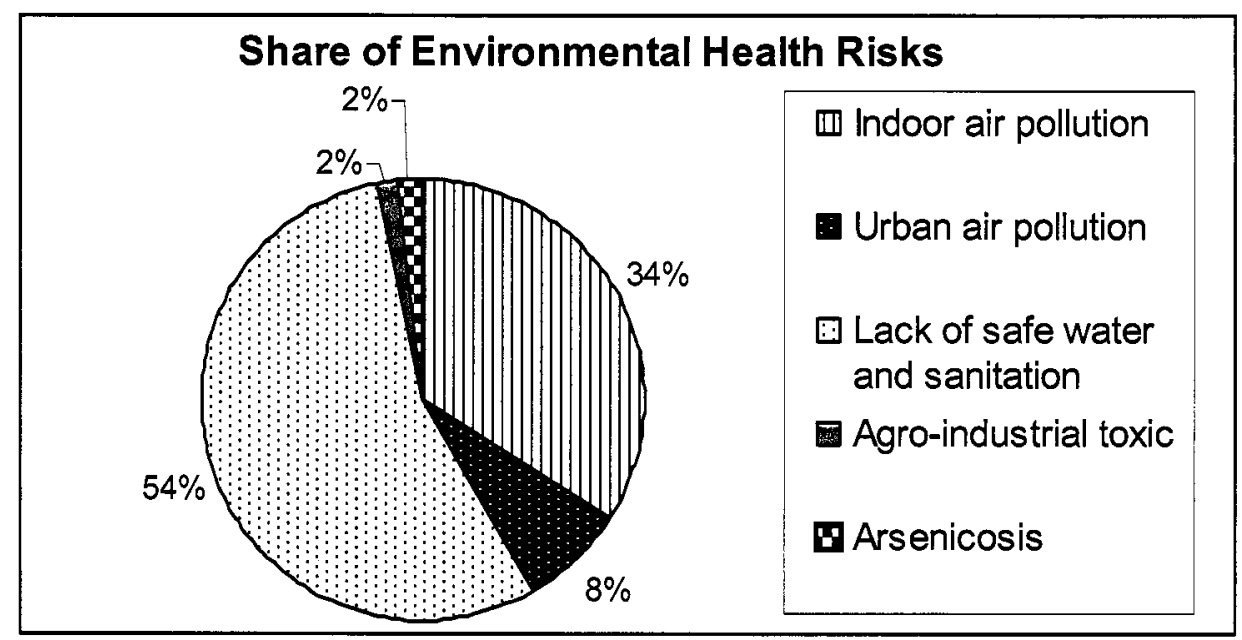

21. Environmental health risks in Bangladesh are dominated by those contributing to the high rates of diarrhoeal disease. Globally, it is estimated that $90 \%$ of the diarrhoeal disease burden is related to poor sanitation and lack of access to clean water and safe food ${ }^{16}$, with more than $90 \%$ of this burden being borne by children. In the two-week period before the 2004 Bangladesh Demographic and Health Survey (BDHS), 8\% of children under five were reported to have suffered diarrhoea, rising to more than $12 \%$ in the most vulnerable $6-23$ month age group. The second most significant set of environmental health risks are those contributing to respiratory infections and disease, either through exposure to smoke from cooking in the home or air pollution in urban areas. These sources contribute to acute respiratory infections in children and chronic lung disease in adults, estimated to account for $36 \%-60 \%$ of all respiratory infections and disease in Bangladesh. In the two-week period before the 2004 BDHS, $20 \%$ of children under five were reported to have suffered a respiratory illness. The third environmental health risk identified in Table 2.1 is exposure to high levels of toxic chemicals, which can lead to an increased risk of certain cancers, particularly those related to renal and gastric functions, as well as those of the skin and blood.

${ }^{16}$ WHO, 1997. 
Malignant neoplasms are estimated to account for about $2.0 \%$ of the total burden of disease in Bangladesh. If between 5\%-25\% of these cancers are attributable to acute and chronic exposure to pesticides and industrial contaminants in the environment, this would suggest that up to $0.5 \%$ of the total burden of disease is due to toxic agro-industrial pollution, equivalent to the share attributable to malaria.

22. The extent of the environmental health risk posed by naturally-occurring arsenic in groundwater is only beginning to be understood. Tubewell testing indicates that some $29 \%$ of the population of Bangladesh is exposed to water with unsafe levels of arsenic (i.e. in excess of $50 \mathrm{ppb}$ ), and some 38,000 potential cases of arsenicosis have been identified. ${ }^{17}$ Limited information on arsenic intake and the epidemiology of arsenicosis makes it difficult, however, to estimate associated rates of sickness and mortality. Using dose-response data from studies carried out in Taiwanese populations, it has been estimated ${ }^{18}$ that about $0.4 \%$ of the total burden of disease in Bangladesh may be attributable to exposure to arsenic levels in drinking water in excess of 50ppb. This estimate includes a range of cancers, heart disease and diabetes considered to be attributable to arsenic, but does not include non-malignant respiratory disease, which recent work indicates may result from ingestion of arsenic. ${ }^{19}$ Further doubt over the extent of the arsenic threat was cast by the 2004 BDHS, which tested the water that surveyed households were drinking on the day of interview. Almost half of the households that reported getting their drinking water from red-marked tubewells (i.e. those previously found to have levels of arsenic in excess of 50pbb) did not have unsafe arsenic levels in their drinking water. To some extent this may reflect tubewell switching, but also may indicate that either arsenic levels vary over time, or that there were errors in the testing and marking of tubewells, or may reflect the possibility that iron in the water may have reduced arsenic levels during water storage.

23. The death and disease caused by poor environmental quality imposes an economic cost associated with reduced quality of life, lost productivity, and health care costs. These costs can be reduced through investments to limit exposure to environmental health risks. An indication of the potential scale of such savings is provided in Table 2.2.

\begin{tabular}{|l|l|l|l|c|}
\hline \multicolumn{5}{|c|}{$\begin{array}{c}\text { Table 2.2: Potential Reductions in Mortality and Morbidity, and Economic Savings } \\
\text { By Reducing Exposure to Environmental Health Risks }\end{array}$} \\
\hline \multicolumn{1}{|c|}{ Exposure Reduced } & $\begin{array}{c}\text { Deaths } \\
\text { Avoided }\end{array}$ & Sickness Avoided & $\begin{array}{c}\text { Saving } \\
\text { (US\$ mill.) }\end{array}$ & $\begin{array}{c}\text { Saving } \\
\text { (\% GNI }\end{array}$ \\
\hline $\begin{array}{l}\text { Indoor Air Pollution: } \\
\text { reduce exposure by 20\% - 80\% }\end{array}$ & $7,600-30,400$ & $\begin{array}{l}0.3-1.2 \text { million } \\
\text { DALYs }\end{array}$ & $114-458$ & $0.23-0.92$ \\
\hline $\begin{array}{l}\text { Urban Air Quality: } \\
\text { reduce PM } \\
20 \%-80 \%\end{array}$ & $1,200-3,500$ & $\begin{array}{l}80-235 \text { million } \\
\text { cases }\end{array}$ & $169-492$ & $0.34-1.0$ \\
\hline $\begin{array}{l}\text { Water Supply and Sanitation: } \\
\text { universal provision of improved } \\
\text { water sources and sanitation }\end{array}$ & - & $\begin{array}{l}0.82-1.94 \text { million } \\
\text { DALYs }\end{array}$ & $313-739$ & $0.63-1.43$ \\
\hline $\begin{array}{l}\text { Arsenicosis: } \\
\text { prevent exposure above 50ppb }\end{array}$ & 9,100 & $\begin{array}{l}0.13-0.17 \text { million } \\
\text { DALYs }\end{array}$ & $48-66$ & $0.1-0.13$ \\
\hline Total & & & $\mathbf{6 4 4 - 1 7 5 5}$ & $\mathbf{1 . 3 - 3 . 5}$ \\
\hline
\end{tabular}

Source: M. Khaliquzzaman, 2004.

\footnotetext{
${ }^{17}$ BAMWSP, 2004

${ }^{18}$ Lokuge et al (2004)

${ }^{19}$ Mazumder et al (2000)
} 
24. As Table 2.2 shows, the estimated benefits of reducing exposure to indoor and urban air pollution by $20 \%-80 \%$, of providing universal access to improved water sources and sanitation, and of interventions to prevent exposure to levels of arsenic in drinking water in excess of $50 \mathrm{ppb}$, amount to $1.3 \%-3.5 \%$ of $\mathrm{GNI}^{20}$

\section{Water Supply and Sanitation}

25. The statutory responsibility for the water supply and sanitation sector lies with the Ministry of Local Government, Rural Development and Cooperatives (MoLGRD\&C). Its Local Government Division (LGD) is responsible for policy making, planning, financial mobilization and allocations, framing of rules and regulations, as well as monitoring and evaluation. The Department of Public Health Engineering (DPHE) is responsible for planning, designing and implementing water supply and sanitation in rural and urban areas, except the cities of Dhaka and Chittagong. The Local Government Engineering Department (LGED) undertakes water and sanitation related activities in municipalities (Pourashavas) and with City corporations on a project basis.

26. City corporations are responsible for drainage, solid waste management, and maintenance of water supply and sanitation systems installed by DPHE or LGED. Dhaka WASA is responsible for water supply, sub-surface drainage and sewerage, while Chittagong WASA deals only with water supply. The statutory responsibilities of Pourashavas include provision, operation and maintenance of water supply, solid waste management and sanitation, but most have limited technical and organizational capacity, and rely on DPHE or LGED for design and construction. Water Supply and Sanitation Committees (WATSAN Committees) have been established in Union Parishads (UPs), and are playing a key role in sanitation, in collaboration with Upazila Development Coordination Committees.

\section{Policies, Strategies and Plans: Recognizing the Need for Action}

27. The National Strategy for Accelerated Poverty Reduction includes sanitation and safe water in the seven-point medium-term strategic agenda, with the specified goals being to (i) reduce the number of people who do not have access to safe water $(26 \%)$ or sanitation $(66 \%)$ by half by 2006 , (ii) reduce waterborne morbidity and mortality, (iii) reduce the number of people subject to arsenic contamination, and (iv) ensure access to sanitary community latrines in villages, bazaars, mosques and schools, with particular attention to women's needs.

28. The main policies guiding water supply and sanitation are the National Policy for Safe Water Supply and Sanitation 1998 (NPSWS\&S) and the National Water Policy (NWP). Both policies include the goal of ensuring that all people have access to safe drinking water. The NPSWS\&S states that all people should have access to safe drinking and cooking water and sanitation services at an affordable cost, and emphasizes participatory planning and management, as well as decentralization and devolution of responsibilities to the local level. The policy also provides for variations in the extent of cost recovery for water supply and

${ }^{20}$ The estimates of sickness avoided and savings for indoor air pollution and urban air quality cannot be directly compared (i.e. cases of sickness are not equivalent to DALYs). If the same approach were used, the results for indoor air pollution would be four to five times greater than those for urban air quality, which is broadly in line with the difference in estimated rates of death from these two sources of risk. 
sanitation investments depending on local conditions and the level of expenditure required to provide access to safe water.

29. The NPSWSS has been supplemented by the National Policy for Arsenic Mitigation 2004 and Implementation Plan (NPAM\&IP). This establishes that villages in which more than $80 \%$ of tube wells are arsenic-contaminated are eligible for emergency response support. Under the emergency response, at least one safe water source is to be provided within a reasonable distance or for every 50 families, with no capital cost contribution required from the users.

30. A National Sanitation Strategy has been drafted, setting the goal of achieving $100 \%$ sanitation coverage by 2010 . According to the Strategy, 100\% sanitation requires (i) no open defecation, (ii) hygienic latrines available and used by all, (iii) proper maintenance of latrines for continual use, (iv) improved hygienic practices, and (v) proper management of solid waste. The guidelines for achieving these goals specify that sanitation is primarily about health and social values, creating and sustaining demand, behaviour change, and an approach that is gender sensitive, placing communities at the center of decision-making, with subsidies provided only for the poorest.

31. Water supply and sanitation is included in the National Health Policy, National Education Policy and National Environment Policy, but has too often comprised disparate project activities without reference to a guiding framework. Recently, however, the Government has approved a Water Supply and Sanitation Sector Development Framework, intended to guide planning, coordination and monitoring with a focus on the devolution of authority to local government institutions, user participation, economic pricing, gender sensitivity, and partnerships between the public and private sectors, and NGOs.

\section{Total Sanitation: Realizing the Full Health Benefits of Clean Water}

32. One of Bangladesh's greatest successes has been to achieve near total access to drinking water that is largely microbiologically safe, with $86 \%$ of the population drinking water from hand pumps, and $10 \%$ connected to piped water. Despite the impressive progress in increasing access to clean water, slow progress in sanitation coverage, combined with poor hygiene habits, has held back the expected health gains. Significantly, the child mortality rate in districts where less than a quarter of households have access to a sanitary toilet is nearly $40 \%$ higher than districts in which more than one-half of households have sanitation access. $^{21}$ Nationally, some $30 \%-40 \%$ of the population has access to a sanitary latrine. ${ }^{22}$ In rural areas, only $30 \%-35 \%$ of the population has such access, and while this total reaches $60 \%-75 \%$ in urban areas, a recent survey ${ }^{23}$ found that only $17 \%$ of urban households are satisfied with the quality of sanitation services.

33. The goal of achieving total sanitation by 2010 was announced in 2003 by the Government as the objective of the Total Sanitation campaign, since when an increase of $15 \%$ in national sanitation coverage is claimed. This ambitious program has been launched based on the experience gained during integrated water supply, sanitation and social mobilization programs in the mid-nineties. With strong political support, a National

\footnotetext{
${ }^{21}$ World Bank (2005)

${ }^{22}$ PRSP (2004)

${ }^{23}$ GHK (2003)
} 
Advisory Committee under the MoLGRD\&C and a National Task Force under the Secretary of MoLGRD\&C have been formed, with sanitation Committees formed at all levels of local government.

34. The focal point of the Total Sanitation campaign is the UP in rural areas, and Wards in Municipalities and Cities. The Government has earmarked 20\% of Upazillas' Annual Development Program (ADP) allocation for improving sanitation coverage. Of this, $75 \%$ is to be used to procure sanitary latrines for distribution to the hardcore poor, and the remaining $25 \%$ is to be used for promotional activities. Planning and decisions are approved at the Upazilla Development Coordination Committee following guidelines provided by LGD. The assignment of subsidized latrines to the hardcore poor is based on lists prepared by the Ward Sanitation Committee using data from the 2003 national sanitation survey, with the production of latrine components being contracted out to private producers at the Upazila or UP level.

35. Recognizing the public health nature of improvements in sanitation, community-wide performance-based incentives for sanitation coverage have been introduced under the Total Sanitation program, consisting of additional resources for those UPs (Tk. 0.2 million/Union) and Upazilas (Tk. 0.5 million/Upazilla) that have achieved 100\% sanitation. In the first round of awards, 95 UPs, 4 Pourashavas and 5 Upazilas were rewarded for achieving total sanitation by February, 2005. A guideline is being prepared by LGD on the use of the awarded funds, focusing on further social mobilization to sustain the sanitary achievements. This forms part of a phased approach, emphasizing elimination of open defecation and the use of hygienic latrines by all in the current first phase, followed by improved sanitation technologies and further social mobilization to sustain improvements in the subsequent phase. While there remain questions about the independence of the process, the Total Sanitation 2010 program incorporates a comprehensive monitoring system involving data collection by WATSAN committees, checked and approved quarterly by district Sanitation Secretariats of DPHE, combined with follow-up surveys to be conducted in 2005, 2008 and 2010.

36. The Government's commitment to Total Sanitation is an essential step towards addressing the single most significant environmental threat to the nation's health, and merits the full support of development partners and civil society. The combination of improved sanitation technologies with the community-wide promotion of hygienic practices will help realize the full health gains achievable as a result of near-universal access to clean water. Studies in rural Bangladesh have demonstrated that integrated water, sanitation and hygiene intervention can reduce diarrhoeal diseases among children by $25 \%{ }^{24}$, and a recent international comparison of water, sanitation and hygiene interventions found that sanitation interventions can reduce the risk of diarrhoeal disease by a third. ${ }^{25}$

\section{Meeting the Total Sanitation Goal}

37. Successful achievement of the goals of the Total Sanitation campaign will entail overcoming a number of challenges, however, not least of which is the allocation of sufficient resources. The PRSP estimates the cost of achieving total sanitation at about

\footnotetext{
${ }^{24}$ Aziz et al (1990)

${ }^{25}$ Fewtrell et al (2005)
} 
US\$450 million ${ }^{26}$, equivalent to about US\$30 per household currently without sanitation. While this level of investment may be more than sufficient for the provision of simple pit latrines (estimated to cost on average about \$14), rehabilitation and expansion of municipal sewerage systems to meet the needs of Bangladesh's burgeoning urban population will require resources of at least this magnitude. The rehabilitation of Dhaka's existing sewerage and drainage system is alone projected to cost about $\$ 100$ million.

38. Sanitation activities in urban areas have been slower than rural initiatives, and will require additional attention if the Total Sanitation 2010 goal is to be realized, particularly regarding the technologies being applied. Even in Dhaka, only about $27 \%$ of the population is connected to the public sewer system. The most common sanitation technologies in urban areas are pit latrines and septic tanks, but in densely populated areas, pits fill too fast and the effluent from septic tanks flows into open drains, making on-site sanitation options inappropriate for such settings. While the long-term aim must be to extend the public sewer system in urban areas, there are many new and expanding developments, as well as existing slums, that will not receive trunk connections in the foreseeable future. There is a clear need for the development of alternative solutions, including, for example, the use of Septic Tank Effluent Disposal Systems (STEDS), which would combine household septic tanks with small-bore connections to low-cost community effluent treatment facilities.

39. Seasonal flooding poses an additional technological and social challenge to the achievement of total sanitation. Flooding to a greater or lesser extent is an annual event in Bangladesh, and must be considered in the development and promotion of sanitation technologies in flood-prone areas. Flood-waters spread disease and contaminate water supplies, causing rates of diarrhea to increase some seven-fold during these episodes. Latrines become a high priority especially for women in shelters and affected households during floods. When asked to prioritize their needs during floods, $60 \%-70 \%$ of women named latrines as their number one concern. ${ }^{27}$ To the extent possible, pit latrines should be constructed with concrete lining in properly compacted earth above flood levels, but such measures will not be possible in all locations. To achieve the goal of year-round sanitation, consideration must be given to providing temporary or permanent latrines in shelters or refuge sites adequate to meet the sanitary needs of the affected community during floods.

\section{Arsenic: Threatening Safe Water Achievements}

40. Since the 1970's, extensive awareness and motivation, technological and financial efforts have been undertaken by civil society, Government and development partners to change drinking water practice away from microbiologically-contaminated surface water to clean groundwater. As a result, there are now some 11 million tube wells installed in Bangladesh, supplying microbiologically clean drinking water to more than $90 \%$ of the population. However, widespread contamination of groundwater with naturally-occurring arsenic has reduced the percentage of the population with access to safe water to about $73 \%$. According to the national survey conducted by DPHE, some 29 million people are exposed to arsenic contamination exceeding 50ppb, and 49 million to levels exceeding $10 \mathrm{ppb}$. In the face of significant technological and institutional challenges, the response to arsenic

${ }^{26}$ PRSP, December 2004, p. 179

${ }^{27}$ B. Hoque et al (1997) 
contamination has been slow, and concern is growing that a switch back to surface water sources will lead to an increased risk of microbiological contamination.

41. It has been estimated that a transition back to untreated surface water sources such as unimproved dug wells or ponds could mean an increase in the risk of diarrheal disease by $20 \%{ }^{28}$ Switching to a safe but more remote tubewell may also increase such risk by reducing the quantity of water used in the household, as may the use of arsenic filtration systems, as higher levels of microbial contamination have been found in filtered water than in the tubewells from which it was taken. ${ }^{29}$ Based on a comparison of these risks, it is calculated that arsenic mitigation interventions provided to households exposed to levels of arsenic in excess of 50pbb need to achieve at least a $77 \%$ reduction in arsenic-related morbidity and mortality to result in a net reduction in the overall burden of disease. This conclusion underlines the importance of targeting arsenic mitigation interventions at households exposed to high levels of contamination, and ensuring that such interventions significantly reduce arsenic exposure without increasing the risk of waterborne disease.

\section{Rising to the Arsenic Challenge: Technology Choices and the Role of Piped Water}

42. The National Policy for Arsenic Mitigation (2004) sets the goal of providing access to safe water for drinking and cooking in arsenic-affected areas, giving preference to surface water over groundwater as a source. Despite this preference, the Government is supporting investments in deep tube wells in many arsenic-affected and coastal areas. Intervention studies of people's chosen water options have indicated that deep tube wells and piped water systems are in high demand and have performed satisfactorily ${ }^{30}$. Conversely, significant concerns remain regarding the microbiological safety of alternative options, such as dugwells and Pond-Sand Filters (PSFs). Household rainwater technologies are growing, but the technology is costly, and the supply seasonal. ${ }^{31}$ A few arsenic removal options have been recently approved by GOB and are undergoing further action research. Operation and maintenance $(\mathrm{O} \& \mathrm{M})$ are important determinants of appropriate technologies. One of the main factors associated with the success and high demand for tube wells has been the low O\&M requirements. In contrast, PSFs and most arsenic removal systems require regular cleaning, and the operational performance of rainwater harvesting systems and dug-wells is seasonally variable.

43. The need to match the service levels of household shallow tube wells with either surface water, which requires treatment, or deep tube wells, which entail higher levels of investment, argues for the promotion of piped water systems where feasible, as these spread investment costs while maintaining water delivery at the household level. In turn, the development of piped water systems requires arsenic mitigation to be addressed as part of a broader program to improve water supply service levels, with important roles to be played by local governments and the private sector. A recent World Bank study of arsenic contamination in South and East Asia suggest that this challenge presents the opportunity to transform government agencies from providers of services to facilitators assisting local governments to help themselves. ${ }^{32}$ The Bangladesh Water Supply Program Project

${ }^{28}$ Lokuge et al (2004)

${ }^{29}$ Sutherland et al (2002)

${ }^{30} \mathrm{~B}$. Hoque et al $(2003,2004)$

${ }^{31}$ Arsenic Policy Support Unit (2004)

${ }^{32}$ World Bank (2005c) 
implemented by DPHE with World Bank assistance supports the scaling-up of the provision of safe water in rural areas and small towns, promoting private sector participation in the provision of piped water systems. Project funds cover $50 \%$ of capital costs, with the remainder borne by the sponsor and users. The goal is to provide 450 villages with functioning piped water supply schemes, providing multiple house connections for wealthier households, yard standpipes for middle-income households, and shared standpipes for poor households.

44. More than half the urban population has access to piped water supply. The four large cities, Dhaka, Chittagong, Khulna and Rajshahi have piped water systems that serve $70 \%$, $55 \%, 51 \%$ and $40 \%$ of the population respectively. In addition, 100 of the over 250 municipal towns have piped water systems. These systems primarily serve the urban core, with peri-urban and slum populations continuing to rely on tube wells. Urban areas will require major investment to meet the growing demand for water, in addition to significant improvements in cost recovery in order to meet operation and maintenance costs. That municipal water supply in Bangladesh can be financially viable has been demonstrated through the District Towns Water Supply and Sanitation Project, where all but two of the 18 municipalities generated profits before depreciation, and three generated profits after depreciation. Even in slum areas, $100 \%$ of water bills have been paid when NGOs were involved in their management. Although there is room for improvement in collections, both the Dhaka and Chittagong Water Supply and Sewerage Authorities (WASAs) are able to cover operating, maintenance, depreciation and financing costs from user fees.

\section{Regulatory Roles and Private Sector Services: Partnerships for Safe Water Supply}

45. As noted in the Bangladesh Country Water Resources Assistance Strategy ${ }^{33}$, improved service levels in water supply will require greater involvement of local governments, the private sector and civil society. As well as supporting higher levels of investment, the private sector can provide services for operation, maintenance, billing and collection. To ensure the quality of these services, the Government should be supported in its plans to establish an independent regulatory framework to supervise and monitor performance, forming an element in the broader transformation of government agencies from service providers to facilitators and regulators.

46. In addition to enhancing the quality of service, achievement of the Government's goals for the supply of safe water will require an expansion of service coverage to better reach disadvantaged social groups. The potential of local governments to assist in attaining this goal has been demonstrated through pilot initiatives in which UPs control and manage funds, transferred directly to them in the form of annual block grants. Further support for the supply of safe water should continue to emphasize the role of local governments in the planning and management of water services.

47. An essential regulatory role in the provision of safe water is the monitoring of drinking water quality. While the arsenic crisis stimulated an impressive nationwide initiative to test tube wells for contamination and to strengthen the analytical capabilities of DPHE laboratories, there is not yet a systematic, quality-controlled program to regularly test public and private drinking water sources. Efforts to develop a water quality surveillance

${ }^{33}$ World Bank (2005b) 
system are urgently required, combining monitoring by service providers, public provision of information, and the setting and enforcement of standards by a regulatory body, a role that could potentially be filled by DPHE or DoE.

\section{Water Supply and Sanitation: A Good Investment}

48. The PRSP states that water supply and sanitation will be recognized as a separate sector in the next Three Year Rolling Plan, and projects that US\$4.9 per capita will be required to meet water supply and sanitation goals, implying a total cost of some US\$650 million. As Table 2.2 indicates, the economic value of the health benefits achievable through universal provision of improved water sources and sanitation may amount to US\$740 million annually, suggesting that the proposed level of investment would pay for itself within one year.

\section{Air Pollution}

49. Respiratory infections and disease account for a greater share of death and sickness in Bangladesh than diarrhoeal disease, and as Table 2.1 indicates, up to two-thirds of these health outcomes may be associated with environmental factors in the form of either Indoor Air Pollution (IAP) or poor urban air quality.

\section{Indoor Air Pollution: A Serious Health Hazard}

50. Recognition of the health impacts of IAP is growing worldwide. ${ }^{34}$ Inhaling smoke from burning biomass can have both temporary and permanent consequences for health. Notable among these are chronic bronchitis among women and acute lower respiratory infections among children, especially pneumonia. Worldwide, it is estimated that about $60 \%$ of deaths caused by air pollution are among children under five as a result of exposure to smoke from dirty cooking fuels. ${ }^{35}$ There is also moderate evidence associating solid fuel use with a range of further health outcomes, including cataracts and blindness, tuberculosis, asthma, adverse pregnancy outcomes, and possibly heart disease. ${ }^{36}$

51. Poor households in Bangladesh depend heavily on wood, dung and other biomass fuels for cooking. As a result, the health impacts of IAP are significant, estimated to account for as much as $8 \%$ of the total burden of disease, as shown in Table 2.1. These estimates were supported by a recent World Bank study ${ }^{37}$, which detected dangerously high concentrations of particulates in indoor air for many poor households in Bangladesh ${ }^{38}$, implying widespread exposure to a serious health hazard. Particularly high levels of exposure to IAP were recorded for women, children and adolescents of both sexes, and these were especially serious for children under five.

52. Fuel choice significantly affects indoor pollution levels, with natural gas and kerosene being cleaner than biomass fuels. The World Bank study in Bangladesh found, however, that household-specific factors apparently matter more than fuel choice in

${ }^{34}$ WHO, 2002

${ }^{35}$ World Bank, 1999

${ }^{36}$ Smith, 2000

${ }^{37}$ Dasgupta et al, 2004

${ }^{38}$ Concentrations of $300 \mathrm{ug} / \mathrm{m}^{3}$ or greater were common in the samples analyzed for the study. 
determining indoor concentrations of harmful particulate matter, with the choice of cooking location, construction material, and ventilation practices being particularly important. These factors were also found to be significant in a similar study conducted in India (see Box 2.1). In addition, the Bangladesh study found great variation during the day, with particulate concentrations during peak cooking periods exceeding those during the least smoky part of the day by a factor of 50 or more. There was little variation within households, however, implying that exposure to dangerous indoor pollution levels is not confined to cooking areas.

\section{Box 2.1: A Comparative Assessment of IAP in Bangladesh and India}

Two recently completed studies* measured exposures to indoor air pollution in rural settings in India and Bangladesh. Both studies provided quantitative information on concentrations and exposure to fine particulate matter for a variety of household fuels and conditions.

Both studies strengthen evidence that cooking with clean fuels reduces exposure to fine particulates compared to cooking with solid fuels, but there are significant differences between the two countries. In particular, concentrations in Indian households using solid fuel are up to 9 times higher than concentrations in those using gas, whereas the difference is only two-fold in Bangladesh. Consistently across the studies, fuel choice, cooking location and ventilation factors were found to be strongly associated with kitchen and living area concentrations. The India study, however, finds that fuel choice is the dominant factor, while the results for Bangladesh highlight the role of ventilation as being more significant in influencing IAP levels.

Together, the studies indicate the need for multiple interventions to reduce exposure to IAP, ranging from improvements in housing design and ventilation, to provision of better stoves that vent smoke outside the house, in addition to efforts aimed at accelerating the adoption of cleaner fuels.

(*World Bank, 2002; Dasgupta et al, 2004)

\section{Changing Behaviour, Technology and Fuels to Reduce Exposure to Indoor Air Pollution}

53. The health impacts of IAP can be mitigated through the use of cleaner fuels, improved efficiency in biofuel use, and improved ventilation. The policies necessary to promote these changes are cross-sectoral, affecting fuel pricing and distribution, small business development, and health education. The use of cleaner forms of energy, such as natural gas, kerosene and electricity, depends both on household income and the price of cleaner fuels relative to biofuels. As biofuels are more expensive in urban areas, where cleaner energy is cheaper, the use of cleaner forms of energy is higher in Bangladesh's towns and cities, particularly among households with a per capita income over US $\$ 2.00$ per day. In rural areas, however, there is little likelihood of the widespread use of cleaner fuels in the new future.

54. International experience indicates that household concentrations of fine particulates can be reduced below $200 \mathrm{ug} / \mathrm{m}^{3}$ through the use of a well-maintained improved stove. ${ }^{39}$ While a number of pilot programs to promote the use of improved stoves have been undertaken in Bangladesh ${ }^{40}$, these have not resulted in their widespread adoption. Despite such efforts, limited information is still a significant impediment to adoption of cleaner, more efficient stoves. Of the households sampled in the World Bank study, only $15 \%$ regarded improved stoves as a viable option, either because they had not heard of them or because they

${ }^{39} \mathrm{~K}$. Ahmed et al, 2005

${ }^{40}$ For example, by the Bangladesh Council for Scientific and Industrial Research (BCSIR). 
did not think they were locally available. Even among families that had considered the option, however, improved-stove use was limited because of concerns about convenience or initial investment cost. Careful assessment of successful improved stove programs in other countries (see Box 2.2) may provide valuable lessons for the development of a more effective approach in Bangladesh, particularly regarding the need to simultaneously stimulate demand and create an effective private sector response.

\section{Box 2.2: The Successful Promotion of Improved Stoves in China}

In the early 1980s, the Chinese government organized the world's largest publicly financed initiative to improve stoves, the National Improved Stoves Program (NISP), which aimed to provide rural households with more efficient biomass stoves, and later with improved coal stoves.

The primary objective of the NISP was to relieve pressure on biomass, rather than to reduce IAP, and consequently it was run by the Ministry of Agriculture (MoA). By the end of the first phase of the program, 130 million improved stoves had been installed, and pressure on biomass had eased in most parts of the country. In the second phase, during the early 1990s, the MoA provided support for stove manufacturers and energy service companies. In the final phase, from the mid-1990s onwards, support for the stove industry was replaced with extension services and certification systems to standardize stoves. The development and dissemination of improved stoves is now left mainly to market actors, with some local government oversight.

Based on household surveys, by the end of the 1990 s about $55 \%$ of China's 236 million rural households had improved biomass or coal stoves. These surveys also confirmed that the use of improved stoves resulted in reduced indoor concentrations of fine particulates, and that the prevalence of childhood asthma and adult respiratory disease fell with the use of improved stoves.

(Source: Xiliang and Smith, 2004)

55. The World Bank study suggests, however, that poor rural families may not have to wait for clean fuels or improved stoves to enjoy significantly cleaner air, as some households already experience relatively clean conditions, even when biomass fuels are used. Since these arrangements are already within the means of poor families, the scope for cost-effective improvements may be larger than is commonly believed. Simple changes in ventilation characteristics of housing (including construction materials, space configurations, cooking locations, and the placement of doors and windows), as well as ventilation behavior (keeping doors and windows open after cooking) can produce large improvements in the quality of indoor air. For children in a typical household, pollution exposure can be halved by increasing their outdoor time from three to five hours per day, and concentrating outdoor time during peak cooking periods. Since better ventilation and longer outdoor time for children are affordable and acceptable for poor families in Bangladesh, and may reduce IAP exposure to much safer levels, promotion of these simple changes is strongly recommended for immediate action. Given the current low level of awareness of the consequences of IAP, however, achieving such behaviour change will require a concerted public education effort aimed at explaining the health benefits of reducing exposure to smoke from biofuels.

\section{Urban Air Quality: Targeting Gross Polluters}

56. Up to $10 \%$ of respiratory infections and disease in Bangladesh may be attributable to urban air pollution, as indicated in Table 2.1. While the problem is most severe in Dhaka, where air quality is worst and the most people are exposed, air pollution is a growing concern in other major cities. Measurements in Dhaka indicate that particulate matter is the most 
significant pollutant, especially fine particulates that cause the most severe health effects. The effect is seasonal, however, with particulate concentrations falling within acceptable levels during the summer rainy season. Currently, other pollutants rarely exceed standards for ambient air quality.

57. A first important step in addressing urban air quality was taken with elimination of leaded gasoline in 1999. A further significant improvement in the quality of air in Dhaka was achieved through the ban on two-stroke three-wheelers (known as baby-taxis) instituted in January, 2003, which reduced ambient concentrations of fine particulate matter by about one-third. Nevertheless, concentrations of particulate matter in Dhaka remain high, exceeding national standards on more than 100 days of the year, and the gains achieved through the baby-taxi ban are being rapidly eroded, in particular through rising emissions from the growing fleet of diesel vehicles providing public transport.

58. To reduce concentrations of particulate matter, measures need to be taken to improve the quality of fuel and to curb emissions from gross mobile and industrial sources. More specifically, the sulphur content of imported diesel should meet international specifications (i.e. not exceeding 500ppm), and initiatives to control emissions should focus on gross diesel polluters, particularly trucks and buses. Reducing fuel sulphur content will reduce emissions from the existing diesel vehicle fleet ${ }^{41}$, as will improved maintenance and operation. In addition, lower diesel sulphur will allow the effective use of cleaner engine technology, which should be promoted through fiscal and regulatory incentives for vehicle upgrades once cleaner fuel is available, especially for fleets of diesel vehicles operating within Dhaka. To get the full benefit of diesel sulfur reduction, it will be necessary to upgrade the bus fleet to Euro-II or higher equivalent standards. Alternatively, bus fleet renewal using $\mathrm{CNG}$ as fuel may be pursued, as emission levels of dedicated CNG buses correspond to Euro-III or better.

59. Initiatives aimed at reducing emissions from industrial sources should be based on assessments of their relative contributions to the particulate load. To the extent possible, such efforts should draw on win-win solutions that provide energy savings in combination with emissions reductions. Such an approach will not only help build private sector support, but also raises the possibility of receiving carbon financing for reduced greenhouse gas emissions. The DoE has largely succeeded in promoting the use of $120 \mathrm{ft}$. high stacks for conventional brick kilns across the country, which has helped reduce local pollutant concentrations. This is an interim solution, however, and the Government has adopted an initiative with UNDP support to promote energy-efficient brick kiln technology for the reduction of emissions from these sources.

60. To target emission reduction efforts, monitor their effectiveness, and build the necessary public support for such initiatives, it is essential to sustain and expand the monitoring of ambient air quality. Currently this is conducted in a limited fashion only in Dhaka, but should be extended to other major cities, as well as to provide better coverage in the capital. While other criteria pollutants should be covered, the primary focus should remain particulates, particularly the respirable fraction, and greater consideration should be given to the potential role of the private sector in providing the technical services required for data collection.

${ }^{41}$ Gwilliam et al, 2004 


\section{Reducing Exposure to Toxic Pollutants}

61. With the fastest industrial growth rate in South Asia (averaging 7.1\% per year from 1990-2003, compared with $5.9 \%$ for the region as a whole ${ }^{42}$ ), and rapid intensification in the use of agro-chemicals (pesticide consumption doubled between 1994 and $2001^{43}$ ), the impacts of toxic chemicals on human health and the environment in Bangladesh are an increasingly important concern. Of the various toxic chemicals, Persistent Bio-accumulative Toxics (PBTs) that degrade slowly and accumulate in living organisms are of particular concern. While a number of inorganic PBTs, particularly heavy metals, merit increased consideration in Bangladesh (see Box 2.3), a particular class of PBTs known as Persistent Organic Pollutants (POPs) has attracted special attention, both nationally and internationally.

\section{Box 2.3: Persistent Bio-accumulative Toxics - Lead and Mercury Emissions in Bangladesh}

Two of the inorganic PBTs of greatest concern in Bangladesh are lead and mercury. The electrical apparatus and supplies sector is the largest generator of lead in Bangladesh, which includes lead-acid storage battery producing units, as well as wire and cable producing plants located primarily in Dhaka, Chittagong, Khulna and Kushtia. Other sectors with potentially significant lead emissions include the iron and steel, and the tile and ceramic manufacturing sectors. Paper and pulp facilities release significant amounts of mercury into the atmosphere, and important among these are the Karnafuli Paper Mill and Karnafuli Rayon Complex (Omar et al, 1985).

62. POPs are highly stable organic compounds produced both directly and as by-products of a range of economic activities, in the agriculture, health, industry, energy and mining sectors, among others. All persist for years before breaking down, and travel great distances through various media from their point of origin, accumulating in the tissue of most living organisms, via food, water and the air. Worldwide, the known effects of POPs (particularly DDT) include their role in thinning eggshells in fish-eating birds and reductions in their reproductive rates. POPs have also been linked to cancer and reproductive abnormalities, while their effects on reproductive and nervous system disorders are also well established.

63. Twelve POPs ${ }^{44}$ have been singled out under the Stockholm Convention for urgent action and control based on their usage and emission characteristics (see Box 2.4). As a signatory to this Convention, which came into force in May 2004, Bangladesh is now faced with the challenge of establishing sustainable POPs management practices and cost-effective solutions for their replacement and safe disposal. The dimensions of this challenge were indicated in the recently completed World Bank South Asia Regional Strategy on POPs ${ }^{45}$ and other analyses $^{46}$ that point to a number of potential sources of POPs, such as rapidly increasing pesticide use, a range of manufacturing industries, and an unregulated shipbreaking sector.

\footnotetext{
422005 World Development Indicators

${ }^{43}$ Department of Plant Protection Wing, Bangladesh. Cited in Meisner, 2004

${ }^{44}$ The pesticides aldrin, chlordane, DDT, dieldrin, endrin, heptachlor, mirex and toxaphene, the industrial chemicals hexachlorobenzene (HCB) and polychlorinated biphenyls (PCB), and dioxins and furans which are unintended byproducts of combustion and industrial processes

${ }^{45}$ Issues and Options in Addressing the Objectives of the Stockholm Convention on Persistent Organic Pollutants in India and the South Asia Region, April 2004

${ }^{46}$ Report on Pesticide Hotspots in Bangladesh, September 2004; Final Report on Industrial Pollution: Sources and Impacts GIS Database September 2002
} 


\section{Box 2.4: The Stockholm Convention on Persistent Organic Pollutants}

The Stockholm Convention on Persistent Organic Pollutants was ratified in May 2004. Some of the key objectives of the Convention include:

- Eliminate production and use of specific pesticide POPs: aldrin, chlordane, dieldrin, endrin, heptachlor, hexachlorobenzene, mirex, and toxaphene.

- Restrict production and use of DDT in disease vector control in accordance with WHO guidelines;

- Develop strategies for identifying stockpiles of POPs and products containing POPs;

- Manage and dispose POPs wastes in an environmentally sound manner

- Develop remediation programs for POPs contaminated sites

- Manage PCBs in an environmentally sound manner and by 2025 , take action to remove from use PCBs found above certain thresholds;

- Develop and implement an action plan to identify the sources and reduce releases of POPs byproducts. Promote the use of Best Available Techniques (BAT) and best environmental practices.

\section{Pesticides - a Continuing Source of POPs?}

64. In Bangladesh, POPs pesticides were completely banned for use in agriculture from 1997, although most were banned much earlier in 1985. Their continued use has been reported ${ }^{47}$, however, possibly attributable to cross-border transfer, continued local formulation, inadequate product labeling and farmers' lack of information. ${ }^{48}$ Significantly high pesticide levels have been found in the food chain. A study of pesticide residues in Mymensingh and Dinajpur districts indicated the widespread presence of DDT and its metabolites in water, soil and rice plant samples ${ }^{49}$. In a survey undertaken by the World $\mathrm{Bank}^{50}$, the use of two POPs (heptachlor and endrin) was reported by farmers in the districts of Comilla, Chittagong, Dhaka, Rajshahi and Mymensingh. DDT, at levels well above the WHO guideline, has been found in a number of samples of surface and groundwater taken in Bangladesh. ${ }^{51}$ Direct evidence of human exposure has been provided through the identification of DDT in the breast milk of mothers in coastal areas where dried fish are widely consumed. ${ }^{52}$ Analyses of dried fish conducted in 1998 found the presence of DDT (allegedly used in the curing process), in some cases at exceptionally high levels presenting a hazard for human consumption ${ }^{53}$, although more recent work suggests alternative chemicals are now being used. ${ }^{54}$ Additionally, significant risks from pesticide POPs are posed by a number of contaminated sites that are likely to require remediation, such as the closed DDT plant in the BCIC Chemical Complex in Chittagong, and obsolete stocks in several agricultural pesticide godowns in Khulna, Chittagong and Bogra districts, as well as the DOH warehouses in Chittagong, together amounting to about $500 \mathrm{MT}$.

${ }^{47}$ Awal, 2001, SUNS 1998, SOS-arsenic.net, 2004, Toxic Link, 2004

48 Ramaswamy, 1992

49 Alam et al. 1999, and Matin et al 1998, cited in Hossain, 2005

${ }^{50}$ Meisner, 2004

${ }^{51}$ Malek et al 2002, cited in Hossain, 2005

52 Personal communication with Dr Shahadat Hossain, Institute of Marine Science, University of Chittagong, Bangladesh

${ }^{53}$ Khan 1998. The use of DDT in drying fish was first reported in Bangladesh by the Aquatic Research Group, Institute of Marine Sciences, Chittagong University

${ }^{54}$ DoE POPs Project 


\section{Manufacturing - a Variety of Likely POPs Sources}

65. An estimation of sector-wise pollution based on applying standard pollution coefficients to manufacturing data for Bangladesh ${ }^{55}$ identified the following the industrial sectors to be of greatest concern (i) steel, (ii) industrial chemicals, (iii) cement, (iv) textile dyeing and finishing, and (v) pulp and paper. Among the POPs produced by these sectors, PCBs are estimated to pose the gravest risks, and the most affected districts are Chittagong, Naryanganj, and Dhaka, which together account for an estimated $90 \%$ of the POPs generated by these sectors. The principal modes of POPs generation in these sectors are as follows:

- steel - scrap from the ship-breaking industry, used as raw material in this sector contributes to the formation of dioxins and furans, and even possibly PCB;

- chemicals - the main sites are the old DDT plant in Chittagong and a privatelyowned owned caustic soda facility, producing elemental chlorine and other chlorine based products;

- cement - POPs are released in the kiln of clinker-producing cement plants, two of which exist in Bangladesh;

- textiles - textile and leather plants contribute more than $20 \%$ of the total dioxins and furans emissions due to usage of chlorinated chemicals ${ }^{56}$, or dioxin-contaminated dyestuffs. ${ }^{57}$ The textile plants located along the Dhaka-Chittagong economic corridor and the leather plants located in Hazaribagh (Dhaka) are hotspot areas;

- pulp and paper - the use of chlorine and chlorinated compounds in bleaching and deinking processes causes dioxin and furan contamination of effluent from this sector, possibly one of the largest sources of dioxins and furans in the country.

66. Other industrial sectors that warrant particular attention for the control of POPs include oil refining and brick-making. Oil refining is known to produce dioxins, furans and PCBs, and the same POPs are likely to be generated by the use of a range of dirty fuels in brick-making, including lignite, tires and furnace oil.

\section{Ship-Breaking - a Potential POPs Hotspot}

67. At present, more than 30 ship-breaking yards operate on the beaches of Chittagong, dismantling some 60-80 large ocean-going ships every year. These beaches constitute the largest ship-scrapping facility for large vessels in the world, accounting for more than half of all vessels above 200,000 dwt scrapped worldwide in 1997-98. Dating from a period when PCB-use was widespread, it is expected that many of these ships contain PCBs in their paint, cables, waste oil, lubricants and electrical systems, estimated to total some $250-800 \mathrm{kgs}$ per ship. ${ }^{58}$ Activities relating to the ship breaking sector that augment the risk of dioxin and PCB contamination include unregulated disposal of wastes (open-air burning of PCB-based PVC cables), recycling of waste oil and use of metal scraps in the iron and steel industry. An

\footnotetext{
${ }^{55}$ M. Huq, 2004

${ }^{56}$ Especially PCP (pentachlorophenol) and chloronitrofen. Das (2005)

${ }^{57}$ For example dioxazines or phthalocyanines

${ }^{58}$ Toxics Link, 2004
} 
investigation of soil samples from steel plate reprocessing plants at ship-breaking yards found elevated levels of PCBs, although these were not detected in adjacent sea sediments. ${ }^{59}$

Power Sector - a Legacy of PCBs

68. The amount of $\mathrm{PCBs}$ that exist in the transformers and oil circuit breakers of the power sector in Bangladesh, as well as the amount that may be stored either for replenishment or as waste, has been quantified as part of the draft POPs National Implementation Plan. While recently-imported equipment is understood to be PCB-free, it is estimated that older equipment may contain some 500 tonnes of PCBs, with perhaps a further one-tenth of that amount in storage or waste containers. Seven PCB-contaminated sites have been identified in Bangladesh, which mainly include electric workshops for transformers and capacitors in Gazipur, Bogra, Chittagong, Dhaka and Jessore.

\section{Other Significant Sources}

69. A number of miscellaneous sectors contribute significantly to dioxins and furans emissions. These include waste disposal and incineration activities (28\%), fossil-fuel power generation and biomass heating including household heating and cooking (15\%) and uncontrolled burning (22\%), as reported in the Draft National Implementation Plan.

\section{Institutions and Policies}

70. Issues associated with the management of POPs and other toxic chemicals raise a range of challenges for Bangladesh. As a first step in meeting these, the registration of all POPs pesticides has been withdrawn, along with all authorizations for the use of chlorinated hydrocarbons as pesticides. In addition, all nine intentional POPs are banned in manufacture, use and trade, except DDT, for which restricted use for vector control is permitted until safer methods can be adopted. As a signatory to the Stockholm Convention, Bangladesh is preparing a National Implementation Plan (NIP) to develop POPs management practices and solutions. This exercise is being led by MoEF, which under the Environmental Conservation Act of 1995 is responsible for chemical safety, in collaboration with the Department of Agricultural Extension (DAE) and Bangladesh Power Development Board (PDB) as coimplementing agencies. On the basis of inventory analysis, infrastructure assessment, and disposal options, the draft NIP proposes a list of priority actions, divided into short- and longterm initiatives. The short-term actions focus on building institutional capacity and establishing the policy framework, while the longer term proposals include POPs control action plans.

\section{Elements of a POPs Management Strategy}

71. The broad elements of a strategy for strengthening the management of POPs would include the following:

- establishing dialogue and partnerships with relevant government agencies and other stakeholders (including industry associations, bilateral agencies and civil society), since recognition of the POPs issue is at a nascent stage;

${ }^{59}$ Det Norske Veritas, 2000 
- identifying POPs-related priorities based on a sound technical understanding of the chemicals management issues as well as relevant national and international policies;

- identifying sustainable intervention programs and policies that deal with cleaning up contaminated sites or obsolete stockpiles, monitoring of exposure and effect, building institutional capacities and implementing cleaner technologies, among others; and,

- engaging in information dissemination and awareness-raising.

\section{Environmental Health: Recommendations and Areas for World Bank Support}

72. Environmental health concerns are multi-sectoral issues, so institutional arrangements are critical to the success of all initiatives. For any particular initiative, it is important to identify a lead agency to push the agenda and coordinate others effectively. It is also important to build awareness of the extent of the health risks involved, as well as the understanding of cost-effective mitigation measures, in order to build broad-based support for their management.

\section{Sanitation}

73. The Government's commitment to Total Sanitation is an essential step towards addressing the single most significant environmental threat to the nation's health, and merits the full support of development partners and civil society. Successful achievement of the goals of the Total Sanitation campaign will entail overcoming a number of challenges, however, not least of which is the allocation of sufficient resources. To achieve the goal of year-round sanitation, consideration must also be given to providing temporary or permanent latrines in shelters or refuge sites adequate to meet the sanitary needs of the affected community during floods.

74. In urban areas, while the long-term aim must be to extend the public sewer system, there are many new and expanding developments, as well as existing slums, that will not receive trunk connections in the foreseeable future. For these areas, there is a clear need for the development of alternative solutions. In addition to the technical assistance provided by the Water and Sanitation Program to the Total Sanitation campaign, the World Bank is also proposing to provide support for improved sanitation through the planned Dhaka Chittagong Water Supply and Sanitation Project, and the Dhaka Environment and Water Resource Management Project.

\section{Safe Drinking Water Supply}

75. The provision of arsenic-safe, microbiologically-clean drinking water remains a major challenge for Bangladesh. Efforts in this area should be accelerated, aimed at providing a choice of technologies to meet the varied situations of the unserved population, targeting arsenic mitigation interventions at households exposed to high levels of contamination, and ensuring that such interventions significantly reduce arsenic exposure without increasing the risk of waterborne disease.

76. Achievement of the Government's goals for the supply of safe water will require an expansion of service coverage to better reach disadvantaged social groups. Urban areas will 
require major investment to meet the growing demand for water, in addition to significant improvements in cost recovery in order to meet operation and maintenance costs. Improved service levels in water supply will require greater involvement of local governments, the private sector and civil society. To ensure the quality of these services, the Government should be supported in its plans to establish an independent regulatory framework to supervise and monitor performance. As indicated in the Bangladesh Country Water Resources Assistance Strategy ${ }^{60}$ the World Bank will continue to be involved in this sector through both the Bangladesh Water Supply Program Project, the Dhaka Chittagong Sewerage and Drainage Sector Project, and the proposed Dhaka Integrated Environment and Water Management Project.

\section{Indoor Air Pollution}

77. Opportunities should be explored to integrate the mitigation of IAP into existing programs, for example through rural energy (Ministry of Energy), clean cooking technologies (including improved stoves and biogas, with leadership from the Ministry of Science and Technology), and village sanitation (Local Government Division). While such initiatives may include a subsidy, at least in initial stages, these should be targeted towards the sustainable private sector provision of such technologies in the longer term.

78. Since better ventilation and longer outdoor time for children are affordable and acceptable for poor families in Bangladesh, and may reduce IAP exposure to much safer levels, promotion of these simple changes is strongly recommended for immediate action. Given the current low level of awareness of the consequences of IAP, however, achieving such behavior change will require a concerted public education effort aimed at explaining the health benefits of reducing exposure to smoke from biofuels. One possible mechanism to promote greater public awareness would be to incorporate IAP messages in the Total Sanitation campaign. The World Bank could support further exploration of this approach through the provision of non-lending technical assistance.

\section{Urban Air Pollution}

79. Mobile sources remain the priority for emissions control in urban areas. Measures aimed at controlling the age of vehicles need to be assessed, as well as the further promotion of public transport. Diesel vehicles are a particular concern in Dhaka, and the World Banksupported Air Quality Management Project has commissioned a study to assess the options for controlling emissions from these sources. It is clear, however, that the sulfur content of imported diesel should meet international specifications (i.e. not exceeding 500ppm), and that initiatives to control emissions should focus on gross diesel polluters, particularly trucks and buses. More generally, it is essential to sustain and expand the monitoring of ambient air quality. Currently this is conducted in a limited fashion only in Dhaka, but it should be extended to other major cities, as well as to provide better coverage in the capital. The World Bank will continue to support initiatives in this area through the Air Quality Management Project, for which a follow-up operation may be considered.

\footnotetext{
${ }^{60}$ World Bank, 2005b
} 


\section{Persistent Organic Pollutants}

80. Although POPs pesticides were completely banned for use in agriculture in Bangladesh from 1997, and recently-imported electrical equipment is understood to be PCBfree, the health risks associated with POPs are an emerging concern in Bangladesh, for which it will be important to establish dialogue and partnerships with relevant government agencies and other stakeholders (including industry associations, bilateral agencies and civil society). The identification of POPs-related priorities must be based on a sound technical understanding of the chemicals management issues, as well as relevant national and international policies. Once priorities are agreed, intervention programs may be established for cleaning up contaminated sites and obsolete stockpiles, monitoring exposure and effects, engaging in information dissemination and awareness-raising, and adopting cleaner technologies. The World Bank can assist the Government in accessing global grant resources to support these activities. 


\section{Chapter 3: Management of Water Quality in Dhaka}

\section{Dhaka: a Mega-City under Stress}

81. Dhaka is the eighth largest city in the world, with a population of about 12 million people in the Dhaka Statistical Metropolitan Area ${ }^{61}$ (DSMA), accounting for about one third of Bangladesh's urban population. By 2015, assuming current population growth trends, the DSMA will have a population of about 21 million, and may be the fourth largest city in the world. ${ }^{62}$ In Dhaka City (the metropolitan area administered by Dhaka City Corporation, DCC), the population density is one of the highest in the world, at more than 20,000 people per square kilometer. ${ }^{63}$ About 4.2 million people live in slum areas, and it is estimated that up to $55 \%$ of Dhaka residents live below the poverty line. Most of the poor lack access to clean water and adequate sanitation facilities, and many live in squalid conditions next to extremely polluted water bodies.

82. Given the size and growth rate of the city's population, and the significance of the DSMA to the national economy (contributing some $20 \%$ of GDP), the host of environmental challenges facing Dhaka constitute a problem of national concern, meriting particular attention in the broader effort to strengthen environmental management within the country.

\section{A Triple Threat: Contamination of the Air, Land and Water}

83. Chief among Dhaka's environmental challenges are risks to human health and natural resource productivity from the poor quality of air, inadequate management of solid waste, and contamination of surface and groundwater in and around the city. While initiatives are underway to better manage air quality and solid waste, little has yet been done to improve water quality, although the economic costs associated with water pollution are estimated to exceed those attributable to poor air quality and solid waste.

84. Despite important steps in reducing air pollution, particularly through the phasing out of leaded gasoline and two-stroke three-wheelers, concentrations of respirable particulate matter in Dhaka exceed standards for more than 100 days of the year, contributing to an estimated 3,500 premature deaths annually as a result of poor air quality in the city. The economic costs associated with death and disease caused by poor air quality in Dhaka are estimated to be in the order of US\$500 million per year. Efforts to address this threat continue under the Department of Environment's (DoE's) Air Quality Management Project, focusing on reducing emissions from gross polluters (particularly trucks and buses), improving fuel specifications (particularly reducing sulphur in diesel), and increasing public support for air quality improvement initiatives through monitoring and dissemination of air quality information.

85. The management of solid waste in Dhaka remains a major challenge. The population of more than five million people living within the area covered by DCC produces about 3,500 tonnes of solid waste daily, of which only $42 \%$ is collected and disposed of at an open,

\footnotetext{
${ }^{61}$ Comprising the areas administered by Dhaka City Corporation (DCC), Dhaka District, Gazipur District, and Narayanganj District

${ }^{62}$ Lizin, 2002

${ }^{63}$ BCAS, 2004
} 
unlined landfill site ${ }^{64}$. The unsanitary conditions created by the poor management of solid waste impose economic costs in the form of health impacts, blocked drainage and aesthetic insults. A promising new direction has been taken, however, with the agreement between DCC and an NGO for private management of the landfill, with carbon financing in support of composting and methane recovery being used to augment the revenue stream. In addition, DCC with support from the JICA is preparing a master plan for solid waste management in Dhaka city.

86. Dhaka is surrounded by rivers and inter-connected with canals which have always formed a life-line for city residents. In the last twenty years, a convergence of unregulated industrial expansion, rural-to-city migration, encroachment of the rivers, overloaded infrastructure, confusion about institutional responsibility for the quality of Dhaka's water bodies, and very ineffective enforcement of environmental regulations have all taken their toll on surface water quality. There is only one sewage treatment plant at Pagla which is currently operating below capacity because of sewerage system failures, and few industries operate effluent treatment systems. Almost all the waste from humans, industry, and millions of farm animals, along with tonnes of pesticides and fertilizers, make their way into Dhaka's surface water untreated, and a percentage of these wastes infiltrate to the groundwater. As a result, pollutant levels in the groundwater are increasing, and many sections of the rivers and canals in the city and surrounding areas, especially the Buriganga and Sitalakhya, are biologically dead during the dry season, spurring widespread public concern and prompting reaction at the highest political levels.

\section{The Economic and Social Costs of Water Degradation}

87. Dhaka surface water is in very poor condition, especially in the dry season. For some six months of the year, the flow rate of the rivers is negligible, often with only a tidal pulse, but the volume of effluent entering the canal and river system remains about the same as during the wet season. Consequently, dilution of contaminants is drastically reduced in the dry season. As Figure 3.1 shows, the most polluted areas are the Buriganga and Sitalakhya Rivers, Tongi Khal, and the canal system in Dhaka East, where very low oxygen levels reflect the breakdown of organic waste, principally domestic sewage and chemical residues from industry. The high levels of oxygen demand in the Buriganga and Sitalakhya Rivers, in particular, reflect the high density of industries discharging untreated waste into the rivers. Some tidal backflow of relatively clean water from the Meghna and Dhaleswari Rivers results in dilution of contaminants in the southern reaches of both the Buriganga and Sitalakhya Rivers, as may be seen in Figure 3.1, but the extent of this positive effect is limited.

88. The very high ammonia levels shown in Table 3.1, particularly in the canal system in Dhaka East, in the Balu River, and in the southern reaches of the Buriganga River, reflect the discharge of sewage into these waterways. Most of this water is unfit for any human use, and is likely to be dangerous to livestock. Of particular concern in the dry season are the high ammonia levels in the raw water used by the Saidabad Water Treatment Plant, which now threaten the plant's ability to treat the water to drinking quality standards. The intake for the Saidabad plant is located at Sarulia, near the confluence of the Balu and Sitalakhya Rivers, one of the Dhaka water pollution "hotspots" (see Figure 3.1). Ammonia in this area increases

\footnotetext{
${ }^{64}$ Waste Concern, 2005
} 
from about $0.3 \mathrm{mg} / \mathrm{l}$ in October to greater than $10 \mathrm{mg} / 1 \mathrm{in}$ March-April, which is twenty times higher than the national environmental quality standard for ammonia in surface water. Ammonia binds to the chlorine in the treatment plant, forming mono, di-, and trichloroamines, which significantly reduce the bactericidal effect of chlorine. As a consequence, the chlorine inputs to the process have to be increased (sometimes from 0.2 ppm to $5 \mathrm{ppm}$ ). This increases the risk to human health, as well as increasing the cost of plant inputs and raising questions about the overall effectiveness of chlorine treatment.

89. The water quality problem is further reflected by high levels of e-coli bacteria, which are indicators of the potential for more harmful bacteria and viruses in the waterways, including hepatitis viruses, typhoid, dysentery, and various other infectious bacteria. Levels of e-coli bacteria higher than $10,000 / \mathrm{ml}$ of water have been recorded in Norai Khal in the last six years. All Dhaka residents are impacted to some extent by deteriorating water quality, but the most vulnerable are the poor, who have few options for accessing clean water and little ability to move away from offensive locations next to polluted ponds, canals, and rivers. In addition to the lost productivity and health care costs associated with waterborne disease, a recent survey of household willingness to pay for improved river water quality in the Dhaka area suggests that the loss of amenity associated with contaminated surface water amounts to about $0.5 \%$ of the region's GDP. ${ }^{65}$

90. Groundwater resources are becoming increasingly polluted. Recent data ${ }^{66}$ on groundwater quality show elevated and increasing levels of dissolved solids, both in the upper ( 5 to 200 meters below surface) and the lower (below 200 meters) aquifer. The total groundwater abstraction from licensed production wells operated by the Dhaka Water and Sewerage Authority (DWASA) and private (mainly industrial) operators is around $700 \mathrm{MCM}$ per year, or $80 \%$ of the total monitored water supply to Dhaka city. The quantity of water abstracted from unlicensed wells is not known, but is estimated to be significant, since groundwater serves as the main water supply for areas that are not connected to the water supply network. Consequently, the infiltration of industrial effluents to groundwater has severe adverse impacts on quality of potable water supplies and potentially poses a serious risk to public health. This risk has only recently been recognized by the responsible agencies, and in response a program to monitor groundwater contamination is being implemented. As more data from this program becomes available, the extent of groundwater pollution, the impact of this pollution on public health, and possible remediation measures can be identified.

91. More than $80 \%$ of the DSMA is still used for agriculture and fisheries, but these activities have declined as pollution has increased. In polluted areas, some $45 \%$ of households report persistent losses in the production of rice, and more than $20 \%$ are experiencing production losses in vegetable crops. Reflecting experience with the death of livestock after drinking river water, less than $15 \%$ of households in highly polluted areas allow livestock to drink river water, compared with more than half in the past. It is estimated that agricultural and fisheries production in the DSMA may be reduced by about one third as a result of poor water quality. ${ }^{67}$

\footnotetext{
${ }^{65}$ Alam et al, 2002

${ }^{66}$ DWASA and IWM, 2005 unpublished

${ }^{67}$ BEMP, 2004a
} 


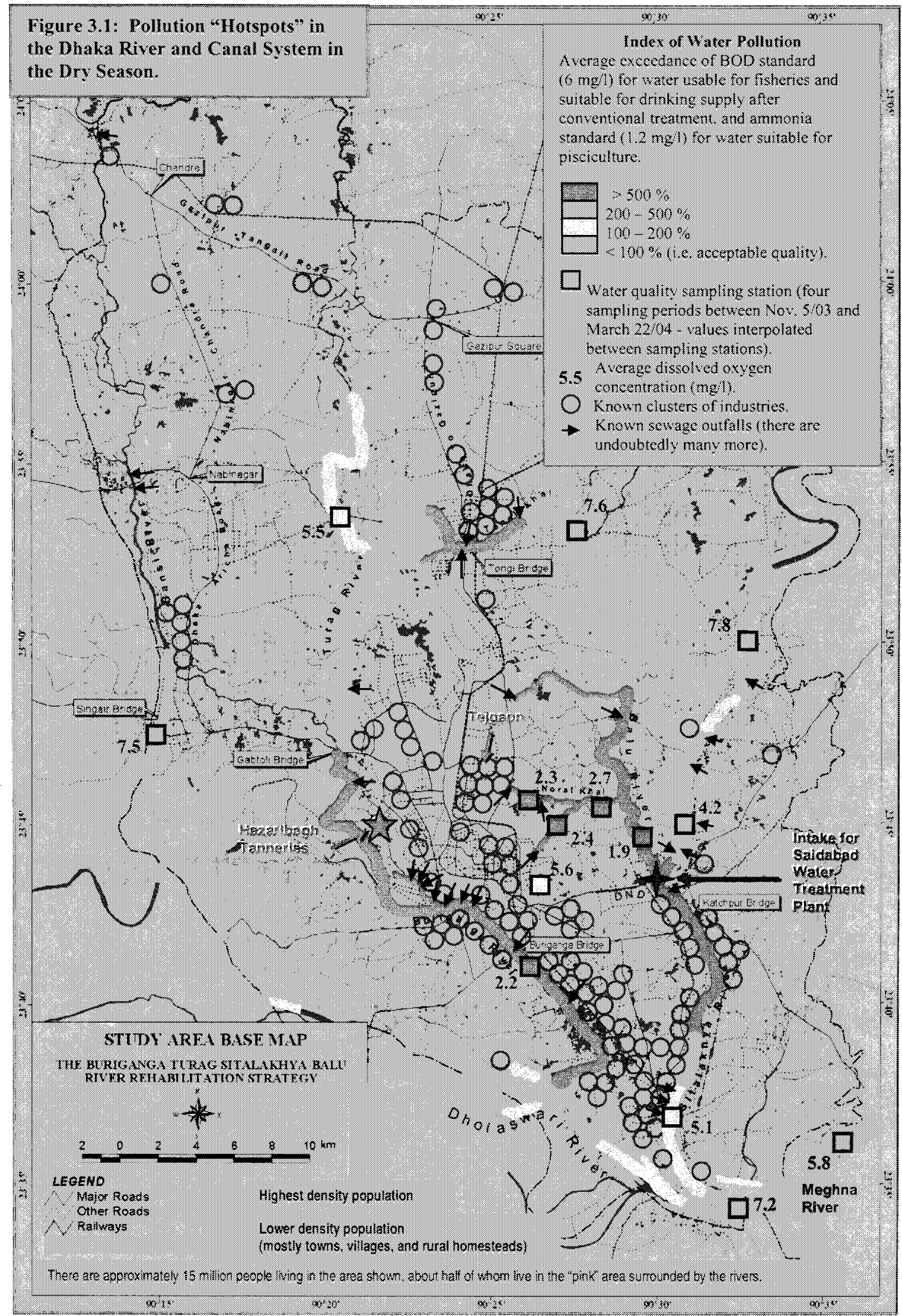


Table 3.1: Water Quality in the River and Canal System around Dhaka, 2003 - 2004

\begin{tabular}{|c|c|c|c|c|c|c|c|}
\hline \multirow[b]{2}{*}{ Location } & \multirow[b]{2}{*}{ Season } & \multirow[b]{2}{*}{ Water Layer } & \multicolumn{5}{|c|}{ Parameter (all $\mathrm{mg} /$ ) } \\
\hline & & & $\begin{array}{l}\text { Total } \\
\text { Dissolved } \\
\text { Solids }\end{array}$ & $\begin{array}{l}\text { Dissolved } \\
\text { Oxygen }\end{array}$ & $\begin{array}{c}\text { Biological } \\
\text { Oxygen } \\
\text { Demand }\end{array}$ & $\begin{array}{l}\text { Chemical } \\
\text { Oxygen } \\
\text { Demand }\end{array}$ & Ammonia \\
\hline & & surface & 19 & 23 & 299 & 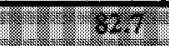 & 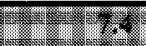 \\
\hline Postogola & Dry & ttom & 319 & 23 & & 136 & 17 \\
\hline (Buriganga River) & & surface & 69 & 8.3 & 09 & 673 & 04 \\
\hline & Wet & bottom & 66 & 8.5 & 0.9 & $20 \div-360$ & 0.4 \\
\hline Convergence of & & surface & 127 & 7.2 & 2,0 & 58.0 & 06 \\
\hline Sitalakhya and & Dry & bottom & 129 & 7.1 & 1.4 & 7.3 & 0.5 \\
\hline Dhaleswari Rivers & & surface & 63 & 8.9 & 13 & 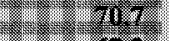 & 0.7 \\
\hline & Wet & bottom & 63. & 9.1) & 13 & 4973 & 08 \\
\hline Narayanganj Ghat & Dry & bottom & 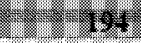 & 5.0 & 92 & $\sqrt{8.207 \%}$ & $2+2$ \\
\hline (Sitalakhya River) & & surface & 63. & 8.6 & 10 & t- 1.3 & 0.4 \\
\hline & Wet & bottom & 63. & 8.5 & 0.9 & 4. 640 & 0.5 \\
\hline & & surface & 19 & 7.2. & 2.0 & 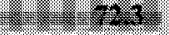 & 0.6 \\
\hline Kanchon & Dry & bottom & 20 & 7.3 & 2.0 & $56,3$. & 0.6 \\
\hline & & surface & 56 & 8.7 & 1.0 & 53.3 & 0.6 \\
\hline & Wet & bottom & 50 & 8.6. & 17. & 50.0 & 0.7 \\
\hline & & surface & 31 & 43 & a3. & 31907 & 26. \\
\hline Demra & Dry & bottom & $23 \%$ & A1 & 13. & 1947 & 30 \\
\hline (Sitalakhya River) & & ce & 56 & 8.8 & 1.4 & $29+6$ & 0.6 \\
\hline & Wet & tom & 56 & 8.4 & 1.5 & 573 & 0.6 \\
\hline$x+3$ & & surface & 57 & 21 & 10 & 1917 & 107 \\
\hline Balu River & Dry & bottom & 98 & 16 & 18 & $4=3$ & 67. \\
\hline & & face & 76 & 6.4 & 1.4 & 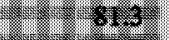 & 0.7 \\
\hline & Wet & bottom & 71 & 6.4 & 1.1 & -6027 & 0.7 \\
\hline & & surface & 278 & 76 & 1.6 & 16.7 & 0.6 \\
\hline Singair & Dry & bottom & 36 & 7,3 & 1.5 & 21.3 & 0.6 \\
\hline & & surface & 66 & 8.5 & 0.7 & 31.3 & 0.4 \\
\hline & Wet & bottom & 65 & 8.3 & 0.8 & 3,3 & 0.4 \\
\hline A. & & surface & 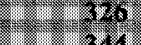 & 6.4 & $\frac{51}{5}$ & $=\sqrt{9.91}=$ & 22 \\
\hline $\begin{array}{l}\text { Ashulia } \\
\text { (Turag River) }\end{array}$ & Dry & $\begin{array}{l}\text { bottom } \\
\text { surface }\end{array}$ & 344 & $\begin{array}{l}6.6 \\
8 ?\end{array}$ & $\begin{array}{ll}45 \\
0.5\end{array}$ & $\frac{2.989}{48 \pi}$ & $\frac{2.16}{10}$ \\
\hline & Wet & bottom & 59. & 8.0 & 0.7 & 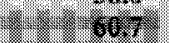 & 0.3 \\
\hline & & surface & 366 & 7.3 & 21 & 41.7 & 165 \\
\hline Uttar Khan & Dry & bottom & 3.376 & 7.9 & 20.120 & 540 & 3.92 \\
\hline & & surface & 53 & 8.0 & 0.8 & 52,7 & 04 \\
\hline & Wet & bottom & 62 & 81 & 0.7 & 44,0 & 0.3 \\
\hline Dholai Khal & Dry & bottom & 8 & & & 1900 & 196 \\
\hline (Dhaka East) & Wet & $\begin{array}{l}\text { surface } \\
\text { bottom }\end{array}$ & & & & & 4 \\
\hline Begunbari Khal & Dry & bottom & 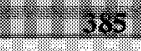 & ang & 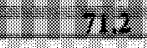 & 163.5 & 218 \\
\hline C) & Wet & bottom & & & & ? & (2) \\
\hline Norai Khal & Dry & bottom & $3 \sqrt{6}$ & 1325 & 20 & 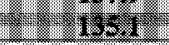 & $2-26$ \\
\hline East) & Wet & $\begin{array}{l}\text { surface } \\
\text { bottom }\end{array}$ & 4 & & & ? & 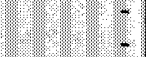 \\
\hline Saidabad Beel & Dry & bottom & 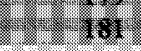 & 5.8 & 62 & $20 \frac{658}{63}$ & $2=2.3$ \\
\hline (D) & Wet & $\begin{array}{l}\text { surface } \\
\text { bottom }\end{array}$ & $17 \%$ & 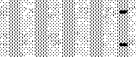 & (2) & ? & 4 \\
\hline
\end{tabular}


92. A benefit-cost assessment conducted for Bangladesh Environmental Management Project (BEMP) ${ }^{68}$ examined the economic costs associated with poor water resource management in the DSMA. Setting aside the costs associated with inadequate water supply and flood control, the assessment identified annual costs amounting to some US\$400 million linked to poor surface water quality, including lost agricultural and fisheries production $(17 \%)$, costs to industry (22\%), lost amenity (21\%), and health costs $(40 \%)$.

\section{Policy and Institutional Factors Affecting Water Quality}

93. The institutional framework for management of the city and its environment is chaotic. There is a serious problem of overlapping jurisdiction between many Government agencies, which often leads to inaction. The legislated roles and responsibilities of Government institutions that have some involvement with Dhaka waterways are summarized in Box 3.1. Currently there is no mechanism for coordinating the planning and implementation of the activities and interventions of all these stakeholders.

\section{Strategic Management of the Sub-Basin}

94. Regardless of the choice of technical interventions to improve the quality of surface water in Dhaka, they need to fit within a coherent long-term strategy, which adopts an integrated perspective to the management of water resources in the Dhaka region drainage sub-basin. Currently there is no such strategy. The RAJUK Structure Plan (1995-2015), which includes protection of waterways and floodplains, has largely been ignored in practice, and is already out of date. In the absence of a single authority having comprehensive responsibility and decision-making power for all water quality and urban habitat issues in the DSMA, reliance must be placed on a coordinating mechanism between the many GoB agencies with roles to play.

95. Building on the Flood Action Plan's integrated land use study for Dhaka, a strategic approach to the management of the sub-basin's water resources would address water quality, water supply, sanitation, and flood management in an integrated fashion. All interventions that deal with water quality will fall under the over-arching policies and directions of the recently approved National Water Management Plan (2004) and therefore need to be consistent with the guiding principles in the plan. The NWMP is a progressive strategy that embraces an increased role for stakeholders in managing water, and the use of economic instruments to encourage wise allocation and use of water, while assigning a more realistic value to access, treatment, and delivery of water, and the use of waterbodies.

\section{Compliance Promotion through Prioritization, Institutional Incentives and Waste Minimization}

96. Although there are sufficient regulations in place to control most activities that may have harmful effects on the urban environment, in practice these are largely ignored and enforcement is very weak. In particular, the current impunity with which industry discharges effluent into rivers and canals must be checked if surface water quality is to be improved, requiring stricter enforcement of environmental clearance conditions and effluent standards. Recognizing DoE's limited manpower and technical capability in monitoring and enforcing

${ }^{68}$ BEMP, 2004c 
environmental regulations, any program of enhanced regulatory activities must be focused on priority sources of contamination. The institutional incentives for DoE staff to strengthen enforcement must be re-examined, based on a consideration of performance indicators, transparency and accountability.

\section{Box 3.1: Responsibilities of Government Institutions Regarding Dhaka Water Quality}

Department of Environment: Under Ministry of Environment and Forests: enforcement of environmental rules (environmental impact assessment; environmental clearances; effluent standards); setting environmental quality standards for water uses; routine monitoring of water quality; technical input to various GoB committees; administration of the Open Space and Wetland Conservation Act, 2000 and Urban Water Body Protection Law, 2001.

Dhaka City Corporation: Under Local Government Division (Ministry of Local Government, Rural Development and Cooperatives): responsible for handling and disposal of solid waste; issuance of business licenses; management of public green spaces; mosquito control; provision of public toilets; maintenance of public bathing and washing locations; surface drainage from roads; maintenance of some lakes (such as Dhanmondi); control of markets; operation of health facilities; flood control measures; regulation of private sources of water supply; city planning; now participating in Dhaka Good Governance Committee, under Principal Secretary, PMO.

Adjacent Districts: Deputy Commissioners, acting under the Ministry of Land, for Dhaka District; Gazipur District; Narayanganj District: local administration of infrastructure and services in these districts, many of which have a direct bearing on water flow and water quality; any project, such as waste treatment, that has land requirements will go through the DCs; municipalities and union parishads in these districts covered by the Pourashava and Union Parishad Ordinances (under Ministry of Local Government, Rural Development and Cooperatives), giving them jurisdiction for waste disposal and pollution management within their boundaries.

Rajdhani Unnayan Kartipakha (RAJUK): Autonomous body under Ministry of Housing and Public Works: planning for development and land regulation in urban areas; jurisdiction for Dhaka City and surrounding areas in Greater Dhaka, including preparation, implementation, and monitoring of a master plan; creation of planned townships, with related infrastructure; development control, including approval of plans for land use; jurisdiction over Gulshan Lake; presently completing Detailed Area Plans for Dhaka.

Dhaka Water and Sewerage Authority: Under Ministry of Local Government, Rural Development and Cooperatives: provision of pure, safe, and dependable water to Dhaka citizens (including Naranyanganj); regular, safe, continuous disposal of sewage; operation and maintenance of drains for stormwater disposal; collection of fees for these services.

Water Development Board: Under Ministry of Water Resources and Flood Control: planning and implementation of water-related projects at the national level that involve infrastructure (direction and flow of water; mostly embankments and flood control); coordination of implementation of the National Water Management Plan (with WARPO).

Ministry of Land: Register of government title for land (through Department of Survey and Land Records), including river beds and contiguous land; through the Deputy Commissioners, leasing of these lands, and eviction, as necessary; administration of land compensation process for private lands.

Department of Public Health Engineering: Under Ministry of Local Government, Rural Development and Cooperatives: outside the DCC area, responsible for rural water supply; monitoring of water quality.

Bangladesh Inland Water Transport Authority: Under Ministry of Shipping: development, maintenance, and control of inland water transport and maintaining navigable waterways; involved in riverbank protection on the Buriganga and demolition of structures in river buffer zone; dredging, shipping terminal maintenance, and waste disposal at these facilities.

Department of Shipping: Under Ministry of Shipping: responsible for survey and certification of ships and boats in the river system (including seaworthiness and waste management).

Ministry of Industry: Overall policy direction for industrial development; a role in development of industry in specified zones and compliance with pollution control regulations in factory design. 
97. In addition to DoE, there is a clear incentive for DWASA to be involved to a greater extent in the enforcement of environmental compliance, since DWASA bears the increasing costs of wastewater and drinking water treatment as a result of indiscriminate effluent

disposal. Stricter enforcement of effluent standards would also help stimulate demand for alternative approaches to waste treatment that may reduce industry's operational costs and increase production efficiency, as well as bringing environmental benefits. In response to this demand, technical assistance for waste minimization initiatives could be provided as part of a broader program of compliance promotion.

\section{Building Support through Consultation, Transparency and Participation}

Even without additional enforcement activities, international experience has demonstrated the power of enhanced monitoring when the results are disclosed, and the environmental performance of individual facilities is publicly recognized. There is significant scope for $\mathrm{DoE}$ to adopt such an approach, focusing on priority sources of contamination, and applying "e-government" techniques to make the results of environmental monitoring and decisionmaking as transparent as possible. Increased transparency would also strengthen the role of community groups and NGOs in the organization of Dhaka environmental management initiatives. NGOs are already making valuable contributions to the improvement of the Dhaka environment, for example through trials with composting and slum improvement projects, and their participation must be welcomed and recognized to build the community support required for stronger regulatory action.

\section{Attracting the Resources Required}

98. The resources required to address Dhaka's environmental challenges will be significant, with estimates ranging up to US\$ 8 billion over 20 years. ${ }^{69}$ Maintenance and expansion of the urban infrastructure has been neglected, and major overhauls are now required. Mobilizing resources of this scale will require private sector participation, in addition to the support of development partners. Attracting private investment, even more so than development assistance, will require institutional reform that provides strategic direction and clarity of roles, and supports the recovery of costs for urban services as well as the transparent enforcement of regulations.

\section{Responses to Water Quality Issues in the Dhaka Area}

99. The deteriorating condition of the Buriganga River in the mid-1990s stimulated the "Save the Buriganga" movement, a collaboration of various Government agencies and NGOs. Most of the effort focused on public awareness, processions, monitoring of the Dhaka canal and river system, and destruction of buildings that encroached on the Buriganga River. More recently, the Prime Minister reactivated the River Committee, which reported in January, 2004, listing a series of proposals that deal with water supply, flow, and water quality (see Table 3.2).

${ }^{69}$ BEMP, 2005a 


\section{Table 3.2: River Committee Proposals for Water Resource Management in Dhaka ${ }^{70}$}

\begin{tabular}{|c|c|}
\hline Proposal or Initiative & 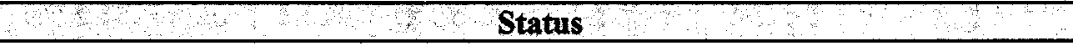 \\
\hline $\begin{array}{l}\text { Flood Retention Ponds in } \\
\text { RAJUK Dhaka Structure Plan }\end{array}$ & $\begin{array}{l}\text { Concept more or less defunct; many of the proposed flood retention ponds have } \\
\text { been filled in; this concept is not being actively pursued by any GoB agency; } \\
\text { RAJUK recently started work on Detailed Area Plans for Dhaka. }\end{array}$ \\
\hline $\begin{array}{l}\text { Eastern Embankment cum } \\
\text { By-Pass Road } \\
\text { (WDB and DWASA) }\end{array}$ & $\begin{array}{l}\text { Included in the Prime Minister's River Committee Report (January, 2004), this } \\
\text { was recently passed over by the Planning Commission; concerns about high cost, } \\
\text { technical complications, and potential negative environment effects; has recently } \\
\text { been re-activated because of the } 2004 \text { flood; undergoing technical feasibility } \\
\text { analysis and environmental screening. }\end{array}$ \\
\hline $\begin{array}{l}\text { Augmentation of Flow in the } \\
\text { Buriganga River, Circular } \\
\text { Waterway Project (WDB and } \\
\text { BIWTA) }\end{array}$ & $\begin{array}{l}\text { These various initiatives included in the Prime Minister's River Committee } \\
\text { Report; augmentation of flow still requires more analysis (potential problems with } \\
\text { upstream water abstraction and negative environmental effects); circular } \\
\text { waterways project partially completed (not fully funded, but a recent } \\
\text { announcement of additional US } \$ 10 \text { million GoB funds for walkways and } \\
\text { barriers); prevention of river encroachment has involved occasional demolition of } \\
\text { structures on the Buriganga River. }\end{array}$ \\
\hline $\begin{array}{l}\text { Saidabad Water Treatment } \\
\text { Plant (DWASA) }\end{array}$ & $\begin{array}{l}\text { Funding for Phase } 2 \text { being sought (now being considered by DANIDA and } \\
\text { SIDA); ongoing issue with ammonia contamination and excessive algae in water } \\
\text { supply; DWASA favours moving the Sarulia intake up the Sitalakhya River (this } \\
\text { is controversial); other options include an ammonia scrubber at Saidabad or an } \\
\text { intake on the Meghna River ( a long-term solution). }\end{array}$ \\
\hline $\begin{array}{l}\text { North Dhaka Sewage } \\
\text { Treatment Plants } \\
\text { (DWASA) }\end{array}$ & $\begin{array}{l}\text { Included in the Prime Minister's River Committee Report; DWASA has had } \\
\text { difficulty securing financing; small "footprint" multi-storey sewage treatment } \\
\text { plants (Bangkok model) promoted during recent consultations in Dhaka. }\end{array}$ \\
\hline $\begin{array}{l}\text { Upgrading the Pagla Sewage } \\
\text { Treatment Plant; Extending } \\
\text { the DWASA Sewage } \\
\text { Network }\end{array}$ & $\begin{array}{l}\text { Some of this work has been undertaken by DWASA, with JICA funding; } \\
\text { however, stalled due to lack of full funding; infrastructure division at World Bank } \\
\text { is actively considering this initiative. }\end{array}$ \\
\hline $\begin{array}{l}\text { Moving the Hazaribagh } \\
\text { Tanneries to Savar (BSCIC) }\end{array}$ & $\begin{array}{l}\text { Included in the Prime Minister's River Committee Report; BSCIC has purchased } \\
\text { some land in Savar and } 200 \text { plots are being prepared, but the tannery industry is } \\
\text { still lobbying GoB for financial subsidies to support the move, and proper } \\
\text { environmental management facilities are not clearly documented; very high } \\
\text { priority initiative. }\end{array}$ \\
\hline $\begin{array}{l}\text { Common Effluent Treatment } \\
\text { Plants (CETP) for Industry } \\
\text { (DoE) }\end{array}$ & $\begin{array}{l}\text { Still only a concept; LGRD has asked for more technical details and cost analysis } \\
\text { from the Bangladesh University of Engineering and Technology; could also to be } \\
\text { supported by a proposed constructed wetland near Norai Khal, for Tejgaon } \\
\text { industries, and common reed beds for textile industry clusters; ongoing } \\
\text { experimentation with waste minimization, settling ponds, and reed beds for the } \\
\text { textile industry in Narsingdi, a collaboration of BEMP, DoE, and textile industry } \\
\text { associations - this has produced positive results showing technical effectiveness } \\
\text { and cost efficiencies; recent interest in combining CETPs with constructed } \\
\text { wetlands in a "hybrid" system. }\end{array}$ \\
\hline $\begin{array}{l}\text { Dhaka Solid Waste } \\
\text { Management } \\
\text { (DCC) }\end{array}$ & $\begin{array}{l}\text { Included in the Prime Minister's River Committee Report; JICA has been } \\
\text { undertaking design work over the last year; Waste Concern has been } \\
\text { experimenting with small composting facilities and is proposing larger-scale } \\
\text { composting and methane recovery at Matuail; full funding still being sought. }\end{array}$ \\
\hline
\end{tabular}

100. Subsequently, the consultative process for the Dhaka Environment Programme (an initiative of $\mathrm{MoEF}$ ) resulted in a portfolio of potential solutions to address water quality issues in Dhaka. The solutions were clustered according to key issues, summarized below, in order of priority (highest to lowest - see Appendix I for details):

\footnotetext{
${ }^{70}$ As of January, 2005, updated from BEMP, 2003
} 
- improvement of water supply;

- treatment and disposal of sewage;

- treatment and disposal of industrial effluent;

- handling and disposal of solid waste;

- flood management, dredging, and improving river navigability;

- management of household liquid waste;

- management of ship oily waste;

- improving aesthetics and opportunities for recreation;

- controlling agricultural runoff.

Investment and Institutional Strengthening for improved Water Supply and Sanitation Services

101. The supply of safe water and treatment of sewage are the clear responsibility of DWASA and require major overhauls of infrastructure, as well as significant investment in new distribution and collection networks and treatment plants. DWASA is presently involved in discussions with a number of Development Partners, including the World Bank, to address these issues. In particular, GoB has requested assistance from the Bank to prepare a project to improve water supply, sewerage, sanitation and storm water drainage services in Dhaka. The sewerage and sanitation project plans, among other improvements, to rehabilitate the existing sewer systems, storm water drains and natural retention reservoirs, and build new storm water pumping stations in Dhaka. The main objective of the "Dhaka Sewerage" sub-component would be to rehabilitate existing trunk sewers and extend secondary and tertiary sewers to reach new customers so that the full capacity of the Pagla sewage treatment plant can be used.

102. DWASA is currently in discussions with development partners to finance an expansion to the Saidabad Water Treatment Plant, rehabilitation and improvement of services of the water supply distribution network, as well as urgently needed improvements to the sewerage network and the Pagla Sewerage Treatment Plant. DWASA and development partners are coordinating closely to ensure that overlaps are minimized and that no gaps occur in the needed investment to Dhaka's water supply, sewerage and drainage system. DWASA has already begun to implement a performance improvement program for the utility, which focuses on key operating and financial indicators to monitor improvement in DWASA's service in water supply, sewerage and drainage operations.

\section{Targeted Enforcement and Low-Cost Treatment Options to Control Industrial Effluent}

103. The remaining priority water quality challenge is treatment of industrial waste. Of the challenges noted above, this is the one that is most in the control of the private sector, and currently the least effectively handled by regulatory agencies. To date there has been little to no enforcement of environmental regulations, and as a result, industry pollutes the surface waters of Dhaka with impunity. To reduce the pollution of surface water bodies, both on-site and centralized treatment of industrial effluents are required. To reduce the pollution of groundwater bodies, a reduction of pollutants leached to the aquifer can be achieved by on- 
site treatment in combination with improved conveyance of effluents to a centralized treatment facility.

104. The Government has requested assistance from the Bank to reduce the pollution of water bodies by industrial effluent. The proposed integrated environment and water management project will invest in treatment options for industrial effluent, and will also build appropriate capacity for improved monitoring of pollution and the more efficient enforcement of environmental compliance. As the main agency responsible for water quality and water treatment in Dhaka, DWASA is likely to be the principal implementing agency for this project, while DoE will be involved in all components, especially those related to environmental monitoring and compliance.

105. The main industry clusters and effluent "hotspots" include the tanneries at Hazaribagh which pollute the Buriganga River, the Tejgaon Industrial Area which drains to the Balu River, the Tongi Industrial Area which pollutes Tongi Khal, the Sayampur and Fatullah industrial clusters in Dhaka South and Narayanganj which discharge to the Buriganga River, and the developing heavy industry strip along the Sitalakhya River. A comprehensive strategy to bring industrial effluent under control at the industrial sites would include at least the following four elements:

- Tighter control on new industrial development in the center of the city, through more effective application of the EIA system. Credible use of the EIA approval process to require investment in adequate on-site or shared effluent treatment facilities would reduce the attraction of land-scarce city center locations for new developments, and would have the effect of encouraging the development of industrial zones outside the city that can properly service all industrial waste.

- In addition to controlling new development, the EIA system could also be used much more effectively to manage effluent from existing facilities. Under the Environmental Conservation Rules (1997), industries in the Orange and Red Categories are required to renew their Environmental Clearance Certificates annually. Although little used at present, this requirement offers a clear opportunity for the DoE to agree on compliance plans with priority polluting facilities, which if combined with an enhanced program of environmental monitoring and regulatory action, would gradually increase pressure to reduce contamination.

- The development of compliance plans linked to annual renewals of Environmental Clearance Certificates would also stimulate demand for technical assistance for waste minimization. Such assistance, potentially drawing on the ISO 14001 model of environmental management systems, could be offered by the DoE as a component of the compliance planning process. The added advantage of the introduction of environmental management systems is that it provides businesses with a tool to optimize production processes whilst reducing waste and improving the efficiency of energy use.

- Development of shared waste treatment facilities. In planning such investments, two key principles should be adhered to: (i) maximize the involvement, both financial and technical, of the industries whose effluent the facilities are intended to handle; and (ii) minimize the capital and recurrent costs involved. In particular, it should be clear 
that the operating and maintenance costs of waste treatment will be borne by those generating effluent, based on a per unit volume charge.

106. A reduction in the discharge of effluents to vulnerable surface water bodies can be achieved through appropriate treatment trains of primary, secondary and tertiary treatment technologies, including wastewater stabilization and retention ponds, as well as constructed wetlands. Due to the high pollutant load of the effluents, a single treatment option will not achieve the desired effluent quality; consequently, a successful treatment strategy is likely to consist of a combination of appropriate treatment technologies.

107. Constructed wetlands in combination with primary and secondary treatment, such as waste stabilization ponds, offer one possible approach to minimize the capital and recurrent costs of treating industrial effluent. International experience has demonstrated the effectiveness of using reed beds to strip contaminants from a variety of waste streams, and recent positive data from reed bed experiments in Narsingdi ${ }^{71}$ have stimulated interest in pilot implementation of constructed wetlands in the Dhaka area. Results from the Narsingdi pilot indicate that constructing and operating a settling tank and reed bed wastewater treatment system, excluding the cost of land, increases the annual operating costs of small and mediumsized textile factories by only $0.5 \%$. Amortized over ten years, the purchase of land required for a reed bed could increase annual operating costs of textile factories by a further $2 \%$. In comparison, the costs of mechanical and chemical waste effluent treatment systems are up to $5 \%$ of the annual operating costs of larger textile factories.

108. Assessment of the feasibility of a constructed wetland initiative in Dhaka will require consideration of the land cost, the practicality of acquiring sufficient land and protecting it from future encroachment, the construction and operational costs, and determination of the potential decrease in pollution load and the associated benefits. These results could then be compared to more conventional wastewater management methods involving mechanical and chemical treatment, which require less land, but have higher construction and operational costs. A potentially important consideration will be whether the wetland area required can serve a dual purpose, for example as a pump pond or storm water buffer. One possible approach is the construction of "hybrid" systems that combine the positive elements of the wetland and mechanical options. These might handle the wide variability of contaminants in the surface drainage in specific Dhaka sub-drainage basins, such as Tejgaon, by combining a common effluent treatment plant for settling of solids and associated contaminants, and a constructed wetland for stripping dissolved contaminants from surface drainage.

109. An initial assessment of opportunities for application of the constructed wetlands approach to managing industrial effluent suggests that it would be worth conducting feasibility studies for the following four locations:

- isolation of wastewater from Tejgaon, and use of a series of linked settling ponds and constructed wetlands (total area of about 20-30 hectares) running between Rampura and the Balu River to strip contaminants (especially ammonia) from water (land availability still to be determined);

${ }^{71}$ BEMP, 2005b 
- application of a small (2-4 hectare) constructed wetland for treatment of waste from a textile industry cluster (5-8 factories) in the Fatullah area (suitable land appears to be available);

- experimentation with settling ponds and constructed wetlands to clean polluted surface drainage in the Goran Chatbari pump ponds on the Turag River (276 hectares of land/pond owned by BWDB are available); and

- development of in-plant waste minimization and common reed beds for small clusters of industries along the Dhaka-Tangail Road (Dhaka District); this area has been surveyed by Waste Concern, providing a good baseline for design and implementation of innovative wastewater management schemes; apparently land acquisition would not be a significant problem.

\section{Water Quality in Dhaka: Recommendations and Areas for World Bank Support}

\section{Strategic Framework for Management of Dhaka's Water Resources}

110. Interventions to improve the quality of surface and groundwater in Dhaka need to fit within a integrated long-term strategy addressing water quality, water supply, sanitation, and flood management. To achieve this goal, a single statutory body should be formed to promote cross-sectoral coordination and minimize jurisdictional conflicts. An important element of the strategic framework will be adequate monitoring of environmental pollution, in combination with public information, aimed at raising awareness of the causes and impacts of environmental degradation, and at disseminating information about related interventions. Such initiatives are essential to build civil society and private sector support, both for the necessary investments, and for strengthened enforcement of environmental regulations.

\section{Compliance Promotion}

111. Industrial discharges into rivers, canals and groundwater must be reduced if water quality is to be improved. This will require stricter enforcement of environmental clearance conditions and effluent standards, focusing on priority sources of contamination.

Compliance plans for existing priority facilities should be agreed through application of the requirement that they renew their Environmental Clearance Certificates annually. Tighter control on new industrial development in the center of the city must be applied through more effective use of the EIA system. To achieve tighter regulatory control it will be necessary to re-examine the institutional incentives for DoE staff, based on a consideration of performance indicators, transparency and accountability, and to better define the linkages between the regulatory roles of DoE and DWASA, as the principle agency responsible for water quality in the Dhaka watershed.

112. In addition to direct regulatory control, international experience underlines the value of providing the public with specific information on sources of pollution, including the identities and performance of the principal actors involved. There is significant scope for DoE to adopt such an approach, focusing on priority sources of contamination, and making the results of environmental monitoring and decision-making as transparent as possible. Heightened public pressure, combined with stricter enforcement of effluent standards, will help stimulate demand for alternative approaches to waste treatment and reduction. In response, technical assistance for waste minimization initiatives, including the development 
of environmental management systems based on the ISO 14000 model, could be provided through DoE as part of a broader program of compliance promotion.

113. A number of mechanisms exist or are proposed through which the World Bank could support compliance promotion initiatives in Dhaka. In addition to budget support for the DoE through the ongoing program of development policy lending, proposed projects for private sector development and water resource management in Dhaka could include components to provide the DoE and DWASA with technical assistance for the initiatives described above.

\section{Investing in Waste Treatment}

114. The World Bank's Country Water Resources Assistance Strategy for Bangladesh ${ }^{72}$ establishes that improving the quality of surface and groundwater in and around Dhaka will require significant investment in effluent collection and treatment. In response to the Government's request, the Bank is helping prepare a project to improve water supply, sewerage, sanitation and storm water drainage services in Dhaka. Bank assistance for a separate project was requested by the Government, to strengthen the management of environmental quality and water resources through investments in appropriate treatment technologies, including non-conventional solutions, such as septic tank effluent systems and constructed wetlands.

115. In addition to Government investment and the support of development partners, mobilizing sufficient resources to effectively address Dhaka's environmental challenges will require private sector participation. Improved compliance with environmental legislation, combined with application of the Polluter Pays Principle, will stimulate demand for private investment, for example in shared waste treatment facilities. Establishing and maintaining the conditions necessary to attract private resources will require the continued transparent enforcement of regulations, combined with institutional reforms that provide strategic direction and clarity of roles, and that support the recovery of costs for urban services.

${ }^{72}$ World Bank, 2005b 


\section{Chapter 4: Management of Capture Fisheries}

116. In 2000, Bangladesh's fisheries sector contributed some US\$1.5 billion to the country's GDP, amounting to about $4 \%$ of the $\operatorname{total}^{73}$, and the seafood export sector is now the country's second largest source of foreign exchange. Bangladesh's inland and coastal/marine capture fisheries represent a safety net for the economic and nutritional needs of many of the rural poor. Four out of five rural Bangladeshis, amounting to as many as 85 million people, are dependent to some extent on aquatic resources. It is estimated that over one million people fish full time and another 11 million fish professionally on a part-time basis, with the fisheries sector providing employment for $9 \%$ of the country's labor force. In terms of nutrition, Bangladesh's aquatic resources, from both capture fisheries and aquaculture, are reported to meet more than $65 \%$ of the country's animal protein needs (twice the regional average and the seventh highest in the world), and are a critical source of essential minerals, vitamins and fatty acids.

117. The fate of Bangladesh's capture fisheries is inextricably tied to the condition of the nation's wetlands. Recent economic studies ${ }^{74}$ indicate that wetlands have almost twice the economic output of rice crops, exceeding Tk. 35,000/ha/year, with the largest share of their direct benefits going to poor people in rural communities. In addition, wetlands provide a variety of indirect environmental services in the form of flood control, ground water recharge and pollution abatement. Any strategy that addresses poverty alleviation in rural Bangladesh must take these fisheries and aquatic resources into account.

\section{The State of Capture Fisheries}

118. In the past decade a wide range of changes affecting fisheries have taken place, including very large increases in fish production from all forms of pond aquaculture, declines in most capture fisheries, encroachment and degradation of natural assets, rapid urbanization, infrastructure investments that have negatively impacted fisheries, and increased pollution. A major constraint to fish production is reduced dry season surface water flows in the Ganges and other rivers, related to the operation of the Farakka Barrage, unregulated water extraction for irrigation, and the impacts of a large number of Flood Control, Drainage and Irrigation (FCDI) projects.

119. Figure 4.1 represents a consensus of opinion on production projections by fisheries sub-sector, based on the 2003 Fisheries Sector Review and Future Development (FSRFD) study. These data are projections from the Household Expenditure Survey (BBS) and also use aspects of Fisheries Resources Survey Service (FRSS) and other Department of Fisheries (DoF) data. It is generally agreed that both freshwater and brackish-water aquaculture will continue to grow at about $5.6 \%$ and $3.2 \%$ per year respectively, which is slower than the $20 \%$ per annum reported in the past decade. There is also a general consensus among most authorities that the capture fisheries, both inland and coastal/marine, are in decline, at rates of about $2.1 \%$ and $1.6 \%$ per year, respectively. There is not unanimous agreement with this statement, however, particularly regarding declines in the marine sector, and there is some evidence that deep water offshore stocks do offer some opportunities for the industrial

\footnotetext{
${ }^{73}$ FSRFD. 2003

${ }^{74}$ MACH Project, Hail Haor Resource Valuation; DANIDA, MAEP and GNAEP Wetlands Study; BCASICLARM Livelihoods Study; Munir, A, 2004
} 
trawler fleet. Nevertheless, data from the Household Expenditure Survey and surveys by the Fourth Fisheries Project (FFP), as well as opinions of fishers themselves, indicate overall declines in coastal and some marine stocks.

Figure 4.1: Fisheries Production by Major Sub-Sector ${ }^{75}$

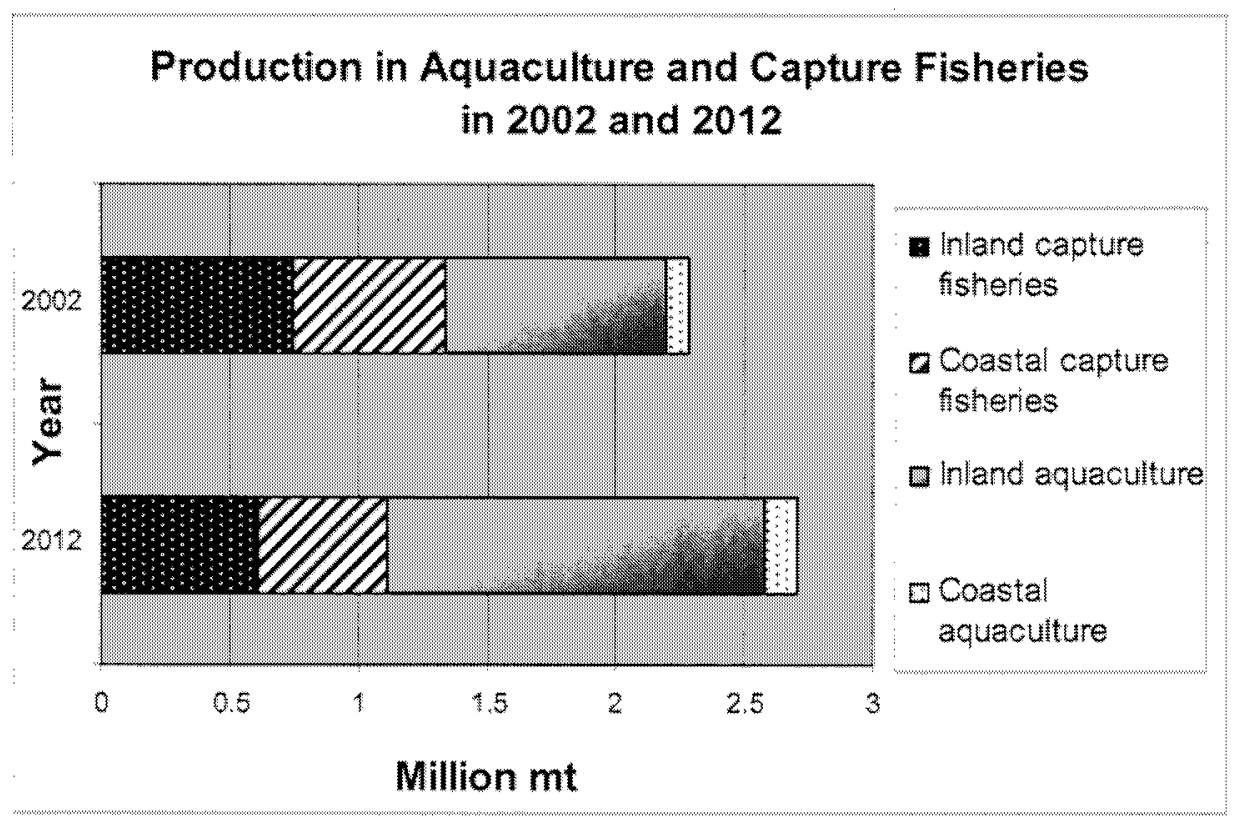

120. As with all biological systems, recovery is possible if political will combines with good management. By late 2004 a remarkable recovery of Hilsa was seen, most likely as a result of Govermment management activities (see Box 4.1). There is still a fear, however, that some of the fisheries, namely the inland major carps, Indian Satmon and other coastal inshore fisheries, may be in danger of collapse. The consequences of a collapse of the sort seen in the North Atlantic cod fishery would impact every citizen of the country, particularly the poor.

\section{The Inland Capture Fishery: a Resource ander Threat}

121. Almost all authorities agree that production in the inland capture fishery has declined, given the continuing losses of floodplain habitat due to agriculture and urbanization, lost connections along critical fish migration pathways, significant reductions in dry season riverine flows, over-fishing, and rapidly increasing industrial, human and agricultural pollution. The IUCN Red Book for Bangladesh suggests that almost $30 \%$ of all inland fish species for which data is available are in some danger of extinction. The Red Book ${ }^{7}$ reports that 54 inland and estuarine fish species out of a total of 266 present in Bangladesh are endargered.

\footnotetext{
Motrat, 2003

76 fourth Wwheries project. 2004

MCN. 2000
} 


\section{Box 4.1: Saving the Hilsa - Showing it Can be Done}

Hilsa remains the most important fish in the capture fisheries, and is the national fish of Bangladesh. In the years 1999-2002 the hilsa fishery showed precipitous declines of as much as $60 \%$. These were likely, in the long term, to have resulted in the collapse of this fishery. In 2004, however, a series of management steps based on recommendations of the DoF/FFP-GEF have contributed to a very notable recovery. This may be one of the first times in Bangladesh that a nationwide effort has led, at least temporarily, to a reversal in the decline of a natural resource.

From the point of view of the hilsa fishery this was a remarkable effort by Government, and a clear success of the DoF, the project and the individuals involved. This effort should be seen as an important first step in what should become a long-term national effort. This combined national effort was an ad hoc endeavor responding to an important national issue, combining a number of key elements:

- Awareness - national concern and wide agreement that an important resource was declining;

- Sound science - a concerned Department and Ministry with an understanding of the problem and an action plan based on sound science;

- Political will - political representatives willing and able to provide the political support necessary;

- Inter-ministerial cooperation - brought about by that political will; and,

- Implementation of the management plan - developed by the relevant government Department.

Source: Based on information collected by the DoF/World Bank funded GEF component of the Fourth Fisheries Project

122. Production from the eight million hectares of seasonal flood-lands is by far the most important component of the inland fishery, which includes floodplains, beels and rivers. As monsoon water annually spreads across the floodplain, nutrients are released and primary production explodes over a very wide area. So long as adequate recruitment is present, there follows tremendous fisheries production. Studies in Bangladesh and throughout Asia suggest that this production could be as high as $300-400 \mathrm{~kg} / \mathrm{ha}$ in high quality floodplains. Production is dependent on a number of factors including the extent, duration and seasonality of flooding, as well as the hydrology of individual water bodies.

123. The dry season represents the most critical season for all species of fish and the greatest impacts occur at this time, when populations are at their lowest levels, fishery habitats are limited, predation is at a peak, and growth is slowed. Competition for food is keen and pressure by fishermen remains high. Reductions, for whatever reason, in dry season aquatic habitat have the potential to reduce parent stocks to below replaceable levels. Basic minimum stream flow requirements are necessary to maintain healthy fish populations and to ensure that sufficient parent stock are available for re-population of the floodplain fishery during the next wet season. Perennial wetlands and minimal riverine flows along with sufficient parent stock are the key to fish production in Bangladesh.

\section{The Shifting Species Composition of the Inland Capture Fishery}

124. The major species group (66\%) caught in the beels and floodplains are now a wide variety of mostly small fish, mainly comprising grazers and detritus feeders, small predators, and small "pelagic" plankton feeders. Carp, including major carps, large catfish and large fish in general, have greatly declined in abundance, but together may still comprise around $11 \%$ of the catch. Smaller Koi (climbing perch), snakeheads, other catfish and other beel resident species with the ability to tolerate low oxygen levels, comprise a significant proportion of the catch, together around $18 \%$. 
125. Overall 40-70 species are typically caught in most beel/floodplain systems. However, $5-7$ species will typically contribute $60-80 \%$ of the catch. Dominant species (commonly more than $10 \%$ of the catch) in the floodplain catch are small prawns (mainly Macrobrachium spp), Puntius sophore and other Puntius species, small Channa, Colisa fasciatus, Aorichthyes seenghala and Heteropneustes fossilis, and a few other fast breeding small species. Prices for all non-aquaculture species including the smallest fish have risen substantially in recent years.

126. There appears to have been a significant shift from larger fish and fish species to smaller fish and prawns. This is probably related to:

- Restriction of breeding migrations for all migratory species;

- Loss of dry season habitats most suitable to the species and the loss of connections for estuarine and riverine species that utilize the seasonal floodplains as breeding and nursery areas;

- Greater susceptibility of larger species to over-fishing (of spawn and adult); and,

- Greater resilience of smaller rapidly reproducing species to over-fishing and to losses of dry season habitat.

In some of the smaller beels and enclosed floodplain areas stocking takes place, and in these systems the proportion of major carps, silver carp, common carp and grass carp is significant. Most of the baors (oxbow lakes) in the Jessore area are stocked, and the catch composition reflects this, with $40-60 \%$ exotic carps, $8-13 \%$ major carps, and $29-42 \%$ other.

127. The river catch was in the past dominated in terms of both value and production by the migratory hilsa (Tenualosa ilisha). The Farraka Barrage in India coupled with heavy fishing of juvenile stocks has resulted in the disappearance of riverine hilsa. Until the 1970's almost all the hilsa consumed came from the rivers, but now most of the catch comes from the Bay of Bengal. However, the jatka or juvenile hilsa catch still occurs in the lower reaches of the Meghna and other rivers which serve as nursery areas for 5-7 months. Prawns, mostly small, are probably the second most important group, contributing $10-15 \%$ of the catch. Other important species are Macrobrachium spp., Clupisoma garua, Pangasisus pangasius, Puntius sophore, Glossogobius giurus, Aorichthys seenghala, Labeo rohita, Catla catla, Wallagu attu and Mystus cavasius. In practice a wide variety of other species are caught, with around 35 species each contributing more than $1 \%$ to the catch.

\section{Open Water Stocking: Ambiguous Impacts}

128. Open water stocking in Bangladesh is the result of the success of the World Bank supported Second Fisheries Project, also known as the Baor Program in the mid-1980's. This program showed that yields as high as $1,000 \mathrm{~kg} / \mathrm{ha}$ could be obtained with intensive stocking of native and exotic carps in the semi-closed baor areas. In the early 1990's the Third Fisheries Project (also supported by the World Bank) and the Second Aquaculture Project (supported by the Asian Development Bank) incorporated open water stocking into their strategies. More recently the DoF is supporting private sector initiatives that block off large seasonally flooded areas. Open water stocking continues to be supported by the DoF, a number of development partners, and many national and international NGOs. All have 
shown the overall technical feasibility and increased yields of high value carps that result from open water stocking.

129. Controversies have arisen, however, regarding the sustainability and cost recovery of stocking programs, as well as social and biodiversity concerns. Surveys undertaken by the Fourth Fisheries Project ${ }^{78}$ alarmingly show that the Fourth Fisheries Stocking Programs have negative or at best no impact on the livelihoods of the poor. Studies by WorldFish of fishers and other community groups who have undertaken stocking have shown that those directly involved in stocking do benefit, but the impacts on the wider community, including other subsistence users of the resource, are ambiguous. ${ }^{79}$

130. Intuitively, cutting off a water body from the floodplain, other wetlands and rivers, is likely to limit biodiversity in that water body, as well as in surrounding open water areas. Short-term studies undertaken by the DANIDA funded Baor Program as well as the GEF component of the Fourth Fisheries Project examined impacts of stocking on fisheries biodiversity. These showed that high stocking rates did negatively impact natural fish stocks and overall biodiversity, while stocking at lower levels did not appear to have an impact. Another system, pioneered in Daudkundi and being promoted by the DoF, calls for shares to be sold to landowners whose lands seasonally flood. Once again, while profitable, issues of access rights of the poor, and impacts on biodiversity, are unknown. What is known is that this system is spreading quickly in a number of areas.

\section{The Need for Management Controls in the Coastal Capture Fishery}

131. The marine and coastal capture fishery is a primary source of income and nutrition for over 484,000 households in the coastal region. ${ }^{80}$ Yearly production is in the order of 0.45 -0.6 million MT. Full-time equivalent employment is thought to be almost 0.2 million. In addition about 0.4 million poor men, women and children are involved in seasonal shrimp larvae collection. As in the case of the inland fishery, much of this work is seasonal with most of the labor provided by the poorest segments of the communities.

132. Unlike the inland fishery there is more of a commercial focus to the coastal and marine fishery. Access to most coastal and marine waters entails the use of a boat and, except for river mouths and estuaries, motorized boats are a requirement. The industrial trawl fishery can exploit deeper water fishery resources up to a depth of 50-200 m, and the prospects for exploiting the deepest waters have not been fully explored.

133. Worldwide, marine fishery resources are in decline, and those in Bangladesh are no different. The majority of opinion from fishers, DoF fisheries professionals and fisheries scientists, is that most inshore stocks are in decline or at best have reached their maximum sustainable yields, and that the peak of coastal and marine production was reached in the late 1990's. This is almost entirely the result of unregulated access and a lack of management controls. While pollution and illegal fishing by foreign trawlers operating in Bangladeshi waters are certainly concerns, over-fishing remains the main issue. Of particular concern has been the hilsa fishery, which accounts for much of the marine catch.

\footnotetext{
${ }^{78}$ World Bank, 2003

${ }^{79}$ P. Thompson, World Fish, Personal Communication

${ }^{80}$ ICZMP, 2003, Personal Communications
} 


\section{Protecting Coastal Breeding and Nursery Areas}

134. Bangladesh's coastal waters hold a wide diversity of fishery resources. The marine environment contains 475 species of finfish and a number of crustacean (shellfish) resources including 36 species of shrimps, and several other traditional and non-traditional fishery items such as cuttlefish, octopus, oysters and mussels. Natural mangrove forests cover almost 600,000 ha primarily associated with the Sundarbans Reserve Forest with another 100,000 ha of planted mangroves, the result of various Government and development partner supported programs. ${ }^{81}$ It has been estimated that every hectare of mangrove generates upwards of $450 \mathrm{~kg}$ of marine catch. There is a need to identify and protect breeding and nursery areas of commercially important fish and prawns, as has taken place on an ad-hoc basis for the hilsa. Outside of the Sunderbans (see Box 4.2) few effective protected areas exist.

\section{Box 4.2: Fisheries Management in the Sundarbans}

The Sunderbans comprise the most important nursery area for the Bay of Bengal fisheries. It has been estimated that every hectare of mangrove generates upwards of $450 \mathrm{~kg} / \mathrm{ha}$ of marine catch. The continued existence and functionality of the Sunderbans mangrove forest is of critical importance to the entire marine fishery of the Bay of Bengal. Through the Sundarbans Biodiversity Project (SBCP - an MoEF project supported by the ADB) a management regime has been developed and is reported to have been adopted. This represents the first attempt at managing a coastal fishery in Bangladesh.

Management of the Sundarbans reserve forest lies with the Forestry Department, under the auspices of the MoEF. Management practices within the Sundarbans are subject to specific protection orders, which prohibit access to specific areas at specific times of year. Access to the Sundarbans is restricted by a permit system, allocated to specific vessels with a history of having fished in the zone. There are no quota or effort limits set in the policies of the Forest Department. Of recent concern is the precipitous closing of the SBCP, but it is not known how this will impact the management schemes put in place.

\section{Impacts of Capture Fisheries Decline}

135. Traditionally the inland capture fishery has been Bangladesh's main source of fish for food. This is no longer the case, with change occurring rapidly over the past 25 years. In spite of declines, the inland fisheries continue to play a significant role as a source of nutrition and income for a large proportion of the rural and urban population. Consumption information from the 2000 Household Expenditure Survey of the BBS shows that average fish consumption in the country declined by $12 \%$ since 1995 , while fish consumption of the poorest $22 \%$ of the population has declined by $38 \%$, evidence that lower per capita fish supplies are pushing fish prices beyond the reach of the poorest consumer.

\section{Loss of Wetlands: a Key Resource for the Poor}

136. The beels, boars, haors and rivers that make up the wetlands in Bangladesh have been undervalued by decision makers and developers, too few of whom are aware of their

\footnotetext{
${ }^{81}$ For example, the ADB Greenbelt Program
} 
true economic value and the environmental services they provide. It is reported that Bangladesh has lost $50 \%$ of its permanent wetland area. ${ }^{82}$

137. Recent studies from a variety of GOB programs ${ }^{83}$ show that wetlands and fisheries are of critical importance to Bangladesh's rural poor. The first economic valuation of a Bangladesh wetland took place in Hail Haor, Molvi Bazaar, and indicated that this wetland has an annual output of approximately $\mathrm{Tk} 30,000^{84}$ per ha. The study mainly considered physical outputs. It did not include water recharge, pollution abatement, existence or a number of other values as data were not immediately available. This conservative estimate found that almost $50 \%$ of the value directly benefited the poor.

138. Apart from fish, the seasonal and permanent wetlands in Bangladesh provide a range of products. These include various food items (plants and animals), medicinal plants, fodder, fuel and building materials, mainly used by the poor. As detailed in FSRFD and DANIDA studies, four out of five rural Bangladeshis, particularly the poor, depend to some extent on aquatic resources. They are increasingly vulnerable to threats to the resource and conflicts over access to resources. With land holdings declining, incomes from rice stagnating, and limited opportunities for other rural income generating activities, increasing pressure is being placed on the remaining wetlands and open fisheries.

139. Surveys conducted by several DoF projects ${ }^{85}$ conclusively show that the poor depend on, and are major beneficiaries of public wetlands for food, income and other purposes. ${ }^{86}$ Data from the MACH wetlands valuation show that as much as $60 \%$ of the benefits from a large haor in Syhlet flow to the poor. An environmental impact assessment of wetlands in Greater Noakhali ${ }^{87}$ conducted for DANIDA showed that $80-93 \%$ of the community utilized those wetlands and that the poorest members of that community derived $15 \%$ of their income from harvesting its products. Surveys of highly degraded wetlands in Sherpur District conducted by the SUFER Project ${ }^{88}$ show similar trends with over $80 \%$ of wetlands users being among the poorest members of their respective communities.

\section{Quantifying Losses from Capture Fisheries}

140. The lack of quality time-series data makes the economic losses in Bangladesh's fisheries difficult to quantify. Overall it is known that during the period 1999-2002 the Hilsa catch declined by as much as $50 \%$ from previous levels. It is further known that major declines have occurred in the major and minor carp fisheries since the 1970's. Estimates by a variety of authors suggest that historical declines in the inland fisheries amount to $30 \%$, while the peak of marine capture fishery is know to have occurred in the 1990's. As Table 4.1 indicates, the annual losses for the species shown could be in the order of US\$ 42 million per year. Applying an average economic value for the decline in all capture fishery species of

\footnotetext{
${ }^{82}$ While alarming, this compares with the continental US, which has seen the destruction of more than $50 \%$ of its wetlands, while California has lost $90 \%$ or more, as studied by the University of California at Berkeley, and quoted by Williams, T. 1996

${ }^{83}$ The MACH Project, the DANIDA funded AEPs, the World Fish Center CBFM program, the Fourth Fisheries

Project and its GEF component

${ }^{84}$ Colavito, L. et al. 2000

${ }^{85} \mathrm{MACH}$, DANIDA, SUFER

${ }^{86}$ Colavito, L, Collis W. J. et al, 2001; IUCN: Wetlands Workshop; DANIDA, 2003.

${ }^{87}$ Winrock. 2003

${ }^{88}$ Ahmed, M. 2003 (draft)
} 
US\$2,232 per tonne ${ }^{89}$ to the annual losses shown in Figure 4.1 suggests that the lost production amounts to some $\$ 56$ million per year, which probably understates the broader economic losses to fishers and the nation as a whole.

Table 4.1: Estimated Physical and Financial Loss due to Declining Production

\begin{tabular}{|c|c|c|c|c|c|c|}
\hline \multirow[b]{2}{*}{ Species } & \multirow{2}{*}{$\begin{array}{l}\text { Maximum } \\
\text { Annual } \\
\text { Production } \\
\text { 1999-2002 } \\
\text { (mt) }\end{array}$} & \multirow{2}{*}{$\begin{array}{c}\text { Average } \\
\text { Annual } \\
\text { Production19 } \\
\text { 99-2002 (mt) }\end{array}$} & \multirow{2}{*}{$\begin{array}{c}\text { Production } \\
2002 \\
\text { (mt) }\end{array}$} & \multicolumn{2}{|c|}{$\begin{array}{l}\text { Physical Production Loss } \\
\text { (mt) }\end{array}$} & \multirow{2}{*}{$\begin{array}{c}\text { Annual } \\
\text { Production } \\
\text { Loss (\$) } \\
\text { Based on } \\
\text { Average } \\
\text { Production } \\
\text { (US\$) } \\
\end{array}$} \\
\hline & & & & $\begin{array}{c}\text { Based on } \\
\text { Maximum } \\
\text { Production } \\
\text { (mt) }\end{array}$ & $\begin{array}{c}\text { Based on } \\
\text { Average } \\
\text { Production } \\
\text { (mt) }\end{array}$ & \\
\hline Major Carps & 9,639 & 2,780 & 1,443 & 8,196 & 1,337 & $1,586,271$ \\
\hline Other Carps & 3,594 & 1,345 & 382 & 3,212 & 968 & 984,203 \\
\hline Inland Hilsha & 112,408 & 79,616 & 62,944 & 49,464 & 16,672 & $39,560,441$ \\
\hline $\begin{array}{l}\text { Indian } \\
\text { Salmon }\end{array}$ & 2,428 & 1,129 & 930 & 1,498 & 199 & 675,330 \\
\hline All Species & & & & & & $\$ 42,806,245$ \\
\hline
\end{tabular}

Source: FRSS data

\section{Policies and Institutions for Capture Fisheries Management}

141. The role of MoFL and DoF as promoters of aquaculture, commercial fishing and other forms of production is clear. They are also the responsible agencies for the regulation of fishing effort and fish quality issues. It is not clear, however, which government agency or group holds primary responsibility for the protection of aquatic habitats (wetlands and coastal habitats), that are the basis for fish production. A number of Ministries including Environment, Water, and Land, and Local Government, hold a variety of mandates in this regard.

\section{MoEF Responsibilities for Aquatic Habitat and Biodiversity Conservation}

142. The Ministry of Environment and Forests (MoEF) is responsible for coordination of the Government's Environment Policy of 1992, giving it overall responsibility for national environmental issues. These include environmental pollution control, conservation of wildlife including waterfowl, responsibility for management of the country's various national parks and protected areas, and implementation of the various international environmental treaties to which Bangladesh is a party. Part of the Environment Policy of 1992 calls for protection of freshwater and coastal/marine resources. As a result of these responsibilities, the MoEF, through both the Departments of Forestry and the Environment, is becoming more involved in wetlands and, therefore, fisheries conservation.

\footnotetext{
${ }^{89}$ The price of US\$2,232 per tonne is calculated as the weighted average price of the losses shown in Table 4-1. Consistent with the economic analysis conducted for the World Bank-supported Fourth Fisheries Project, the economic value of fish consumed domestically is assumed to be equal to the financial value, as no significant distortions due to taxes or subsidies are involved.
} 
143. The Forest Department (FD) controls the two most important wetlands of the country, the Sunderbans and Tanguar Haor. The MoEF has implemented the only fisheries

management scheme in the coastal sector, as a result of the Sunderbans Biodiversity Project's Fisheries Management Program. In Tanguar Haor, the most important freshwater wetland in the country and Bangladesh's second Ramsar site, the MoEF has responsibility for overall management. In addition, through the UNDP-funded Sustainable Environment Management Project (SEMP) the MoEF is overseeing a number of further wetland management schemes.

144. The Department of Environment (DoE) under the MoEF is responsible for protecting overall biodiversity and under the Environmental Conservation Act is able to designate Environmentally Critical Areas (ECA) as areas for environmental protection. The DoE has designated coastal areas, urban lakes and large wetlands as ECAs. This includes Hakaluki Haor, the second most important wetland area in the country and a potential Ramsar site. While having a general responsibility for conservation and the environment, the MoEF does not have a specific mandate in the area of aquatic resource protection. In general, these organizations lack the capacity and the in-house expertise to manage fisheries. However, the DoF, while having expertise in the areas of fisheries management and to a certain extent community management, lacks a background in protected area management.

\section{Leasing of Water Bodies by the Ministry of Land}

145. Apart from those areas controlled by the MoEF, the Ministry of Land (MoL) controls 3,773 open water areas (about 1,126,000 ha) and 8,549 closed or semi-closed water bodies (about 14,000 ha). Total revenue from leasing these assets in 1998 was Tk. 127 million. ${ }^{90}$ The major purpose of the lease system remains revenue generation. MoL lease policies have been and remain an area of contention within Government and the NGO community. Leasing rates and methods of awarding leases continue to stir controversy and it has long been recognized that the current lease system is part of the reason for the continued decline of Bangladesh fisheries and wetlands.

146. Determining which Ministry or Department controls the lease process is a highly political issue, and remains subject to discussion, but there is no doubt of the need to add conservation elements to leasing agreements, and to eliminate illegal fishing methods (for example drying, poisoning, and use of illegal gear) for individual leases. In addition, lease agreements could include requirements for small sanctuaries and specific management practices established in conjunction with local government and their communities.

\section{Areas of Institutional Reform: Cross-Sectoral Coordination and Community Participation}

147. Complex institutional and governance issues, engaging a mix of formal and informal institutions, public and private, and involving a range of cross-sectoral linkages and areas of responsibility, characterize the fishery sector. Both the recent FSRFD study (2003) and the Bangladesh Biodiversity Strategy and Action Plan (BBSAP, 2004) emphasize the need for improved mechanisms to coordinate management and planning of the broader natural resources and rural development sectors. Both follow the reasoning of the National Strategy for Accelerated Poverty Reduction and the MDGs, which support more cross-sectoral coordination and community participation. Both the FSRFD and the BBSAP recommend

\footnotetext{
${ }^{90}$ Islam, M.N., 1999
} 
that high level committees be formed to coordinate inter-institutional relationships and management of natural resources. They suggest that future investment in the sectors be channeled through these committees.

\section{Capture Fisheries: Recommendations and Areas for World Bank Support}

148. The recent success of the DoF hilsa management program, and the achievements of a number of other DoF programs such as MACH, CBFM-II and others, point the way forward for management of the inland and coastal/marine capture fisheries. At the national level, development partners should align their priorities with the Government's strategic planning for fisheries, including the draft Inland Capture Fisheries Strategy. Within this strategy, the actions that are needed to reverse the decline of Bangladesh's capture fisheries are reasonably clear, as summarized below.

\section{Protect Dry Season Water Flows}

149. The World Bank's Country Water Resources Assistance Strategy for Bangladesh concludes that the availability of dry season water is the most critical issue facing the nation's inland capture fisheries. ${ }^{91}$ It is estimated that $50 \%$ or more of the perennial wetlands of Bangladesh have been drained, encroached, filled or otherwise lost in the past 30-40 years. This has negatively impacted the poor, fish production, plant and animal biodiversity, as well as a variety of environmental services that wetlands provide. Given the direct connection between the poor and the wetlands of Bangladesh, and in line with the recommendations of the PRSP, there is a need to preserve dry season water. This will entail the conservation of dry season flows in the major rivers, conservation and rehabilitation of perennial wetlands, potentially including some re-excavation, and management of these areas. As part of this effort, capture fishery requirements for dry season flows should be estimated, and the information provided to the Ministry of Water Resources for use in planning and international negotiations. Water quality, as well as quantity, is also important, and pollution from industrial, urban and agricultural sources must be controlled to protect aquatic habitats.

\section{Establish National Sanctuary Systems}

150. Designation of protected areas large and small, fresh and salt water, is the first step in ensuring the continued sustainable use of Bangladesh's aquatic resources. In addition to protecting the major breeding and nursery areas through nationally designated sanctuaries, significant benefits would be derived from establishing small sanctuaries as an element of the lease for all water bodies. This would require revision of $\mathrm{MoL}$ lease procedures to require conservation elements that include (at a minimum) establishment of small local sanctuaries. Where communities agree, such small sanctuaries should be made permanent though Government recognition.

\section{Develop and Implement Fisheries Management Regulations}

151. An important step towards sustainable fisheries management would be the development and implementation of regulations covering gear use, mesh sizes, and closed seasons appropriate for the individual inland and marine areas, based on sound science and

${ }^{91}$ World Bank, 2005 
community participation. Such initiatives should aim to limit entry to the fisheries, but protect the access rights of true subsistence fishers. Where appropriate, communities should be encouraged to self-regulate entry. Leasing can be a means to limit access and manage the capture fisheries resource in a biologically sustainable way, but this will require reform of the existing system's emphasis on short-term revenue generation, and a renewed focus on community-based fisheries management. In the marine setting, this process will require boat registration and limits on the entry of new boats into the fishery. To build community support and offset any possible negative social or economic consequences, suitable mitigation must be provided to impacted fisher communities. A separate regulatory concern is the need to ensure that impacts on fisheries are more consistently addressed in the environmental assessment of infrastructure that may restrict fish migration, particularly investments in roads, embankments and drainage structures.

\section{Integrated Coastal Resource Management}

152. Based on the assessment of continuing decline in marine inshore resources, high poverty incidence in coastal regions, particularly among landless people dependent on the capture fisheries, and the critical need to manage and regulate the artisanal marine capture fisheries, the adoption of an Integrated Coastal Resource Management framework addressing poverty and the long-term viability of the coastal/marine ecosystem is recommended. Strategically, the support should be multi-sectoral and lead to livelihood diversification, reduced pressure on marine inshore resources, devolved and strengthened monitoring and law enforcement capacities, and effective participation of local communities in coastal resource management. This strategy could take place within the framework being developed by the Integrated Coastal Zone Management (ICZM) project. ${ }^{92}$

\section{Enhance Monitoring of Fisheries}

153. Fisheries statistics are at present unreliable. There is significant disagreement over the actual state of the country's fish production and fish biodiversity. Investments and specific management decisions are almost impossible to make without current reliable information. Improving the fisheries database involves spreading the ownership of the data and involving universities, FRI, NGOs, the private sector and others in civil society in the collection and assessment of fisheries information. Catch monitoring must also be improved through a revision of the FRSS, which would entail establishing a separate group within FRSS to monitor the open water catch.

\section{Reducing Barriers to the Import of Fish}

154. Maintaining stable prices for the country's most important source of animal protein will also help relieve pressure on capture fisheries. The key to stable prices is increased supplies. There is little or no scope for the further expansion of capture fisheries given the current levels of exploitation. The only internal source where sustainable fish supply increases are possible is aquaculture, mainly from inland ponds, and it is extremely unlikely

\footnotetext{
92 The GOB, Dutch and DFID-funded project works within the Water Resource Planning Organization (WARPO) of the Ministry of Water Resources. At present it does not cover fisheries but aims at laying the foundation for an integrated coastal development process. In consultation with the Government its objectives include the development of the following: (i) Coastal Zone Policy, (ii) Coastal Zone Development Strategy, (iii) Priority Investment Program (PIP) within 2005
} 
that internal production will meet demand. The reduction of import duties and other barriers, particularly on cheaper fish, should be a part of the effort to increase supplies and reduce the intensity of the exploitation of capture fisheries.

\section{Maintaining Assistance for Capture Fisheries}

155. Government and development partner assistance have been instrumental in shaping the sector, particularly in the areas of inland aquaculture and to a lesser extent the inland capture fishery. There has been continuous assistance provided over the past three decades by development partners to the Government supporting the expansion of aquaculture and small scale management of inland open water capture fisheries. In this period more than US\$ 350 million has been invested by international organizations.

156. International financial assistance has been allocated in decreasing order of importance to (i) aquaculture (50\%), (ii) inland open water fisheries (40\%), and (iii) coastal/marine capture fisheries (5\%). At present, inland aquaculture continues to be strongly supported by DoF and a variety of development partners. Brackish water (shrimp) aquaculture is rightfully led by the private sector with some support from Government agencies and donors. Earlier support to the inland capture fishery mainly focused on open water stocking but the subsector is now receiving more broad-based support from Government and development partners. The coastal and marine capture fisheries have not enjoyed the long-term support that has been provided to aquaculture and the inland capture fisheries. Following the focus of the MDGs and National Strategy for Accelerated Poverty Reduction on pro-poor policies and growth, the key priorities for continued World Bank support to the fisheries sector in the midto long-term should be in the areas indicated above. 


\section{Chapter 5: Sustaining Soil Quality}

157. Soil performs a number of important services or functions, among which the following are of particular importance:

- Supporting the growth and diversity of plants and animals by providing a physical, chemical and biological environment for the exchange of water, nutrients, energy and air;

- Regulating the distribution of rain or irrigation water between infiltration and runoff, and regulating the flow and storage of water and solutes, including nitrogen, phosphorus, pesticides, and other nutrients and compounds dissolved in the water;

- Storing, moderating the release of, and cycling plant nutrients and other elements;

- Acting as a filter to protect water quality, air and other resources; and

- Supporting structures and protecting archeological treasures.

158. The term "soil quality" is used to describe the ability of soil to perform these functions. The USDA Natural Resources Conservation Service ${ }^{93}$ defines soil quality as:

"The capacity of a specific kind of soil to function, within natural or managed ecosystem boundaries, to sustain plant and animal productivity, maintain or enhance water and air quality, and support human health and habitation. Changes in the capacity of soil to function are reflected in soil properties that change in response to management or climate."

159. Maintaining the functions of soil is thus central to the achievement of sustainable development. In exploring evidence for a degradation of the soil resource, it is important to identify first the soil function of interest and then to relate this to a measurable soil property or properties. An example of soil function is 'the ability of soil to provide raw materials for construction of dykes, roads and dwellings'. The related soil property is the extent, in terms of both area and depth, of soils of particular clay content or type. From this example it is clear that both the function of soil and the related soil properties may be measured.

\section{Challenges Facing Agriculture in Bangladesh}

160. Agriculture accounts for some $23 \%$ of GDP and more than half of total employment, so the ability of soil to sustain agricultural production is an issue of national concern. Given the overriding importance of agriculture to Bangladesh, the soil function that has received the most attention to date is the capacity of the soil to 'sustain crop productivity'. The terms soil productivity or soil fertility are used interchangeably to capture the relevant related soil properties. In addition to concerns that soil productivity is declining, there are reports of a degradation of soil that may affect other aspects of soil quality. This chapter outlines briefly the future challenges facing agriculture in Bangladesh, including the implications of climate change, and reviews agricultural productivity at the national and district levels, as well as evidence that a decline in soil productivity is occurring, before recommending ways to strengthen the strategy for monitoring of soil quality.

${ }^{93} 2001$ - http://soils.usda.gov/sqi/files/sq one 1.pdf 
161. In Bangladesh a combination of factors create a challenging situation for agriculture, particularly for rice production. Domestic demand for rice is increasing, there is a limited flow of foreign exchange to pay for rice imports and the government strategy is to meet this demand through national production. Historically, increases in production were achieved through introducing higher yielding modern rice varieties to raise levels of yield in both the Aman and Boro crop, and by increasing the area of land cultivated, mainly by expanding the area under irrigated Boro. Opportunities for future expansion of the cropped area are severely constrained by a number of factors:

- Urbanization and industrialization are encroaching on the available land, competing for and contaminating water resources;

- More profitable agricultural options than rice production are available. Agricultural diversification is likely to compete for land (particularly irrigated higher lands used for Boro production); and,

- Sea level changes expected as a result of climate change will inevitably impact upon land use in lower lying areas, while in higher lands adaptation to water scarcity also associated with climate change will require adoption of crops with lower water requirements.

Given this context, any future increases in rice production will have to be achieved through increased yields of both Aman and Boro crops.

\section{Trends in Agricultural Productivity}

In the early to mid-1990s concerns were raised that production increases achieved over the previous three decades in rice-based cropping systems may have involved a trade-off against long-term sustainability ${ }^{94}$. Increases in crop production slowed and rice crop yields declined. A decline in soil quality (expressed as soil fertility or soil productivity) was inferred as the cause. These concerns are widely articulated in the literature and reflected in the National Strategy for Accelerated Poverty Reduction. This section revisits these trends.

162. Cereals production in Bangladesh has maintained a long run trend rate of growth over the last four decades of around $2.5 \%$ per year. Figure 5.1 shows the four-crop running average of grains production. Intensification of agricultural production associated with the introduction of improved, shorter duration rice and wheat varieties that were less photoperiod sensitive, together with the expansion of surface irrigation, led to a structural change in the cereals production system. Initially this occurred with an increase in wheat production and then, more significantly, of Boro rice production (Figure 5.2). A minor trend has been the decline, relatively small in absolute terms, of $A u s$ production, and other rabi crops partly to make way in the cropping system for the rise of Boro. To get a clearer understanding of the trend in production, it is necessary to consider when particular factors such as the introduction of new technologies, or shocks such as natural and man-made disasters (such as floods and adverse price movements), influenced production.

\footnotetext{
${ }^{94}$ Asaduzzaman, 1995; Brandon, 1995; Pagiola, 1995, Scherr, 1999
} 
163. Using a kinked exponential growth $\operatorname{model}^{95}$, it is possible to identify trends and shocks in crop production, as shown in Figure 5.3. Between 1971 and 1972 gross crop production fell dramatically and is modeled as a discontinuity. This reflects the disasters of 1970-1972, including the cyclone of 1970 and the liberation war in 1971. In the period before this, a rate of growth was maintained and is modeled as a constant rate. From 1972 to 1977 a new faster rate of growth was maintained as cereals production recovered to its previous trend line. From 1978 until the present total cereals production is modeled as maintaining a constant rate of growth slightly faster than that maintained up to 1971, although there have been quite significant deviations from this trend, particularly in the mid-1980s and mid$1990^{\prime} \mathrm{s}$, at the points marked as slow-downs in Figure 5.3.

Figure 5.1: Growth of Total Cereals Output (ln '000 tons)

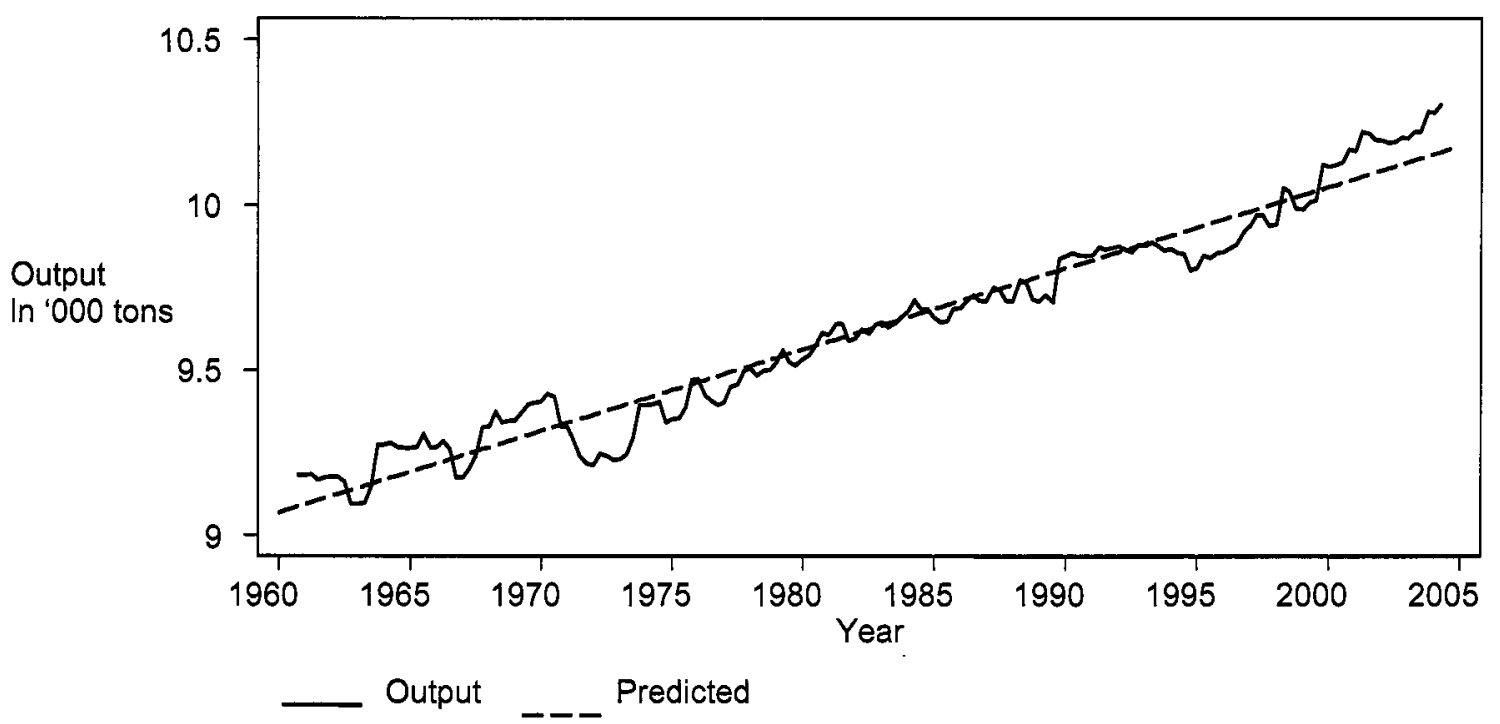

Note: Output is the crop wise moving average of the 4 crops (wheat, boro, aus and aman) Predicted is the expected output from $\ln$ (output) $=9.07+0.0062^{*} y(r s q=0.95)$ Which is a long run growth of $2.48 \%$ per annum since there are 4 crops per year

164. The underlying determinants of production levels however are not clear. Some have argued that production is determined by price ${ }^{96}$, but while the relationship between price and production holds reasonably well up until the late 1990s, there has been a significant rise in production in the last 5 years, notwithstanding continuous low real rice prices. This may have been in part due to the Government's focus on rice production during this period, and may also reflect recovery from the 1998 floods. The effect of liberalizing markets in Bangladesh has been to establish a relative low parity price for rice, based on imports from India ${ }^{97}$, and it is not unreasonable, therefore, to anticipate that rice production may now begin to slow.

\footnotetext{
95 (Boyce, 1986, 1987)

96 Ahmed (2001) does this with data up to 1996-7

${ }^{97}$ Previously Bangladesh imported from Thailand and other sources. In the1990s the private sector has developed trade with India as the most profitable source of staples imports. Obviously trends in Indian agriculture, prices etc., has an effect on these parity prices. It is not clear that India will remain a reliable source of imports for Bangladesh if the food situation were to deteriorate there, given the history of interventions in the grain trade by Indian governments.
} 
Consequently, pressure on soil resources may well be reduced as a result of lower levels of agricultural protection.

Figure 5.2: Production of Major Cereals in Bangladesh 1960-2004

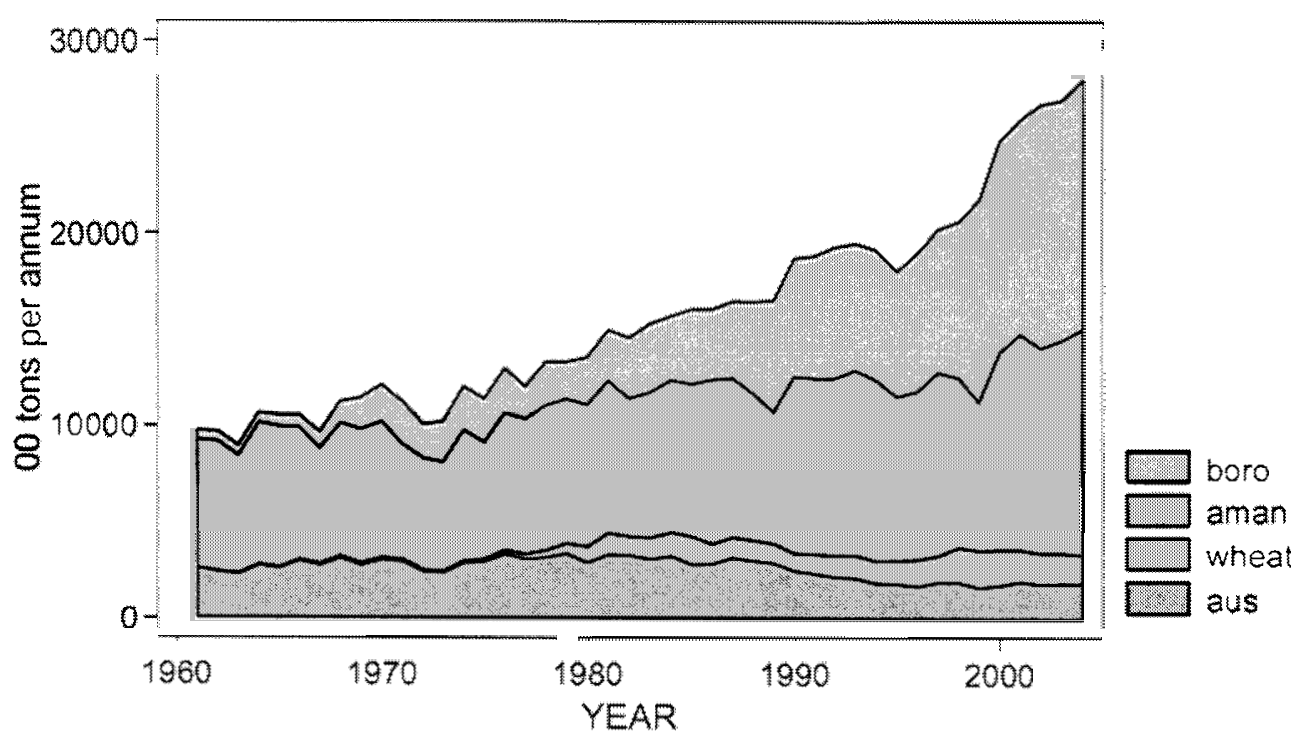

Figure 5.3: Index of Total Grains Production $(1960=100)$

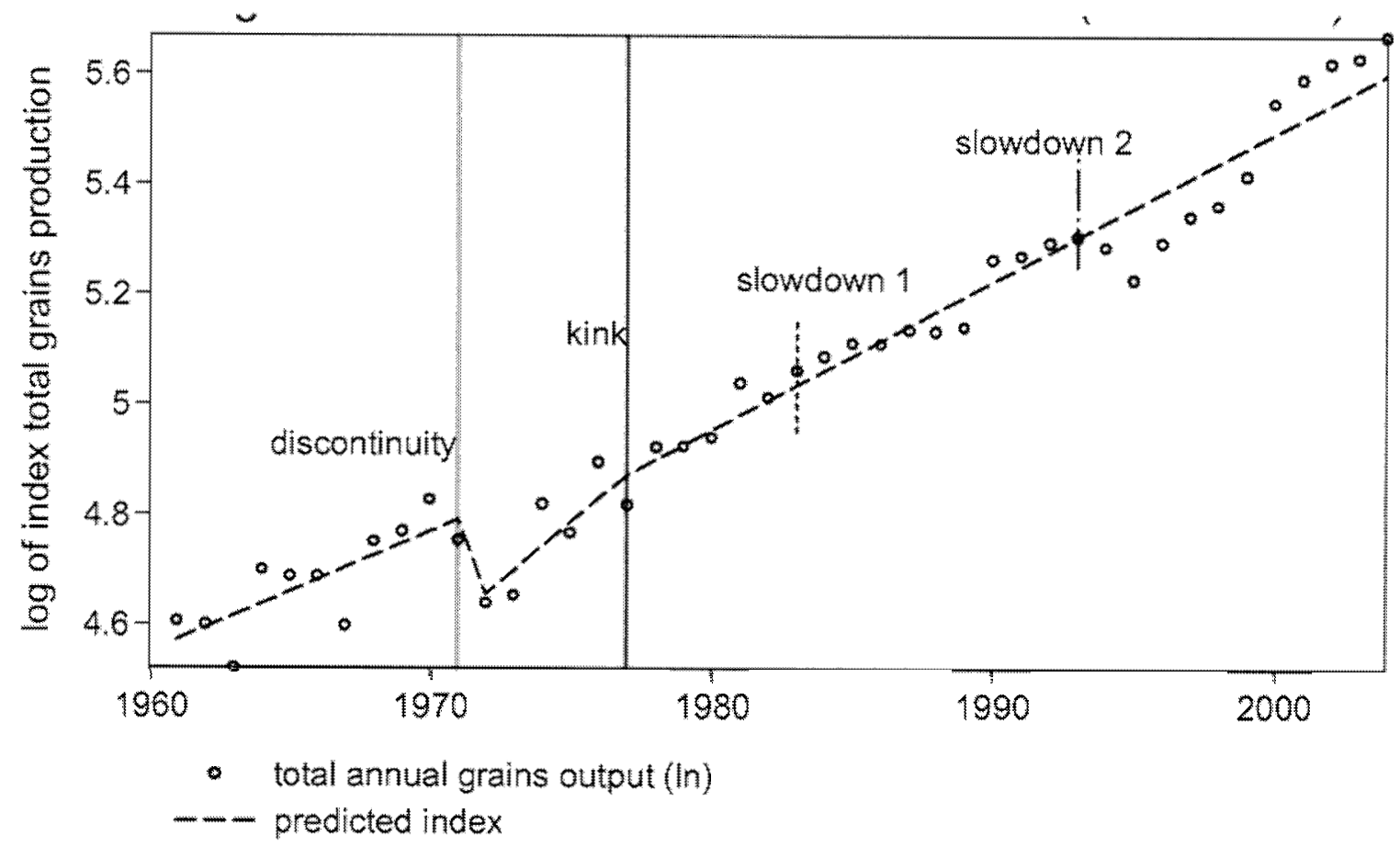




\section{Evidence of Declining Soil Productivity and Soil Quality}

165. The growth trend in agricultural production and the influence of agricultural and food market developments on production were discussed above. As described earlier it is important to distinguish soil functions associated with soil quality. The following sections explore the evidence for a decline in soil productivity (i.e. the function of soil to sustain plant productivity), and then consider evidence for a wider decline in soil quality.

\section{Evidence of a Decline in Soil Productivity: Yield and Total Factor Productivity}

166. Long term rice-wheat experiments provide a useful starting point in this analysis. These experiments are generally established with the technical optimum in mind. Typically, such experiments provide a measure of yield (plant productivity) at specified levels of inputs and, in some cases, yield response to inputs over time. So, where inputs are constant, and evidence of pests and disease absent, a decline in crop production, measured as yield, may signal a decline in soil productivity. Long-term experiments constituted a major component of the evidence that yields were declining in the early 1990s. This evidence was typically drawn across a number of countries and agricultural situations, some of which differ from Bangladesh in both environmental characteristics and cropping pattern, and show no consistent yield impact. Dawe et al., (2000) analyzed long-term yield trends in 47 experiments in rice-rice and rice-wheat systems, and argue that yield decline is not very common, particularly at yield levels actually achieved by farmers. Duxbury et al., (2000) reviewed rice-wheat experiments on the Indo-Gangetic plains and showed that rice yields were declining in eight and wheat yields in three out of 11 experiments. However, Saleque et al. (2004b) found no evidence of a yield decline for the years 1990-1999 for a field experiment at the BRRI experimental farm at Gazipur.

167. Given that the Boro crop is dominated by HYV crops, and that management practices have remained constant with time ${ }^{98}$, it is reasonable to expect that yield trends in the Boro crop yield in farmers' fields may reflect underlying soil productivity (and improvements in varieties). Pagiola (1995) analyzed yield trends at the district level and found that yields between 1979/80 and 1993/4 had shown the greatest decline in those districts which had been early adopters of HYVs. These observations were particularly worrying because they raised the prospect that a more widespread decline might occur with time.

168. It can now be seen that the analysis by Pagiola was influenced by the period in the early 1990 s where yields and production were below trend. District level yield data for the period $1979 / 80$ to $2002 / 03$ suggests that the yield trends are stable or increasing. The only district where the yield trend is negative is the Chittagong Hill Tract, which is not a major rice producing area. In 12 out of 21 districts the increase is significant. For a number of districts, however, the yield trend is flat, which may indicate continued cause for concern, given the need to increase yields. While more detailed trend analysis of the sort presented earlier could be used to describe these data, in the absence of reliable explanatory information, the value of such interpretation is limited.

169. As described earlier, assessment of yield trends as a proxy for soil productivity assumes inputs over time are constant. Whilst this is reasonable as a first approximation,

\footnotetext{
${ }^{98}$ Ahmed, 2001
} 
Total Factor Productivity (TFP) which provides a measure of output relative to inputs, provides a way to account for changes in management when interpreting production data. Data on total factor productivity for rice production in Bangladesh are limited, however. A key constraint is the lack of available data on fertilizer use at the district level, particularly since the liberalization of the fertilizer market. Given the lack of reliable data on input use, it is not currently possible to calculate TFP at the district level for Bangladesh. Ahmed (2001) who compiled information on TFP using data available at a national level in Bangladesh for the periods 1975/76-1986/87 and 1987/88-1997/98 found that TFP grew throughout this period by around $1 \%$ per year if constant rice prices are used. Using current prices ${ }^{99}$, there is evidence that, whilst TFP continued to grow, the rate of annual growth in productivity slowed in the second decade $(1987 / 8-1997 / 98)$. Ahmed attributed this slowing to a lower growth in rice prices compared to input costs.

\section{Nutrient Balances}

170. Nutrient balances are proposed as an indicator of likely future soil fertility issues. They are not a direct measure of either soil function or soil property. However, they can be relatively easily derived from data that would be used to calculate TFP. Negative balances over time indicate a trend to deplete soil resources. Visual symptoms in a crop of nutrient deficiency or positive crop responses to a particular nutrient input ${ }^{100}$ confirm that soil resources are depleted, or in a form that is not available to the plant.

171. A national nutrient budget for Nitrogen $(\mathrm{N})$, Phosphorus (P) and Potassium (K) was calculated using a partial budgeting approach that considered national data on crop yields (BBS data) and fertilizer input data from the MMIS. ${ }^{101}$ This analysis suggested that the $P$ budget was somewhat negative and has not changed over the last 20 years, while the $\mathrm{K}$ balance is much more negative. $\mathrm{N}$ inputs suggest a surplus application, but this reflects the fact that typically more than $50 \%$ of nitrogen fertilizer added to rice soils is lost. Once losses are accounted for, then the balance becomes negative. These data are somewhat in conflict with other evidence, however. Ahmed 2001 reports that the balance of N:P:K applied to rice was $50: 30: 20$ and that the ratio had shifted to $72: 15: 12$ by $1996 / 7$.

172. Partial nutrient balances were assembled at the AEZ level using data from the SFFP demonstration database. ${ }^{102}$ These data allowed comparison of farmers' practice and yields for a Boro - fallow - T Aman rotation. The findings were that the balance for nitrogen ranged between -50 and $0 \mathrm{~kg} \mathrm{ha}^{-1} \mathrm{yr}^{-1}$, phosphorus was between -10 and $+5 \mathrm{~kg} \mathrm{ha}^{-1} \mathrm{yr}^{-1}$ and the potassium balance was always very negative at -225 to $-100 \mathrm{~kg} \mathrm{ha}^{-1} \mathrm{yr}^{-1}$. Ripjma further reported that the balances were less negative in the Barind areas (AEZ 25, 26 \& 27) in comparison with the Ganges Floodplains (AEZs 11,12 \& 13). However, Ripjma cautioned that whilst the findings indicate trends and confirm the potential to identify areas of concern, the data did not reflect actual cropping patterns and intensities in all locations.

\footnotetext{
${ }^{99}$ Given that there is an expected relationship between output price (i.e. rice price) and input prices this is appropriate.

${ }^{100}$ This holds for macro-nutrients excepting $\mathrm{N}$ and all micro-nutrients

${ }^{101}$ (Ripjma, 2004).

${ }^{102}$ (Rijpma et al., 2004).
} 


\section{Crop Biophysical Indicators}

173. The relationship between nutrient uptake and grain yield can be used to diagnose crop biophysical constraints. Again this is not a direct measure of either the function or related soil property, but may provide important diagnostic information. A limited data set shows the relationship between grain yield and $\mathrm{N}$ uptake obtained for the Boro rice crop at four locations (Dhamrai, Daulutpur, Gabtali and Shibgaj) during 1998 and 1999. ${ }^{103}$ These results fall around the lower limit for accumulation established by Witt et al. (1999), suggesting that sink formation was limited by factors other than nitrogen. Simply put, the plant is not delivering the level of yield that would be expected given the measured level of $\mathrm{N}$ uptake by the crop.

174. The results suggest some factor other than $\mathrm{N}$ uptake limited yield. In this study, application of the macro-nutrients $(\mathrm{P}$ and $\mathrm{K})$ and compost did not have any significant impact on yield. Other factors such as micro-nutrient deficiency, pests, disease, lack of water, low radiation may have limited yield. The data set is not sufficiently comprehensive to draw widespread conclusions, however the analysis does provide a useful example of how the aspects of crop performance can be used as an indicator of underlying soil productivity issues.

\section{Evidence for a decline in Soil Quality: Quantitative measurements}

175. The soils and environmental characteristics of Bangladesh have been extensively mapped and used to inform planning, land use and management decisions (see Box 5.1). The soil survey and analysis to date has focused on describing environmental characteristics and measuring soil chemical properties that may determine soil suitability for, and fertilizer requirements of, agricultural crops.

\section{Box 5.1: Soil Mapping in Bangladesh}

The first soil map of Bangladesh (then East Pakistan) recognized seven soil tracts combining physiographic, parent material and soil units. Reconnaissance soil surveys by the FAO-UNDP Soil Survey were undertaken from the early 1960s. This mapping was completed by the Soil Survey Directorate of the Government of Bangladesh (now the Soil Resources Development Institute, SRDI) in 1975 and led to the publication of the first soil map of Bangladesh at a 1:1 million scale. Further detailed analysis was carried out through the FAO/UNDP supported Agroecological Zones (AEZ) project study in the 1980s. The AEZ maps are at a scale of $1: 250,000$.

AEZs, while providing a useful characterization of the environment, remain broad units of characterization. Recognizing this, SRDI pursued the 'Upazila Nirdeshka' program to collect basic information on land, soil and water resources that would serve to identify resource management domains (RMD) as a spatial management unit that offers opportunities for the identification and application of resource management options to address specific land management issues. The Upazila Nirdeshka maps are completed at a scale of 1:50,000. SRDI have published 403 Upazila Nirdeshaka (previously called Thana Nirdeshka) and a BARC GIS Project has so far digitized and updated 300 of these maps (BARC 2004).

Research on soil fertility and fertilizer use at the farm level was also started in the 1960 s with the establishment of the Soil Fertility and Soil Testing Institute of East Pakistan. The first fertilizer recommendation guide was published by BARC in 1979. These recommendations were revised and developed over time. By 1989 the guide was revised to establish cropping pattern-based generalized fertilizer recommendations for moderate yield goals for the main AEZs. Generalized fertilizer recommendations were developed for the major crops.

${ }^{103}$ (Hossain 2001). 
176. Rahman et al. (undated report) compares soil properties that may affect soil productivity under different physiographic units sampled in 1967 and 1998. The results suggested a decrease in $\mathrm{pH}$, indicating acidification, and a decrease in calcium, magnesium and potassium, with no consistent change in organic matter, $\mathrm{N}$ or $\mathrm{P}$ status. It should be noted that this survey appears to be based on a limited sample ( 24 observations) and no details of how methods were standardized or controlled between 1967 and 1998 were provided. Nor is evidence of a loss of soil function recorded.

177. A framework that identifies key soil functions, for the specific complex situation in Bangladesh, does not yet exist, and is beyond the scope of this chapter. Thus it is difficult to comprehensively review the wider evidence for a decline in soil quality. Well-recognized, localized, soil degradation problems exist in Bangladesh. Deforestation for example is leading to erosion in the Chittagong Hill Tracts and salinization is reported to have increased by $22 \%$ since $1973 .{ }^{104}$ While important, and likely to affect a number of soil functions, these problems have limited geographic extent. A study by the $\mathrm{FAO}^{105}$ suggested that in the late $1980 \mathrm{~s}$, the total degraded land in Bangladesh represented $7.4 \%$ of the total land area. When compared to other countries in the Asian Pacific region, this level of degradation was low, with only Myanmar and Tonga estimated as having lower levels of degradation. Emerging problems include the depletion of groundwater, and a build-up of arsenic in soil as a result of irrigation with water contaminated with naturally-occurring arsenic, although there it is not yet clear what concentration of arsenic in irrigation water would have a quantifiable impact on agricultural yields or human health. ${ }^{106}$

\section{Qualitative Assessments}

178. Farmers are aware of subtle changes in soil properties and associated functions. Saleque (2004a) found that farmer's assessment of soil fertility were consistent with measured soil properties. Hossain (2001) found that farmers in Bangladesh reported a beneficial change in soil properties associated with a change in management of organic matter inputs. With application of compost the soils were reported to be less hard. The change could not be substantiated through soil chemical measurements, including soil organic matter status, but was reflected in measures of soil physical behavior.

179. Assessments of soil quality, or of changes in quality, can draw upon qualitative data of different types, obtained in different ways. Gaunt et al. (2001) found a keen awareness amongst the farmers of the non-sustainability of parts of their farming systems, and of the need for better management of soil fertility and pests. The resource intensive approach taken by Gaunt, using participatory methods working through focus groups and drawing on a relatively small sample at distinct locations. Rahman (2004) used such an approach to design a questionnaire which was then used in a survey to interview a total of 406 households. In this study farmers were asked to respond to a set of twelve specific environmental indicators which had been identified in previous focus group discussions. As shown in Figure 5.4, soil fertility was ranked as the major problem ( $86 \%$ of those interviewed agreed), followed by

${ }^{104}$ (Muzib, 2004)

${ }^{105}$ Reviewed by Scherr (1999)

${ }^{106}$ World Bank, 2005 
effects on human health $(76 \%)$, reduced fish catch $(73 \%)$, increased disease in crop $(68 \%)$ and compacted/hardened soll $(56 \%)$.

Figure 5.4: Environmental Concerns of Farmers

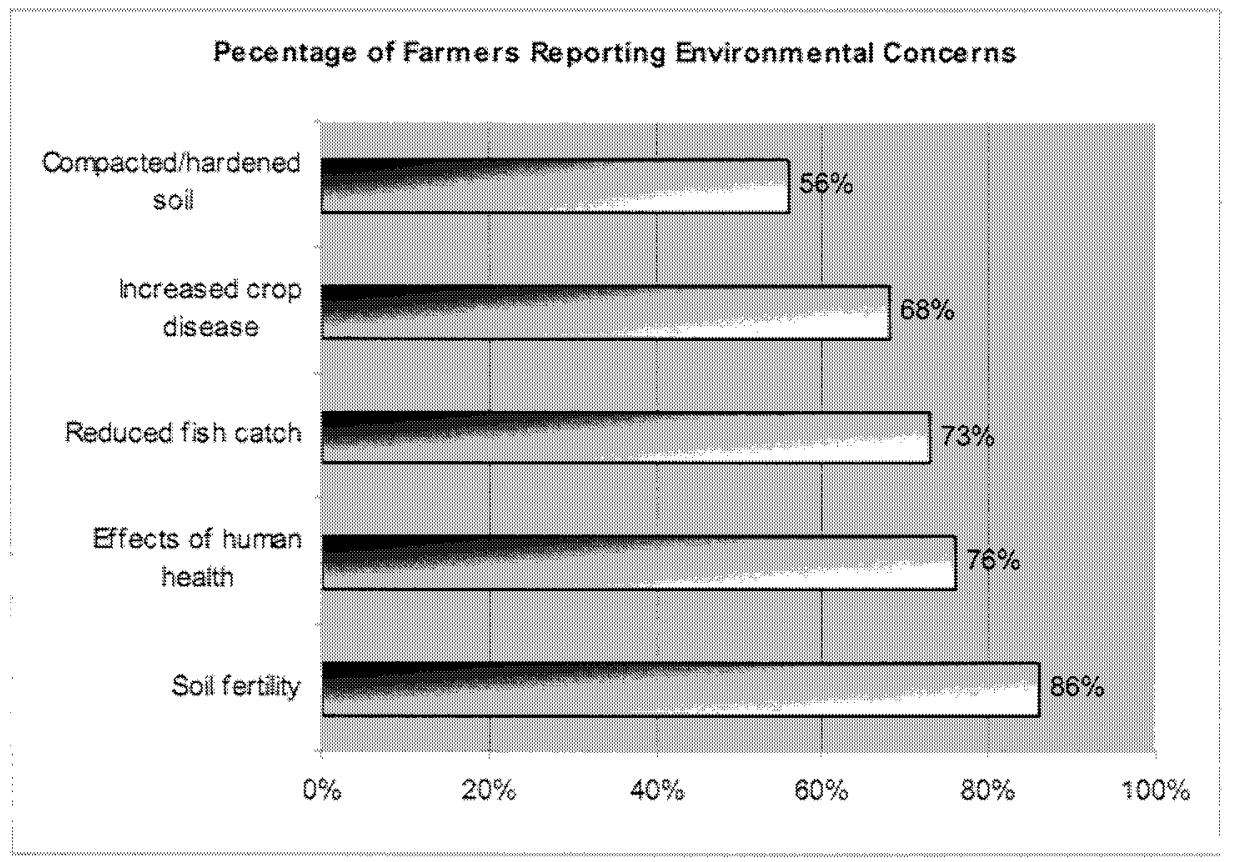

Source: Rahman, 2004.

180. Both these papers recognized a relationship between intensification of crop production and an associated reduction in fish production that lead to problems in achieving a balanced diet and associated health issues. These observations may indicate that at least in some locations the soll's function to protect water resources had declined, or a capacity had been exceeded.

181. Taken together these findings and those from elsewhere confirm the value of observations made by farmers and rural households. Although, as observed by Rahman (2004), awareness tends to be of visible impacts, and less obvious issues, such as the now well-publicized arsenic contamination of water, may go undetected by such qualitative measures.

\section{Conchusions: No Clear Evidence of Declining Soil Productivity or Soll Quality, but sone} Causes for Concen

182. A framework for assessing soil quality in Bangladesh does not yet exist. Total cereals and rice production has maintained a long term increasing trend. Production and particularly fluctuations in production are influenced by a number of factors including price and natural events in addition to underlying soil productivity. There is insufficient evidence to support the assertion that agricultural production is declining as a resut of a decline in soil productivity. However, there are causes for concern: 
- Existing soil test protocols established to measure soil fertility and inform agricultural management decisions are too narrowly defined to monitor the functions of soil that are defined by soil quality;

- Sufficient data are not available to ascertain whether soil productivity has declined, but limited evidence from repeated soil sampling at the AEZ level may suggest decline in soil properties associated with soil productivity;

- Fertilizer inputs are imbalanced and nutrient mining is occurring, particularly for potassium;

- Limited crop physiological observations suggest poor rice crop performance;

- Qualitative evidence suggests deterioration of soil quality and impacts of intensification of rice production on human health and fish production;

- Scientists have expressed concerns that salinization, acidification and arsenic contamination are emerging soil quality problems.

\section{Implications of Climate Change}

183. Agricultural production and soil quality are both influenced by the environmental impacts (externalities) associated with actions elsewhere, and likewise environmental externalities of agricultural production must be considered. These externalities create impacts and costs for society that are not captured by a field-based assessment and financial analysis of crop production, and may also have an impact upon future agricultural practice. The externalities associated with rice production include:

- Depletion of groundwater due to use for irrigation;

- Point source pollution, such as arsenic in some situations;

- Non-point sources pollution, derived from agricultural and other sources; and,

- The production of avoidable methane $\left(\mathrm{CH}_{4}\right)$ and nitrous oxide $\left(\mathrm{N}_{2} \mathrm{O}\right)$ emissions.

While detailed review of these externalities is beyond the scope of this chapter, it is important to note that these externalities have negative impacts in the context of the definition of soil quality introduced above. The implications of climate change for agriculture in Bangladesh are considered briefly.

\section{Adaptation to Climate Change}

184. Climate change is likely to influence agriculture in Bangladesh. Sea level changes expected as a result of climate change will inevitably impact upon land use in lower lying areas as flooding and salinity increase, while in higher lands adaptation to water scarcity also associated with climate change will require adoption of crops with lower water requirements. As indicated earlier this may imply a slowing, or reversal of the expansion of the irrigated Boro rice area. 


\section{Mitigation of Climate Change}

185. Agricultural systems produce greenhouse gasses. Carbon dioxide $\left(\mathrm{CO}_{2}\right)$, methane $\left(\mathrm{CH}_{4}\right)$ and nitrous oxide $\left(\mathrm{N}_{2} \mathrm{O}\right)$ are important greenhouse gases emitted from agricultural systems. These gasses have different reactivity in the atmosphere, with $\mathrm{CH}_{4}$ and $\mathrm{N}_{2} \mathrm{O}$ approximately 30 and 320 times more reactive than $\mathrm{CO}_{2}$ per unit in the atmosphere. Methane is produced under anaerobic conditions and $\mathrm{N}_{2} \mathrm{O}$ is produced by biological action upon nitrate as oxygen becomes depleted in soil during wetting. Thus the level of $\mathrm{CH}_{4}$ and $\mathrm{N}_{2} \mathrm{O}$ emissions from a rice field depend on water and other management factors. If continuously flooded, rice fields become anaerobic and the levels of $\mathrm{CH}_{4}$ emission are high ${ }^{107}$, while aeration or drying reduces $\mathrm{CH}_{4}$ emissions.

186. Emissions of $\mathrm{N}_{2} \mathrm{O}$ loss are much less clearly understood. Studies have shown that $\mathrm{N}_{2} \mathrm{O}$ emissions are low under irrigated conditions. ${ }^{108}$ Although $\mathrm{N}_{2} \mathrm{O}$ emissions are low during the period fields are flooded, $\mathrm{N}_{2} \mathrm{O}$ emissions increase when the soil surface of rice fields dry or nitrogen fertilizer is applied in the floodwater. Research to date has, typically, looked at crop losses associated with crop management factors such within seasonal drying, fertilizer form and application, and other management activities affecting $\mathrm{CH}_{4}$ and $\mathrm{N}_{2} \mathrm{O}$ emissions. Such studies of rice field emissions consider only emissions during the period of crop growth and do not address $\mathrm{N}_{2} \mathrm{O}$ emissions during times of non-rice cropping, particularly during land preparation for transplanting rice. ${ }^{109}$

187. Mineral Nitrogen $(\mathrm{N})$ that accumulates as Nitrate $\left(\mathrm{NO}_{3}\right)$ under aerobic conditions between crops is lost upon irrigation. These losses of $\mathrm{N}$ are predominantly in gaseous forms, but the amount lost as $\mathrm{N}_{2} \mathrm{O}$ is uncertain. The findings of Bronson et al. (1997) indicated that these transitional losses amounted to some $30 \%$ of mineral $\mathrm{N}$ that accumulates in soil prior to flooding at the time of land preparation. Given average levels of mineral $\mathrm{N}$ of $50 \mathrm{~kg} \mathrm{~N} \mathrm{ha}^{-1}$ measured in soils prior to irrigation ${ }^{110}$ this would equate to $23.6 \mathrm{~kg} \mathrm{~N}$ (equivalent to $7.3 \mathrm{t} \mathrm{CO}_{2}$ $\mathrm{ha}^{-1}$ ). Zheng et al. (2000) measured lower fluxes during the transition upon flooding the rice crop. Emissions were approximately $5 \mathrm{~kg} \mathrm{~N}$ (equivalent $2.4 \mathrm{t} \mathrm{CO}_{2} \mathrm{ha}^{-1}$ ).

188. These transitional losses of $\mathrm{N}_{2} \mathrm{O}$ can be avoided either through improved management of the fallow period and rice crop establishment phase or, where control over irrigation exists, by growing an alternate upland crop. Thus emissions from rice agriculture in Bangladesh could be reduced by:

- Diversifying of agricultural production;

- Management of the transition phases, together with improvements in the efficiency of rice production.

189. The potential for emissions avoidance of $\mathrm{CH}_{4}$ and $\mathrm{N}_{2} \mathrm{O}$ range from $4-11 \mathrm{t} \mathrm{CO}_{2}$ per hectare where Boro rice is replaced by an upland crop. Emissions under the improved technologies scenario will depend on strategies adopted and whether transitional losses can

\footnotetext{
${ }^{107}$ Absolute levels depend on factors such as soil type, levels of organic matter incorporation, however IPCC (1996) use irrigation as the factor to estimate $\mathrm{CH}_{4}$ emissions, reflecting its dominant control.

${ }^{108}$ (Freney et al. 1981)

${ }^{109}$ (Chen et al. 1996; Xing and Zhu, 1996)

${ }^{110}$ (Hossain, 2001)
} 
be avoided, but importantly increases in the efficiency of rice production will reduce the emission intensity, that is the emissions of $\mathrm{CH}_{4}$ and $\mathrm{N}_{2} \mathrm{O}$ per ton of rice produced.

\section{Sustaining Soil Quality: Recommendations and Areas for World Bank Support}

\section{Indicators of Soil Quality: Developing a Framework for Monitoring Soil Quality}

190. Given the importance of the soil resource to sustainable development in Bangladesh, and the critical importance of increases in agricultural productivity, immediate actions should be taken to strengthen the monitoring of soil quality and productivity. A review of the current state of the art in monitoring of soil quality should be undertaken to enable Bangladesh to identify headline indicators of soil function and associated soil properties that it would be desirable to measure, both qualitatively and quantitatively. These indicators should be in line with international best practice, but sensitive to the complex situation in Bangladesh, and selected to inform ongoing efforts to improve agricultural production. Identification of these indicators should form part of the process of developing a framework for soil quality monitoring, incorporating a methodology for monitoring. Existing surveys should be reviewed against this framework to identify gaps and redundancies.

\section{Total Factor Productivity as a Measure of Soil Productivity}

191. Effective monitoring of soil productivity requires consideration of total factor productivity, which in turn means the collection of information to supplement soil quality data. Such information must include data at an appropriate level of aggregation on agricultural production and trends, prices and quantities of labor, fertilizer, pesticides, and other inputs, as well as socio-economic and environmental conditions.

\section{Define Institutional Roles and Responsibilities for Monitoring Soil Quality}

192. A variety of institutions have a role to play in monitoring soil quality. While SRDI is primarily responsible for soil monitoring and BARC provides coordination, a number of institutions including NARS, BRRI, BARI, and various universities support relevant research, and DAE, BBS and MMIS are important sources of data. To more effectively monitor soil quality, it is important to more formally establish institutional responsibilities, and to agree on mechanisms for the collation of data from these diverse sources.

193. Details of existing surveys in relevant GoB institutes and Ministries should be collated and reviewed for complementarities and overlap. Key surveys are the annual survey undertaken by BBS on crop production, irrigation, cropping pattern and land uses, SRDI Long term Soil Fertility Monitoring and Salinity Monitoring Surveys, and MMIS data on agricultural inputs. ${ }^{111}$ Effective monitoring will require either revision of component surveys and co-ordination between institutions undertaking these surveys, or expansion of monitoring efforts within relevant organizations. A key to compatibility between surveys will be to agree an appropriate environmentally and politically relevant unit for future monitoring and

\footnotetext{
111 The BBS survey provides data on the production of rice, and other important crops, which are obtained from a sample of 5,000 five-acre plots nationwide. The sample design and selection of clusters was finalized in 1963 and these data are reported and aggregated at the district level. Hoque and Sider (2004) indicate that 5\% of the clusters are no longer operational and highlight the need to update and revisit the sample design to reflect changes both in land-use and the landscape.
} 
underlying sample design. The potential to collate data at the Upazila level should be considered. Having defined a framework for monitoring soil quality, the design of the existing SRDI Long Term Soil Fertility Monitoring and Salinity Monitoring surveys should be reviewed to assess relevance, cost effectiveness and robustness of design, and the results to date should be published. A number of development partners, including the World Bank, are in a position to help strengthen the soil monitoring framework through ongoing and proposed technical assistance to the agriculture sector.

\section{Leveraging Funds Available Through Carbon Emissions Trading}

194. The Kyoto protocol established that avoided greenhouse emissions in developing countries could be offset against emissions by industrialized countries (those listed in Annex 1 of the protocol). Markets enable emissions reductions to be traded creating a source of income. To date, the strategy for carbon trading in Bangladesh has focused on reducing emissions from industry, energy and waste. An initial review suggests that an opportunity exists to monetize avoided greenhouse gas emissions associated with rice production through carbon emissions trading. Research support is needed to substantiate the extent of this opportunity, and technical assistance is required to help develop a pilot project. Such a pilot would aim to demonstrate how an income stream from carbon trading can provide support to promote crop diversification and the adoption of improved agricultural technologies. The Designated National Authority is open to the idea, and should be approached by the agriculture community, in particular BARC and MoA, to further develop this concept, with technical assistance from the World Bank as necessary. 


\section{Chapter 6: Institutions for Environmental Management}

195. Environmental issues are key to economic growth and poverty reduction in Bangladesh. In its relatively short history as an independent nation, the government has made significant strides in the development of policies and institutions for environmental management. A number of public sector environmental institutions have been established particularly at the national level. There is growing public awareness of environmental issues which have entered into the vocabulary of many public sector institutions. Further, the government has affirmed its commitment to the Millennium Development Goals (MDGs), including the goal of ensuring environmental sustainability, which requires the integration of the principles of sustainable development into country policies and programs, and reversal of the loss of environmental resources. The Government is also committed to the Plan of Implementation adopted at the World Summit on Sustainable Development (WSSD) in Johannesburg in 2002, and is party to a range of international environmental agreements, including the Kyoto Protocol. Despite these achievements and commitments, however, the present approach to environmental management, as illustrated in this chapter, remains centralized and ad-hoc, with implementation falling far short of legislated intention. This chapter provides a brief analysis of environmental institutions in Bangladesh, highlighting key areas where institutional strengthening is needed.

\section{The Institutional Context for Environmental Management}

196. After independence in 1971, some of the key environmental initiatives undertaken by the Government were the enactment of the Water Pollution Control Act, 1973, the Bangladesh Wildlife Preservation Act, 1973, and the Environmental Pollution Control Ordinance, 1977. It was in the 1980s that environmental issues became seen as much more linked to broader development issues and became institutionalized in 1989 with the establishment of the present Ministry of Environment and Forests (MoEF).

197. Formal responsibilities for environment management are vested in MoEF, but many other institutions, directly and indirectly, are involved in managing or shaping the environment. These include public sector, private sector and civil society organizations. At the highest level, the National Environment Council (NEC), established in 1993 and headed by the Prime Minister, and the Executive Committee of the National Environment Council (ECNEC), headed by the Minister of Environment and Forest, are designed to provide guidance to line Ministries on national environmental issues. Moreover, the Planning Commission of the Ministry of Planning has the authority to supervise and coordinate crosssectoral and inter-ministerial activities influencing the use of environment and natural resources. The potential role of this Ministry is important since it controls funding for the implementation of the Government's Five Year Plan. Development partners and civil society have also exerted an important influence on environmental decision-making, with a range of NGOs now active on both 'green' and 'brown' environmental issues.

198. While the institutionalization of environmental issues into broader development practices has been gradual and in many respects (such as EA laws) donor driven ${ }^{12}$, since the beginning of the 1990's, the Government has taken a number of important steps to strengthen environmental management in Bangladesh. An enabling legal environment has been created,

${ }^{112}$ (Ahammed \& Harvey, 2004) 
in particular through the Environment Court Act (2000), and the Environmental Conservation Act (1995) and Rules (1997), followed by a series of new pieces of environmental legislation issued since $2000^{113}$. Environmental policy formulation has been led by the development of the National Conservation Strategy (NCS) in 1991, adoption of the National Environment Policy (NEP) in 1992 and National Forest Policy in 1994, and the National Environment Management Action Plan (NEMAP) in 1995. Practice lags behind legislation and policy, however, despite isolated examples of successful initiatives, such as the elimination of leaded gasoline, the phasing-out of two-stroke three-wheelers from the streets of Dhaka, and the ban on thin polythene bags.

\section{The Ministry of Environment and Forest: Custodian of the Environment}

199. Until 1989, there was no separate Ministry dealing exclusively with environment. In August of that year, the MoEF was created, with the Forest Department being transferred to the new Ministry from the Ministry of Agriculture, and the Department of Environmental Pollution Control being transferred from the Local Government Division, and in the process being re-named the Department of Environment.

\section{A Broad Environmental Mandate, but Resources Focused on Forestry}

200. The main function of the MoEF is to act as the guide and custodian for the conservation and development of the environment and, in the pursuit of that goal, to ensure through appropriate laws and regulations that natural resources, including land, air, water and forests, are exploited and managed in an environmentally sustainable manner. The mandate of the MoEF is broadly defined by the National Environmental Policy (1992) and the National Forest Policy (1994), and is described in the allocation of business among the Ministries of the Government of Bangladesh. As indicated below, the formal functions of the MoEF emphasize forest management activities:

- Define overall Government policy regarding forests and the environment, and to implement and evaluate such policies through its departments;

- Manage forest resources, and conserve and develop forest land, forest resources and wildlife;

- Maintain natural and environmental stability;

- Increase the country's forest resources in a planned manner and arrange to meet the demands for these resources; and,

- Effect environmental improvement and pollution control.

The MoEF is a permanent member of the Executive Committee of the National Economic Council (NEC), a key decision-making body for economic policy issues. The NEC also has the authority to approve all public investment projects.

\footnotetext{
${ }^{113}$ Including the Environment Conservation (Amendment) Act 2000, Environment Conservation (Amendment) Act 2002, Environment Court Act 2000, Conservation of Play Ground, Open Space, Parks and Natural Wetlands Act (in all municipal areas of the country), 2000, Environment Court (Amendment) Act 2002, Brick Burning Control (Amendment) Act 2001, and Three Amendments (in 2002 and 2003) to Environment Conservation Rules 1997.
} 
201. The MoEF pursues its activities through five institutions: the Forest Department (FD), Department of Environment (DoE), Bangladesh Forest Industries Development Corporation (BFIDC), Bangladesh Forest Research Institute (BFRI), and the Bangladesh National Herbarium. There are about 8,900 staff under the different agencies of MoEF, of which more than three-quarters are in the FD (6,939 employees), and fewer than $3 \%$ in the DoE. MoEF has an annual budget (both development and revenue) of about BDT 2 billion (about US\$34 million), which is less than $0.5 \%$ of the Government's total revenue and development budget. Of this total, over $80 \%$ is allocated to the FD and less than $1 \%$ to the DoE. Of the total MoEF budget, about $30 \%$ is used for the payment of salaries, compared with $60 \%$ of the DoE budget allocated for this purpose. Largely as a result of the focus of MoEF resources on forestry, institutional capacity for environmental planning and monitoring, essential functions of a national environmental custodian, remains weak. MoEF does not have any system in place to monitor environmental quality, biodiversity, status of protected areas, levels of pollution or environmental degradation, and there is no mechanism to make such information available to the public on a regular basis.

\section{The Insufficiently Funded Mandate of the Department of Environment}

202. The DoE was formed in 1989 with a mandate for environmental management later formalized under the Environment Conservation Act, 1995 (ECA'95). The DoE is headed by a Director General, with Divisional offices in Dhaka, Chittagong, Bogra, Khulna, Barisal and Sylhet (see Appendix II for an organogram of the DoE). As the technical arm of the Ministry, DoE is responsible for environmental planning, management, monitoring and enforcement. The mandate of the Department has expanded over time, evolving from an exclusive focus on pollution control to include natural resources and environmental management, now covering:

- monitoring environmental quality;

- promoting environmental awareness through public information programs;

- controlling and monitoring industrial pollution;

- reviewing environmental impact assessments and managing the environmental clearance process; and,

- establishing regulations and guidelines for activities affecting the environment.

In addition to the above duties, DoE also coordinates implementation of a number of international protocols and conventions to which Bangladesh is a signatory. In economic terms, most of the functions that DoE is mandated to serve (e.g. monitoring environmental quality and industrial pollution, environmental awareness and education, establishing regulations and guidelines) are public goods. One exception is the environmental review and environmental clearance process which is a service that DoE provides for a fee to developers, which has both public and private good characteristics.

203. While ECA '95 assigns the DoE broad responsibilities for the control of pollution, its natural resource conservation mandate is more constrained. Only limited power is assigned, extending to the designation of Ecologically Critical Areas (ECAs - eight of which have now been declared), and the prescription of uses of such areas. DoE's legal authority to declare any ecosystem an ECA is also a source of contention between the DoE and the FD. Further, 
modalities for management of these areas have yet to be established, although a GEFsupported project has been initiated to build the capacity of DoE for the management of coastal and wetland biodiversity at Cox's Bazar and Hakaluki Haor.

204. DoE continues to be understaffed, with only 191 staff positions, of which only 85 are managerial or technical, the lowest level of environment agency staffing per capita in SouthEast Asia. By comparison, Hong Kong has a similar agency with more than 1500 staff. ${ }^{114}$

$\mathrm{DoE}$ is also under-budgeted relative to its broad mandate, with a revenue budget allocation of about BDT 25 million (less than US\$ 0.5 million). The Department's revenue budget covers only salary, limited travel and certain basic logistics, with most programmatic and logistical requirements being met from project budgets supported by a variety of development partners. The lack of coordination between these projects, and the impossibility of transferring resources between them, are significant factors in contributing to the further fragmentation of DoE's already limited capacity.

\section{The Environmental Clearance Process: Dominant, but not Transparent}

205. DoE, including its six divisional offices, is responsible for reviewing and approving EA reports. According to provisions made in ECA 1995, DoE is authorized to issue environmental clearance on all types of industrial and non-industrial units and projects. This environmental clearance process dominates DoE's workload. In 2000-2001, DoE processed almost 1,300 environmental clearance applications, a threefold increase since the enactment of the ECA in $1995 .{ }^{115}$ The requirement for higher impact facilities to annually renew their environmental clearances increases the administrative burden on the Department still further.

206. ECA 1995 requires that no industrial unit or project be established without obtaining an Environmental Clearance Certificate from DoE. All projects are categorized into one of four groups: Green, Orange A, Orange B and Red. DoE offices in each of the six divisions receive applications and issue Environmental Clearance Certificates for proposed investments within that division. The divisional offices verify supporting documents and pass it on to the divisional head, who assigns an inspector for follow-up. For Green and Orange A category projects, once the inspector submits his report (typically within 5-7 days) the divisional head makes a decision within three days of receiving the report. Files for Orange B and Red category projects are sent to the Senior Chemist/Assistant Director. The files are then forwarded by the divisional office to the Environmental Clearance Committee of the DoE in Dhaka, and then passed to the Director General of the DoE for final clearance ${ }^{116}$. Most Environmental Clearances issued by DoE are from the Dhaka divisional office.

207. The EA process is not transparent in part because of legal loopholes and limitations in EA laws and regulations. There is no legal requirement for public consultation during the Environmental Assessment (EA) process, or even for the provision of information to affected people in conducting these assessments, ${ }^{117}$ although there have been instances when DoE has arranged for the presentation of an EA in the presence of DoE staff and invited experts.

\footnotetext{
${ }^{114}$ See Lam and Brown, 1997

${ }^{115} \mathrm{DoE}, 2002$

${ }^{116}$ BEI, 2006

${ }^{117}$ Ahammed \& Harvey, 2004 - although the EIA Guidelines for Industries 1997 suggest that an environmental impact assessment should involve the public, this has no legal force.
} 
Asking for public comment and input into decision-making depends upon the interest of the entrepreneur. Clear legal provisions for EIA compliance and monitoring are also absent. As such, there is little emphasis on project monitoring, and implementation of EIAs is ad hoc and dependent on the requirements of donor agencies where these are involved. ${ }^{118}$

208. The EA process is a major source of external influence on the Department. There are several reasons for this. While the ECA 1995 requires environmental clearance for development projects, it also reserves the ability of the Government not to require any environmental clearance. This keeps open the possibility for project proponents to exert influence to avoid this requirement. ${ }^{119}$ Wide powers are accorded to the Director General of the DoE who has significant discretionary power to suggest any actions necessary to meet the objectives of the Act, including the power to order closure of industrial units in the event that they do not meet adequate environmental standards. Further, in order to obtain environmental clearances, businesses and project proponents rely on a number of intermediaries or service providers to help obtain environmental clearances from DoE and its divisional offices.

209. A survey of fourteen such service providers showed that in addition to the official fees charged by the DoE for providing environmental clearances, in at least half the cases unofficial fees were paid by service providers in order to obtain an environmental clearance certificate. ${ }^{120}$ In the case of "Red" category clearances, the average value of the unofficial fee reported by the service providers was approximately US\$500. This constituted only $5 \%$ of the total fees paid for clearance, however, with some $90 \%$ being paid to the service providers (usually about US $\$ 900$ for "Red" category clearances, rising to more than US\$10,000 for very large developments). In principle, the services provided include preparation of EIAs and EMPs, but the lack of transparency and consultation in the process provides little incentive for the effective identification and mitigation of potential environmental impacts. The issue of rent-seeking is certainly not peculiar to DoE and cuts across public sector institutions in Bangladesh (see Box 6.1). In DoE and its divisional offices however, the emphasis on the EA clearance process has come at the cost of compromising its work in other technical areas. For example, the engagement of laboratory personnel in environmental clearance activities has caused the labs to be left unused, and staff to be unavailable for routine monitoring activities. ${ }^{121}$

\section{Weak Environmental Monitoring Capacity}

210. With the bulk of its effort focused on the environmental clearance process, DoE has little spare capacity to systematically monitor and analyze environmental information. Although monitoring environmental quality has been conducted on an ad hoc basis for years, there has been no systematic compilation, interpretation, or subsequent publication of these data. Without any quality control or public scrutiny of the data, the little environmental data available is generally of questionable reliability. An important step towards quality-assured environmental monitoring has been taken, however, with the systematic collection of air quality data under the Air Quality Management Project, and the DoE's recent commitment to publish an Air Quality Index on a daily basis.

\footnotetext{
${ }^{118}$ Momtaz, 2002

119 Ahammed \& Harvey, 2004

${ }^{120} \mathrm{BEI}, 2006$

${ }^{121}$ Interviews conducted for preparation of this report, 2004
} 


\section{Box 6.1: Governance in Bangladesh}

The pervasiveness of corruption is a broad public sector governance issue in Bangladesh. As a recent World Bank study points out, even after a quarter of a century of independence, the State does not ensure "rule of law" or provide a well functioning regulatory and policy environment (World Bank, 2002). The cross-country corruption perception index prepared by Transparency International places Bangladesh 145 out of 146 countries surveyed (TI, 2005).

Contributing to weakness in public sector governance is a weak judiciary, a corrupt public sector procurement system and police. For instance, surveys undertaken by the Bangladesh Chapter of Transparency International, revealed that $89 \%$ of respondents believed that it was almost impossible to get quick and fair judicial judgments without money or influence, and $63 \%$ of households involved in court cases had bribed court officials (World Bank, 1999).

Research undertaken as part of a Bank study titled Taming Leviathan also provides evidence for clientelism and patronage in public administration, as well as estimates of the economic costs of poor governance. For example, surveys show that as a result of bribes paid, the registered price of land is reduced by $25 \%$ on an average, amounting to a loss of Tk. 400 million of government revenue annually (ibid.). Due to rising public pressure, the Government passed the Anti Corruption Commission Act in 2004, which created legal space to establish an independent body to address corruption, (replacing the earlier Bureau of Anti-corruption, itself believed to be widely corrupt). The extent to which this new body will be autonomous remains to be seen.

Bangladesh's National Strategy for Accelerated Poverty Reduction (2005) recognizes that "a major thrust of the PRS [Poverty Reduction Strategy] has to be on ensuring good governance", and governance is the core focus of the World Bank's Country Assistance Strategy (CAS) for the period 2006-2009. The CAS emphasizes the broader governance issues facing Bangladesh, including an overly centralized public sector, unhealthy competition between major political parties, weak public financial management, corruption related to procurement, and a weak civil service and judiciary, all of which compromises effective service delivery, including law and order, and is detrimental to the investment climate.

\section{Organizational Culture of DOE}

211. Numerous studies based on empirical work in developing and developed countries have pointed out the importance of leadership for organizations to perform well. ${ }^{122}$ Committed leadership is seen as key to sustaining worker motivation, a sense of organizational mission and clear performance expectations. DoE and MoEF however, are characterized by frequent changes of leadership. In DoE, the leadership of the Director General has been severely compromised by the fact that this position has changed hands more frequently than once a year, for the last seven years.

212. Another key factor contributing to high performing organizations is an implicit trust and contract between leaders and employees, as illustrated by research in a range of developing and developed countries. ${ }^{123}$ Worker dedication and motivation is further supported by an organization that is perceived as having a high sense of mission, is client responsive and is anchored by a management style that encourages worker participation, decision-making and problem solving. By contrast, the operating environment within DoE is characterized by frequent changes in management, administrative red tape that delays decision-making, and an organizational culture that is influenced by informal lines of authority to higher levels. Director Generals are always appointed from backgrounds not

${ }^{122}$ Wilson, 1989, Grindle, 1997; Khaleghian and DasGupta, 2005

${ }^{123}$ Grindle, 1997 
linked to management of the environment. Moreover, interviews with various staff and stakeholders showed that there is lack of accountability in the internal workings of the organization. Externally DoE is seen less as an advocate for environmental sustainability and more as a policing agent, contributing to its "image crisis". Moreover, DoE is a very centralized department with representation at the divisional level only. Effective application of the Department's limited resources is hampered by the lack of regular coordination between the DoE and its divisional offices, to whose work little importance is attached. This is discussed in more detail below.

\section{The Forest Department: Defining Roles in Conservation and Social Forestry}

213. The FD, established in 1862, is responsible for the conservation and management of Bangladesh's forest resources through implementation of the Forest Policy, Forest Master Plan, and enforcement of the Forestry Act, as well as implementation of aspects of the National Environment Policy, such as those pertaining to the conservation of biodiversity and wildlife, and the sustainable management of forestry resources. The FD is headed by the Chief Commissioner of Forests, and forest management takes place through officers working at the divisional level. ${ }^{124}$ In addition, each of the divisions is divided into circles staffed by forest officers, rangers, and guards, with each forest officer covering two or three upazilas.

214. Bangladesh has limited forest cover, at $10 \%$ of land area, down from $20 \%$ in the $1960 \mathrm{~s} .{ }^{125}$ In part, the decline can be attributed to governance issues linked to the forest sector. An issue widely reported in the press is the complicity of FD officials in illicit tree felling ${ }^{126}$, and fieldwork carried out during the course of this study reinforced the widespread believe in the lucrative nature of some FD postings.

215. Over the last two decades the FD has shifted its emphasis away from policing and conservation towards community and extension-related roles associated with the rising importance of Social Forestry. The National Forest Policy (1994) marked a departure from the commercial emphasis of earlier policies, emphasizing a commitment to sustainable development, poverty alleviation, the participation of local communities, support for private sector afforestation initiatives, and global environmental concerns (including biodiversity conservation and climate change). Implementation of this policy took an important step forward with the enactment of the Forest Amendment Act, 2000, which established Social Forestry as a function of the FD.

216. The Forest Sector Review, $2004^{127}$, recommended that the FD be split into two directorates, (i) the Directorate of Park Service and Conservation, and (ii) the Directorate of Social Forestry, both to be placed under an Inspector General for Renewable Natural Resources. The role of the Directorate of Park Service and Conservation would be to manage protected areas and Ecologically Critical Areas (as declared by DoE), while the Directorate of Social Forestry would manage community forestry initiatives, including those in Reserve Forest areas. To date, there has been little progress in implementing these reforms.

\footnotetext{
${ }^{124}$ Forestry division do not coincide precisely with administrative divisions.

${ }^{125} \mathrm{FAO}, 2000$. The FAO definition requires both that tree cover be $10 \%$ or more, and that the predominant land use be forestry. MODIS satellite imagery suggests that the true area with $10 \%$ or more tree cover may be as much as $35 \%$ of total land area.

${ }^{26}$ TI, 2000

${ }^{127}$ Bangladesh Forest Department (2004). The Forestry Sector Review Report.
} 


\section{Environmental Management at Sub-National Levels}

217. Bangladesh has a long tradition of sub-national government. Since independence, sub-national government structures have changed periodically with different political regimes, none of which have lasted for a long enough time to become rooted and consolidated as effective institutions of service delivery. ${ }^{128}$ Currently, there are six divisions, 64 districts or zilas, 460 sub-districts or upazilas, 4,500 union parishads and 68,000 gram sarkars. Of these, the principal elected local government structures are the union parishads. There is no elected representation at the divisional, district or upazila level. Officers at these levels operate with upward accountability, representing a deconcentrated model of infrastructure and service delivery. Representatives are elected, however, to union parishads and pourashavas (municipalities). At the village level, Gram Sarkars, established through the Gram Sarkar (Village Government) Act promulgated in 2003, function with 13 members representing identified socio-economic groups.

218. There is no uniform structure to sub-national representation of central government agencies, with the FD, for example, being structured around forest cover, and a divisional structure that differs from those of local government. Most of the larger government agencies, however, follow the administrative pattern, with a hierarchy of offices down to the Upazila level.

219. At the sub-national level, it is the upazila administration that is principally responsible for basic service delivery. Many central government departments and agencies are represented at this level but the officers remain under the authority of the central government. Planning and coordination of development activities in the upazila are undertaken by the Upazila Nirbahi Officer (UNO), who is appointed by the central government and the Upazila Development Coordination Committee (UDCC). The UDCC consists of the chairmen of each union within the upazila, and who chair the committee on a rotating basis. Members of Parliament (MPs) act as special advisors to the UDCC, exercising considerable influence, and the UNO is a member secretary. The UDCC is responsible for allocating the Annual Development Plan (block) grants within the upazila. Formal responsibilities of the UDCC include reviewing, preparing, and overseeing development projects, and advising union parishads on development schemes. Coordination at this level is weak, in part because neither the Deputy Commissioner at the district level, nor the UNO are responsible for preparation and coordination of comprehensive regional development plans. ${ }^{129}$ Upazila level offices of government organizations normally report to two different bodies, first to their own higher level official at the district level, and second to the upazila administration, which is effectively the UNO.

220. Union parishads have been vested with a range of development functions, including construction and maintenance of small scale infrastructure (katcha roads, bridges, canals, and culverts), potable water supply, and flood control infrastructure. They are also responsible for planning and monitoring of the $\mathrm{ADP}$, and local revenue mobilization and collection. They generate very little revenue of their own, however, depending heavily on block grants from central government allocations, supplemented in some cases by resources from local programs supported by development partners and NGOs. They also have little discretion

${ }^{128}$ Westergaard \& Mustafa Alam, 1995

${ }^{129}$ ADB et al. 2003 
over using the money that is collected and face numerous restrictions in the use of block grants by detailed guidelines. Further, decisions relating to implementation of programs in basic services such as health, education, and water supply, lie with government line departments at the upazila level. Even though union chairman could potentially play an important role through their participation as chairman of the UDCC, in practice their roles are largely constrained to advocacy.

\section{Partially De-concentrated Model of Environmental Management}

221. The environmental management system in Bangladesh constitutes an extremely centralized and partially deconcentrated model of environmental management. At the divisional level, there is a Divisional Environmental Advisory Committee headed by the Divisional Commissioner with representation from various government agencies. While the MoEF has forest officers posted below the divisional level, the DoE does not have any representation below this level. An important gap in existing formal rules (the Constitution and other laws) is that the divisions, districts, upazilas, unions do not have a clearly defined role to play in environmental management. Lack of an appropriate mandate and institutional arrangements below the divisional level is a key factor contributing to difficulties in implementing environmental policies and regulations.

222. DoE has divisional offices in each of the 6 administrative divisions of the country. ${ }^{130}$ In addition to their role in the environmental clearance process discussed earlier, they play a monitoring and enforcement role, but are not mandated to provide technical advice to firms and stakeholders (see Box 6.2). Moreover, they get little systematic support from the DoE headquarters at the national level to carry out their activities. The mandate of the Divisional Environmental Advisory Committees is to advise on environmental issues, give directives to district level agencies, and coordinate among line agencies at the regional and local levels. These institutional arrangements have not been fully functional, however, and as a result, Divisional Environmental Advisory Committees rarely meet, and lack authority to ensure implementation of decisions taken.

223. At the upazila level, there is no designated environmental focal point or coordination mechanism, and little consideration is given to environmental concerns. Except in rare cases or complaints, officials at the upazila level are not in touch with the divisional offices of the DoE. Field visits to several upazilas during the course of this study found that environmental issues are addressed in an ad hoc manner by sectoral officers at the upazila level, particularly when activities in one sector (for example, agricultural runoff) influence activities in another sector (such as productivity and sustainability of fisheries in local ponds). There is no leadership or mechanism, however, for addressing environmental sustainability issues across sector activities at the upazila level. Line ministry representatives pursue sectoral agendas, with environmental sustainability falling through the cracks. ${ }^{131}$ Considering that officers at this level are not elected but appointed at the national level, leadership from the line ministries will be crucial in greater integration of environmental issues at the upazila level. Further, the UNO and the UDCC could play a much greater role in addressing environmental sustainability issues at this level.

\footnotetext{
${ }^{130}$ Namely Dhaka, Chittagong, Khulna, Rajshahi, Barisal and Sylhet

${ }^{131}$ Examples might include health officers interested in providing health services but not in environmental health issues, or agricultural officers focusing on productivity but not agro-chemical environmental risks
} 


\section{Box 6.2: Functioning of Divisional Offices of the DoE}

A field visit to the Rajshahi divisional office of the DoE, located in the town of Bogra, provides a snapshot of the capacity constraints faced at this level. There are 17 staff in this office, but only one environmental inspector (compared to three inspectors in the Dhaka division), and the revenue budget allocation for the divisional office was approximately US $\$ 30,000$ in FY05.

The divisional office is mandated to issue environmental licenses for investments falling under the ECA 95's Orange-A category (Orange-B and Red categories fall under the purview of DoE at the national level). Within this category, there are numerous small- and medium-scale industries (e.g. rice husking, brick making, dyeing and handloom industries). One constraint faced by the Bogra staff is that many firms do not know they have to obtain environmental clearances.

The main role of the office is monitoring environmental quality and inspection, including oversight of a number of large public sector firms, including sugar mills, distilleries, and a chemical factory, all of which are highly polluting. Monitoring capacity is very limited, however, and the divisional office is not mandated to provide technical advice to firms.

The divisional DoE collects fees for issuing and renewing environmental clearances. There is little incentive for the staff to do this systematically, however, as this revenue is returned to the national exchequer. Regarding linkages with other levels of government, interviews suggested that guidance from the center to the Divisional office is ad hoc, and there are no links between the Divisional office and upazila or union offices.

Source: World Bank

\section{The Potentially Important Environmental Role of Union Parishads}

224. Union parishads presently have a limited role in environmental governance. Their mandates include maintenance of village markets, public ponds, graveyards, and recreational places. A potentially important environmental role for union parishads is conferred under ECA ' 95 , which requires that while applying for environmental clearance from the DoE, the applicant is to obtain and submit a No Objection Certificate issued by the Chairman of the union parishad (or Municipal Chairman in pourashavas, and the City Corporation Executive in metropolitan areas). With no systematic review or assessment process in place, however, these certificates are normally procured through private negotiation. Nevertheless, if greater public consultation could be introduced into this process, union parishads could perform a valuable role in environmental management, particularly considering their unique positions as locally-based elected representatives.

225. In addition to the No Objection Clearance function in the EIA process, union parishads perform a variety of further environmental management roles, particularly in the development of local infrastructure, management of water supply and sanitation investments, and influence over the allocation of natural resource leases, including fisheries. At the upazila level, union parishad Chairmen are members of various committees and chair the UDCC by rotation. With enhanced awareness of environmental concerns, union parishads could become an important local force for environmental protection and improvement.

\section{Environmental Management in Other Sectors: Incentives and Coordination}

226. The MoEF and its Departments, while directly mandated to undertake environmental management functions, only account for a small percentage of total public expenditure on environmental management. Line ministries whose activities have major implications for the 
environment include Energy, Transportation, Agriculture, Fisheries and Livestock, Water Resources, and Relief and Disaster Management, among others. Almost $10 \%$ of public expenditure is allocated for environmental purposes, based on a broad definition of environmental expenditures that includes the following categories:

- Degradation related public expenditures - including public expenditures for activities such as the establishment of laboratories for soil testing, for arsenic testing in water, for clean fuel projects, projects for reduction of water logging, and other cleanup activities;

- Resource related public expenditures - including public expenditures for programs such as afforestation, establishment of eco-parks, aquaculture development, integrated coastal management, and agricultural research programs;

- Water related public expenditures - including public expenditures on water supply, sanitation, and canal maintenance;

- Disaster related public expenditures - including public expenditures on flood protection structures, programs to develop early warning system of disasters, river bank protection programs, and construction of shelters.

A recent review of public environmental expenditures in Bangladesh conducted for this report ${ }^{132}$ found these resources to be allocated between the four categories described above as summarized in Figure 6.1.

Figure 6.1: Public Environmental Expenditures

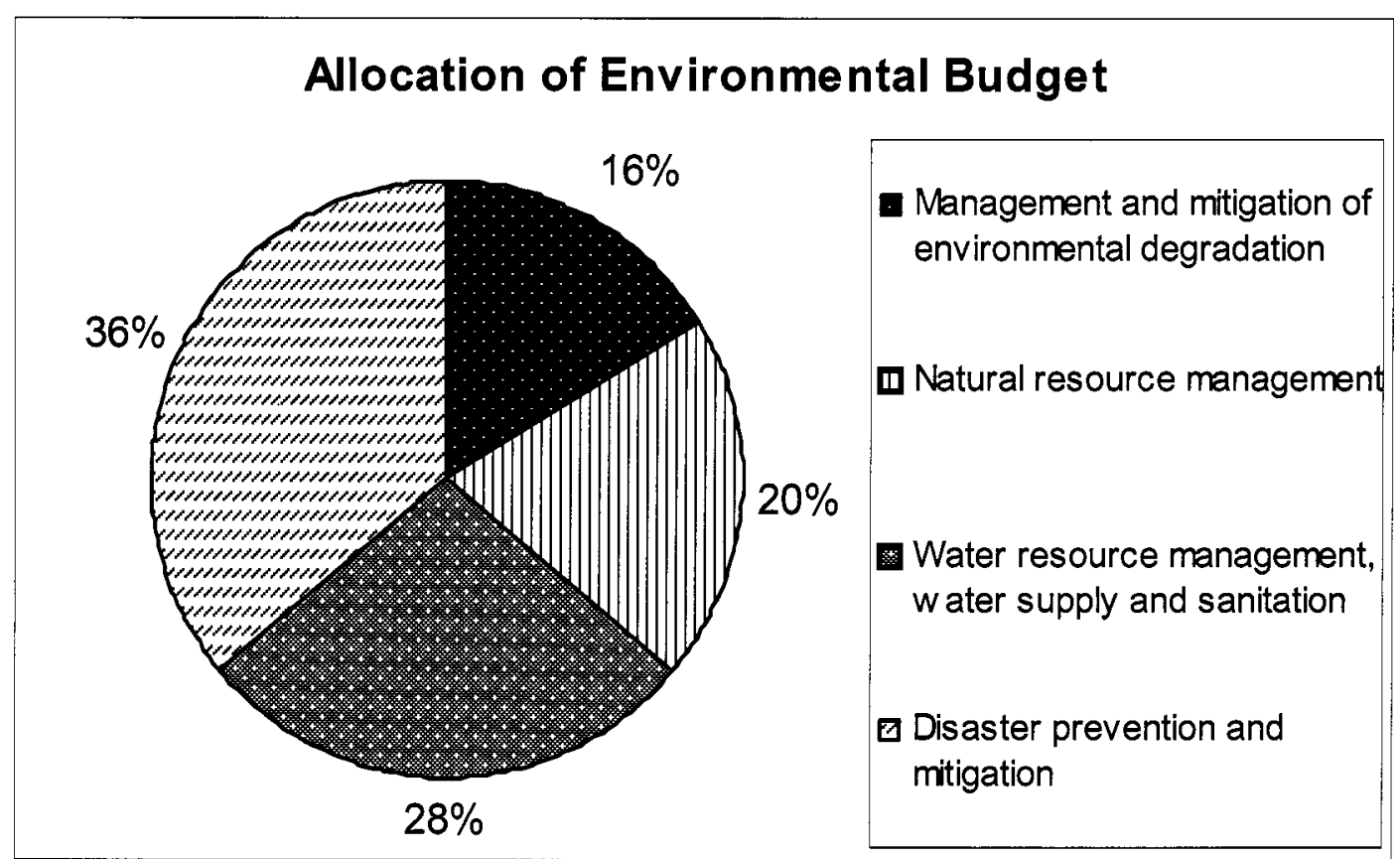

${ }^{132}$ E. Haque, 2005. Public Expenditures on the Environment in Bangladesh - background paper for CEA 
227. Trends in public expenditure for environmental management are indicated in Table 6.1. In this Table, degradation and resource related public expenditures as defined above are grouped together as EE1, on the basis that these primarily constitute expenditures on environmental monitoring, protection and remediation. Water and disaster related expenditures as defined above, which are more associated with the provision of services and protection from natural disasters, are added to EE1 to form a more broadly defined category of environmental expenditures, EE2.

228. As Table 6.1 indicates, the level of public expenditure on the environment has been relatively consistent over the last decade, with EE1 at about $0.5 \%$ of GDP, and EE2 approximately equivalent to $1.5 \%$ of GDP. The increase in environmental expenditures in 2001-02 was largely a response to the floods of 1998, which were followed by an increase in public expenditure for a variety of purposes, including flood control and afforestation. The higher levels of EE1 expenditure in 1995-96 are not directly comparable, as they include expenditure on sanitation, which is incorporated in the EE2 estimates for subsequent years.

Table 6.1: Trends in Environmental Expenditure

\begin{tabular}{|l|c|r|r|r|}
\hline & $\mathbf{1 9 9 5 - 9 6}$ & $\mathbf{1 9 9 8 - 9 9}$ & $\mathbf{2 0 0 1 - 0 2}$ & $\mathbf{2 0 0 2 - 0 3}$ \\
\hline & & & & \\
\hline EE1 share of Public Expenditure & $5.24 \% *$ & $3.28 \%$ & $4.62 \%$ & $3.28 \%$ \\
\hline EE1 share of GDP & $0.70 \%^{*}$ & $0.44 \%$ & $0.69 \%$ & $0.48 \%$ \\
\hline MoEF share of EE1 & - & $2.67 \%$ & $3.14 \%$ & $5.03 \%$ \\
\hline & & & & \\
\hline EE2 share of Public Expenditure & - & $10.81 \%$ & $13.01 \%$ & $9.11 \%$ \\
\hline EE2 share of GDP & - & $1.46 \%$ & $1.94 \%$ & $1.33 \%$ \\
\hline MoEF share of EE2 & - & $0.81 \%$ & $1.11 \%$ & $1.81 \%$ \\
\hline
\end{tabular}

Sources: E. Haque, 2005, Public Expenditures on the Environment in Bangladesh (background paper for CEA), and C. Brandon, L. Rylander, 1997, Private/Public Sector Roles in Improving Pollution Management in Bangladesh.

Notes: EE1 covers degradation- and resource-related public expenditures as defined above. EE2 includes water- and disaster-related public expenditures as defined above, as well as all EEl expenditures.

*EE1 estimates for 1995-96 include expenditures on sanitation, which in subsequent years are included in EE2.

229. Table 6.1 also indicates MoEF's share in public environmental expenditures. While this share has been rising, it is striking to note that the Ministry only accounts for $5 \%$ of the Government's budget for environmental monitoring, protection and remediation (EE1), and less than $2 \%$ of environmental expenditures more broadly defined (EE2). These figures serve to underline first, the importance of environmental management policies and actions in other ministries, and second, the need for MoEF to play a proactive role in coordinating crosssectoral environmental initiatives. The status of these twin imperatives is considered briefly below.

\section{Sectoral Capacity for Environmental Management: Building Systems and Incentives}

230. A range of sectoral policies have significant consequences from an environmental perspective, in particular the Water Policy, Forest Policy, Fisheries Policy, Tourism Policy, Energy Policy, Petroleum Policy, Agriculture Policy, and Industry Policy. While the integration of environmental concerns into sector policies is still poor, there have been recent 
improvements, for example the inclusion of references to environmental management in the Industrial Policy (see Box 6.3). While such developments mark a growing recognition of the need to ensure environmental sustainability in sectoral initiatives, there is not yet any systematic process through which the environmental soundness of such policies may be assessed and monitored. ${ }^{133}$

\section{Box 6.3: Industrial Policy (1999) - a Glass Half Full}

One of the 17 objectives of the Industrial Policy is "to ensure a process of industrialization which is environmentally sound and consistent with the resource endowment of the country" (Chapter 2, Section 2.12).

The section on Institutional Support, under 'Environmental Protection', states "To control pollution of the environment, relevant provisions of the Environmental Conservation Act 1995 and rules framed there-under will be enforced. All sponsoring authorities must ensure that new projects incorporate requisite environmental studies, environment pollution control and other environment related precautionary measures. Existing industries, which are likely to cause environmental pollution and endanger public health, must take appropriate measures for controlling environmental pollution. Industries will be encouraged to obtain ISO 14000 certification." (Chapter-XV, Section 15.6).

Despite these good environmental intentions, however, none of the 24 strategies of the policy relate to environmental management, and the chapter on fiscal and financial incentives provides no resources for pollution management.

The National Council for Industrial Development (NCID) was instituted in 1999 to provide effective guidance for implementation of the Industrial Policy, and is headed by the Prime Minister, with the Minister for Environment and Forest included as a Member. The Executive Committee of the NCID, however, does not include any representation from MoEF.

231. A growing number of line agencies are undertaking initiatives to build environmental management capacity, such as measures adopted by the Local Government Engineering Division (see Box 6.4). The further development of environmental management capacity within key sectoral agencies is essential to meet the Millennium Development Goal of ensuring environmental sustainability, and by distributing the burden of day-to-day environmental management, will enable MoEF to focus on more effective regulatory oversight. In order to strengthen the incentives for development of sectoral environmental management capacity, a key element of MoEF's oversight role is to build demand for improved environmental performance, in particular through the provision of public information based on monitoring of environmental quality and the analysis of potential responses.

\section{Cross-Sectoral Coordination: a Proactive Strategy for MoEF}

232. MoEF is responsible for working with other ministries to review and monitor the impact of development projects on the environment across all sectors. Public sector projects under consideration by the Planning Commission are in principal passed to the MoEF for environmental review. With limited technical expertise available to fulfil this role, however, the opportunity offered by this 'environment lens' in the public planning process is not utilized to its full advantage, and several recent studies have pointed to the lack of

${ }^{133}$ Rahman and Aina, 2005 
coordination between MoEF and line Ministries. ${ }^{134}$ No specific guidelines for the preparation and review of environmental assessments for non-industrial projects have been issued, and the process of providing environmental clearances for such public sector projects is ad hoc. While there is a need to monitor the implementation of environmental management plans for development projects undertaken by line ministries, DoE lacks the resources, and further, has no authority to undertake legal proceedings against line agencies in the event that they do not address the environmental impacts of their activities.

233. The analysis presented in the preceding chapters underlines the challenges inherent in developing effective cross-sectoral coordination for environmental management. For example, as considered in Chapter 3, the management of water quality in Dhaka requires coordinated action by DWASA, DoE, Dhaka City Corporation, Bangladesh Water Development Board, Ministry of Industry, and the Department of Shipping, in some cases with overlapping mandates and jurisdictions. In addition, the interests of key industries, such as tanneries and textiles, must be represented, and mechanisms provided to inform and empower local citizens and community groups affected by poor water quality and lack of access to sanitation.

\section{Box 6.4: Environmental Management at LGED}

The Local Government Engineering Department (LGED) plays a pivotal role in rural infrastructure development. In order to be able to deliver sustainable projects, LGED has pursued a strategy of mainstreaming environmental concerns in project development and implementation, and has supported training in environmental management, both for its staff and other stakeholders, including contractors selected to execute works under LGED programs.

Environmental aspects have been considered in LGED projects since 1992, when the first edition of "Guidelines on Environmental Issues related to Physical Planning" was published. These guidelines have since been supplemented with more specific guidance, for example the "Environmental Codes of Practice" prepared for the Rural Transport Infrastructure Project supported by the World Bank. Under the same project, an Environmental Information Management System is also being piloted to ensure that top executives in the Department have access to environmental management information for all on-going projects.

Recent studies, however, have pointed to the limited application of LGED guidelines in rural infrastructure projects (Ahammed \& Harvey, 2004). The authors attribute this in part to the urgent need for infrastructure in Bangladesh and of the relative marginalization of environmental concerns with respect to development concerns.

234. A strategy for MoEF to take a more proactive role in the cross-sectoral coordination of environmental management would encompass the following four elements: (i) building demand for change through systematic monitoring, analysis and public disclosure of environmental information; (ii) analysis and recommendation of options for the mitigation of impacts; (iii) facilitation of processes aimed at developing consensus between sectors and relevant stakeholders on agreed courses of action; and, (iv) establishment of indicators and performance-based incentives for implementation, with associated monitoring and evaluation. Although still at an early stage, the reduction of emissions from diesel vehicles is an example of an issue on which the DoE is taking concrete steps to build consensus and coordinate action by a variety of agencies (see Box 6.5).

${ }^{134}$ See Ahammed \& Harvey, 2004; Momtaz, 2002 


\section{Box 6.5: Catalyzing Cross-Sectoral Action - the Case of Diesel Emissions}

With two-stroke three-wheelers now banned from the streets of Dhaka, the worsening air quality can be attributed mostly to diesel vehicles, estimated to contribute more than $80 \%$ of emissions from mobile sources. A study conducted by DoE in 2005 recommended a variety of measures to address emissions from these vehicles. Other than those relating to tightening of emission standards, however, implementation of most of these recommendations lies outside the purview of the MoEF, as outlined below:

- Bangladesh Road Transport Authority, the Ministry of Communications, and the Dhaka Transport Coordination Board have the primary roles to play in (i) promoting the replacement of the bus fleet with $\mathrm{CNG}$ or cleaner diesel vehicles, (ii) establishing bus franchise conditions that include emissions standards, and (iii) setting fares and protecting routes to provide adequate revenue for investment in fleet maintenance and renewal. Bangladesh Road Transport Authority also plays the lead role in incorporating emissions tests in vehicle fitness tests;

- The National Board of Revenue has a key role to play in establishing incentives for investment in cleaner vehicles through duties that reflect the environmental costs of importing old diesel vehicles and engines;

- The availability of cleaner fuels depends primarily on the Petroleum Corporation, which must implement the recommendation to import low sulfur diesel, and the Rupantrita Pakritick Gas Company Limited, responsible for ensuring adequate availability of CNG for the renewed bus fleet.

While implementation of these recommendations lies outside its direct control, MoEF has an important mandate to promote these actions through the provision of air quality information and policy analysis. By building public awareness of the health risks posed by diesel emissions, and by establishing inter-agency consensus on appropriate remedial actions, MoEF can be instrumental in creating the public support and institutional momentum necessary for action. The Ministry can also play a role in sustaining such momentum through the provision of financial support for investments in cleaner transportation. The DoE has made important advances in this direction by distributing the diesel options study and constituting a cross-sectoral committee to recommend specific measures for emissions reduction.

\section{Role of the Judiciary}

235. Currently environmental cases may only be heard by the two Environmental Courts established in 2002 under the Environment Court Act, 2000, in Chittagong and Dhaka. The number of cases brought to date is limited, and the record of successful prosecutions is poor. Until recently, only nine cases had been brought in Chittagong, mostly against hill cutters. In one case a verdict against the defaulter was pronounced in the form of a nominal fine. In the last year, however, about a dozen further cases have been lodged, mostly against brick kilns. In Dhaka, only about ten cases have been filed by the DoE, but in total some 84 cases have been brought before the Dhaka Environment Court. Most of the recent cases have been filed against polluting textile dyeing industries by private parties, whose motivations have become a cause of concern to the DoE. As the number of cases heard has been minimal, the Environment Courts have requested permission to also entertain non-environmental suits.

236. The higher courts (the High Court and Supreme Court) have considered public interest litigation cases on environmental matters, with the Bangladesh Environmental Lawyers Association (BELA) playing an instrumental role in introducing this practice, inspiring the judiciary to take a more active role at the highest level in cases of environmental 
interest. An important achievement won by BELA in response to its appeal was the Supreme Court decision in 1998 to grant citizens and NGOs the right to enforce environmental laws. ${ }^{135}$

\section{NGOs and Civil Society}

237. A large number of environmental and natural resource management NGOs have played an important role in raising awareness of environmental issues, piloting innovative environmental management practices, and introducing environmental considerations into broader decision-making. For example, the Forum of Environmental Journalists, Bangladesh (FEJB), has been particularly effective in creating environmental awareness, and a number of State of the Environment Reports have been produced by civil society organizations. Field research carried out as part of this study also indicated that numerous NGOs are active at the upazila and union levels in undertaking activities such as tree planting, delivery of sanitation programs, and working with fisherman to improve the sustainability of fisheries. In Dhaka, NGOs are involved in the management of municipal solid waste, and have been successful in accessing carbon financing to support their initiatives.

238. The Coalition of Environmental NGOs (CEN) was formed in the late 1990's, attached to the Association of Development Agencies Bangladesh (ADAB), to coordinate the engagement of civil society on environmental issues of concern, but did not develop into an authoritative entity. As a result of the activities of environmental NGOs, civil society has become more confident and forceful in asserting its views on environmental issues, and the DoE has become increasingly receptive to working with civil society groups. In addition to this activist stance, some of the larger, more broadly-based NGOs have established their own environmental units, both to help manage the environmental impacts of their own activities, and to promote environmentally beneficial investments.

239. The private sector plays a dual role, acting both as a major source of environmental degradation ${ }^{136}$, and providing a range of environmental management services. The provision of professional environmental services has not grown at the rate it might have, however, in part due to the low level of private sector engagement by the DoE, as well as the limited emphasis placed on the quality of EIAs and environmental data collection. International clients, both private investors and development partners, are an important source of demand for such inputs. There have also been isolated examples of good collaboration between the public and private sectors to address specific environmental concerns, such as the phasing out of ozone depleting substances and the introduction of appropriate low cost pollution management technology into the textile sector.

\section{Strengthening Institutions for Environmental Management: Recommendations and Areas for World Bank Support}

240. As the analysis above suggests, weaknesses in implementation of environmental laws and regulations in Bangladesh can be attributed to a number of governance factors, including:

\footnotetext{
${ }^{135} \mathrm{http}: / /$ www.elaw.org/news/impact/text.asp?id=321

${ }^{136}$ see Matin, 1995
} 
- overly centralized environmental management system with practically no institutional mechanism at the lower administrative levels (upazila and below) to address environmental issues;

- MoEF resources disproportionately allocated to the forestry department;

- low revenue allocation to DoE and heavy dependence of the Department on donor funds;

- weaknesses in formal laws, such as the absence of a legal requirement for public disclosure and participation in EA laws and regulations;

- the top-down organizational culture of DoE, combined with the lack of horizontal accountability between DoE and sector Ministries, and lack of vertical accountability between $\mathrm{DoE}$ and its divisional offices.

241. Strengthening environmental management in Bangladesh will therefore require action on a number of fronts, from national planning down to local decision-making, and across a variety of sectors. At the national level, more regular functioning of the National Environment Council and its Executive Committee would greatly enhance inter-sectoral coordination. At the local level, establishing a mechanism for public consultation prior to a No Objection Certificate being issued by the union parishad Chairman would significantly improve accountability in the process. Continued efforts to build environmental management capacity in sectoral agencies, and to strengthen environmental assessment in public sector planning, are essential to achieving the MDG of mainstreaming sustainable development into country policies and programs. Above all, however, it is clear that a crucial requirement for better environmental management in Bangladesh is improved functioning of the DoE.

\section{Strengthening DoE by Implementing its Strategic Plan}

242. Given the wide remit of DoE's mandate, and the extremely limited human and financial resources at the Department's disposal, it is essential that the Department target its actions to achieve the greatest impact with the scarce resources available. Recently, DoE undertook an institutional assessment and developed a strategic plan (and an action plan for its implementation) to clarify its goals, expected results and major initiatives (see Box 6.6) through the CIDA-supported Bangladesh Environment Management Project (BEMP) project. ${ }^{137}$ This plan was approved by DoE and should be implemented. One limitation of this plan, however, is that it does not sufficiently address strengthening of DoE capacity at sub-national levels.

243. Even with a concerted effort to target its activities, by any reasonable standard there are not enough human and physical resources to allow DoE to fulfil its mandate and implement its Strategic Plan. ${ }^{138}$ In a country of 130 million, the DoE has been allocated only about 75 managerial and technical staff, barely more than one officer for each of the country's administrative districts. When DoE was first created in 1989, there was a government commitment to allocate 650 staff over time. The organizational structure recommended by BEMP to enable DoE to implement its Strategic Plan suggests:

\footnotetext{
${ }^{137}$ In targeting the use of its scarce resources, an outstanding issue requiring clarification is the role of the DoE in natural resource management and biodiversity conservation

${ }^{138}$ BEMP, 2003. Restructuring the DoE Organization
} 
- expansion from 191 to 490 posts, with field positions increasing from 121 to 361 (see Figure 6.2);

- creation of a standards and enforcement branch, with capacity for legal support; and

- separation of the enforcement, monitoring and clearance functions at the field level.

\section{Box 6.6: Strategic Plan of the DoE}

Mission - DoE's mission is to help secure a clean and healthy environment for the benefit of present and future generations through:

- Fair and consistent application of environmental rules and regulations;

- Guiding, training and promoting awareness of environmental issues;

- Sustainable action in critical environmental problems that demonstrate practical solutions, and that galvanize public support and involvenent.

Strategic Priorities - DoE's five-year strategy involves working to improve the DoE's performance in all areas of its mandate while focusing on five strategic directions:

- Enforce the Environmental Conservation Act and meet international obligations;

- Administer the environmental clearance process competently and transparently;

- Address major air and water quality management problems;

- Expand public awareness efforts;

- Build DoE capacity.

Building Capacity - to better fulfll its mandate, the capacity of the DoE has to increase significantly. Accordingly, the first steps are (i) restructuring the Department, and (ii) increasing the number and competence of its human resources.

Source: Strateric Plan of the DoE 2002

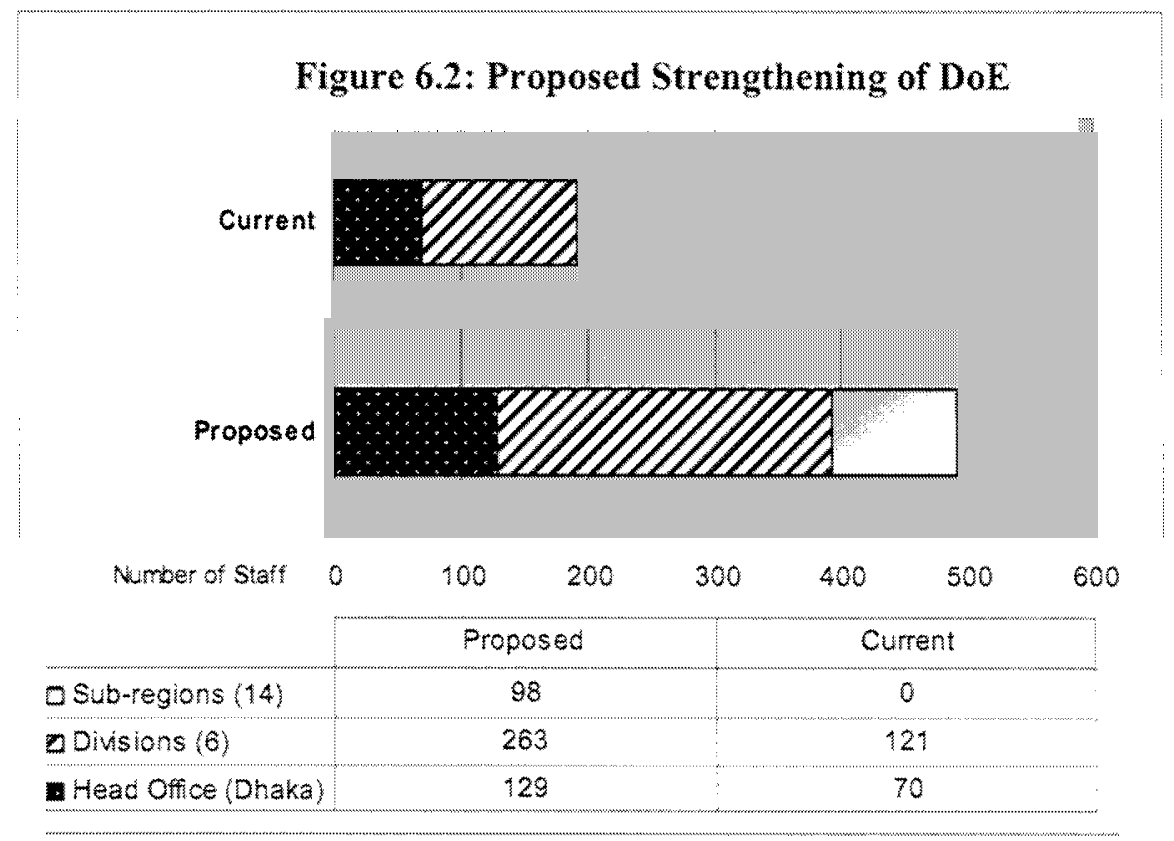

Source: BEMP (2003) - Restrueturing the DoE Organization 
244. DoE is primarily a regulatory and enforcement department, and to successfully carryout its mission, it needs staff in the field with access to adequately funded logistical and laboratory resources. The emphasis on additional field positions will allow DoE to expand is field presence to 20 regional offices, bringing greater community presence and more effective response to complaints and enforcement issues. While the medium-term goal is to develop field offices in each of the 20 "old districts", over the longer term the aim is to expand coverage to each of the country's 64 administrative districts.

245. As indicated above, DoE provides no systematic support to its divisional offices. Moreover, the divisional offices of the DOE cannot provide technical advice to the industries they monitor. Even though they are engaged in revenue collection (through fees for renewal of environmental clearances), they have little incentive to do this systematically, since these resources are returned to the exchequer. A change in roles and incentives would allow divisional offices to play a stronger role in providing technical advice to the firms they work with, such that they are seen less as a policing and more as a technical support agency.

246. An additional human resource issue that is seen by many DoE staff as an impediment to higher performance, is the lack of an environmental cadre within the Civil Service. Although pay and compensation remain the same, a cadre permits incumbents to transfer between ministries, and to participate in training at the Bangladesh Public Administration Training Centre or the Academy of Planning and Development. Perhaps most importantly, the establishment of an environmental cadre would allow DoE staff to rise beyond the level of Director, which is equivalent only to the grade of Deputy Secretary. The existence of such a cadre would provide more attractive career paths, and would help strengthen the Government's environmental management capacity beyond the DoE.

247. A difficult but equally important factor that needs to be addressed is the organizational culture of DoE, including the frequent changes in leadership, current top-down style of management, and lack of internal and external accountability. Addressing this "image crisis" is likely to go a long way in improving its relations with other sector Ministries and the broader citizenry.

248. Securing the financial support necessary to implement DoE's Strategic Plan will be challenging. To enhance the credibility of this effort, three principles should guide the allocation of any new resources:

- increases in financial resources and staffing should be accompanied step-by-step with improvements in transparency, accountability and organizational culture in DoE;

- while project financing may provide essential resources for training, equipment, and specific studies, such support must be accompanied by the increases in revenue budget necessary to finance DoE's evident need for increased staffing; and,

- given DoE's heavy dependence on donor funds for programmatic requirements, a mechanism for better coordinating projects and funds needs to be established.

With significant additional resources recently committed by CIDA for technical assistance to DoE, the most important role for the World Bank will be to help address the revenue budget issues through its dialogue with the Ministry of Finance and ongoing program of 
development policy lending. The need to implement the DoE's Strategic Plan is reflected in the policy matrix for the series of Development Support Credits supported by the World Bank, and will continue to be incorporated in future development policy lending discussions.

\section{Improving Transparency and Accountability in the EA Clearance Process}

249. Transparency is a crucial element in effective environmental regulation. Informing the public and allowing it to participate in environmental decision-making can help build pressure against polluters, reward good performers, and strengthen the credibility of environmental institutions. Several specific actions can be taken to improve transparency and accountability in the EA clearance process in Bangladesh:

- Placing information about environmental clearances on the web: a first step in this direction would be for DoE to place information related to environmental clearances and complaints on the internet, and to update this on a regular basis, to help establish public confidence in the environmental decision-making process;

- Legal requirement for public consultation in EA clearance process: if the assessment of environmental impacts is to become an effective and meaningful process, public consultation must become a part of the statutory process, particularly for potentially high risk projects. A first step in this direction would be for the government to prepare an appropriate amendment to ECR ' 97 , requiring such consultation to take place;

- Establishing guidelines for EA of non-industrial projects: given that there are currently no legal guidelines for non-industrial projects, the current practice used by project sponsors (including line Ministries) is to send project proposals for environmental clearance to DoE with or without EIA. The clearance of such projects takes place after review by DoE, but the process is ad hoc. Given the importance of addressing environmental considerations, clear guidelines should be prepared by DoE for EA of non-industrial projects, such that the process of granting clearances is not discretionary but has full backing of the law; and

- Delegation of select environment clearance functions to sub-national level: the ECA ' 95 and ECR '97 make no provision for the environmental clearance function of the DoE to be devolved to upazila or union authorities, even for small scale, low impact investments falling under the Green Category. Limiting the list of industrial facilities specified in the ECR '97 as requiring clearance from DoE, and delegating responsibility for clearance of less polluting facilities to local authorities would freeup scarce DoE resources to focus on more serious environmental risks.

\section{Strengthening DoE's Monitoring and Enforcement Functions}

250. Bangladesh has a dearth of reliable data on all indicators of environmental quality, including air quality (both urban and indoor), water quality (both drinking water and surface water), soil degradation, biodiversity, and forest cover. The lack of capacity for sampling, monitoring, and laboratory testing greatly hinders the enforcement of the government's environmental standards and deprives civil society of the ability to participate effectively in environmental decision-making. To help meet the pressing need for more reliable and comprehensive environmental information, the data gathering resources of private sector 
bodies and research institutions should be harnessed. The role of government, particularly $\mathrm{DoE}$, could then shift from being the primary collector of environmental data to ensuring data quality, analyzing the results, synthesizing information, and disseminating the findings. Such arrangements could be established by MoEF through executive order.

251. In building DoE's ability to manage and disseminate environmental information, it will be important to prioritize and focus efforts around agreed strategic goals. At the national level, the provision of an annual environmental scorecard would provide such a focus, and build pressure for improved environmental performance. Using a small set of indicators of key environmental concerns in Bangladesh, the scorecard would be updated annually to track improvements and setbacks in environmental management. Locally, focus could be provided through a program to publish the environmental performance of industrial facilities, initially targeting selected industrial facilities of particular concern. This would both encourage industries to improve their performance, and at the same time would provide direction for improved monitoring by DoE.

252. While considerable strides have been made in environmental legislation, enforcement remains largely absent, with existing legal instruments left untested in the judicial system. The DoE has prosecuted very few offences under ECA ' 95 , even at the recently established Environment Courts in Chittagong and Dhaka. If the DoE could bring more environmental cases to court and those were tried properly, this would help build the credibility of the government's environmental intentions. To do so, DoE's capacity in legal affairs will have to be strengthened, and the Department may need assistance in prioritizing suitable cases for action, collecting evidence, preparing the cases, and taking prosecutions to court. Given the difficulty of pursuing legal remedies for environmental purposes, however, DoE should also place greater emphasis on other forms of incentive for enhanced environmental performance, especially financial benefits, in the form of waste-minimizing win-win solutions.

\section{Strengthening Environmental Management Institutions at Sub-national Levels}

253. For DoE to exercise its authority more effectively, it needs to have a more regular and coordinated interaction with its divisional offices. Moreover, officers at the divisional level need to be able to provide technical advice to firms since they are much more in direct contact with industries, firms and stakeholders. At the upazila level, given that $\mathrm{DoE}$ has no presence, environmental issues must be addressed by the UNO, line ministry representatives and UDCC, and integrated into local development plans. Considering that officials at the upazila level work in a system of upward accountability, these objectives will be more easily facilitated if the signals for prioritizing environmental concerns come from senior line ministry officials.

254. At the union level there is no constitutional mandate to address environmental issues, and consequently elected union parishad officials cannot be held broadly accountable for environmental concerns without constitutional changes. Greater specific accountability could be introduced, however, through the process of issuing No Objection Certificates for environmental clearances. At present, these are obtained through private negotiation with the chairman of the union parishad. Mandating a process of public consultation in the issuance of these certificates would enhance transparency and help incorporate environmental concerns in development planning at the local level. Support for the development of such a 
process could be provided through the World Bank's broader program of assistance for local governance.

Incentives for Improved Environmental Performance by Industry

255. Regulatory approaches to improve environmental management should be complemented with incentives for voluntary improvements in environmental performance. In the case of industry, there is scope for this to be achieved through the promotion of wasteminimization and eco-labelling initiatives. While this would primarily attract exportorientated businesses, particularly in the garment manufacturing and aquaculture sectors, consideration could also be given to the promotion of an eco-label for the domestic market. 


\section{Chapter 7: Environmental Constraints to Growth - Priorities for Additional Action}

256. The environmental challenges chosen for analysis in the CEA were selected jointly by MoEF and the World Bank based on their relevance to growth and poverty reduction, as well as a consideration of the additional value of further analysis. These criteria led to the selection of the following five topics:

- environmental risks to human health;

- protection of water quality in Dhaka;

- management of capture fisheries;

- sustaining soil quality; and,

- strengthening institutions for environmental management.

Based on the analysis presented in the preceding chapters of this report, the economic costs associated with these sources of environmental degradation may amount to more than $4 \%$ of GDP. The estimated share of each factor is indicated in Figure 7.1 , below.

Figure 7.1: The Costs of Environmental Degradation

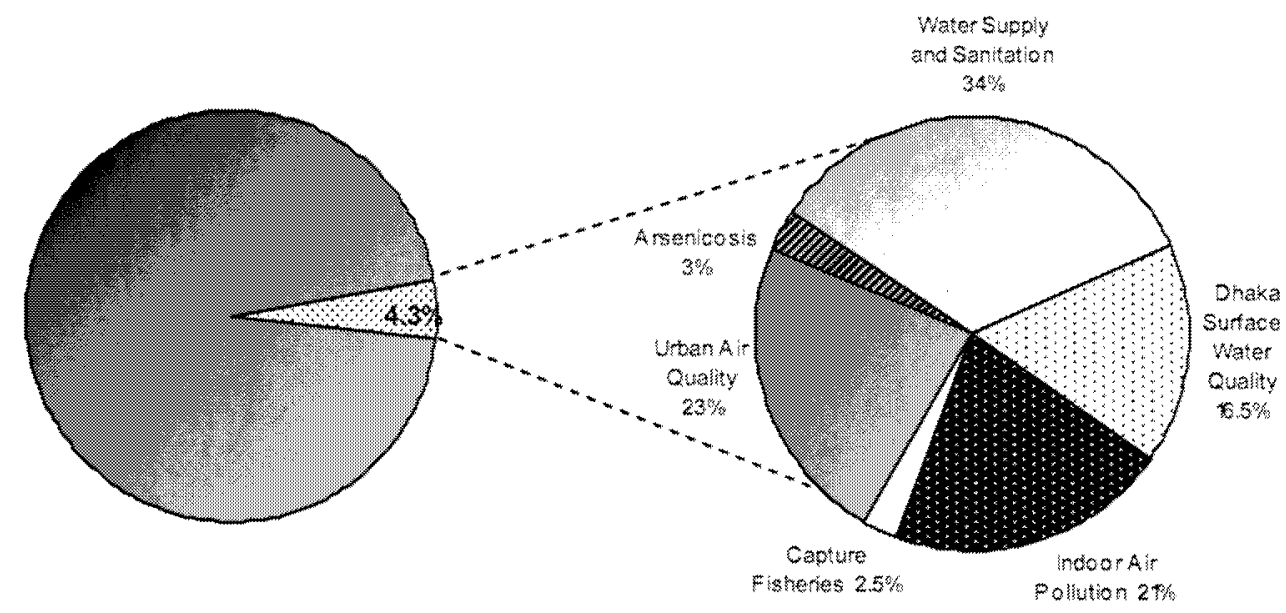

Share of GDP

Share by Source

257. Among the sources of envirommental degradation reviewed, the lack of access to safe water and sanitation imposes the greatest costs, equivalent to almost $1.5 \%$ of GDP, as a result of the productivity lost through the premature death and sickness caused by water-borne disease. In addition to these losses, the poor quality of surface water in and around Dhaka imposes additional costs amounting to more than $0.7 \%$ of GDP, in the form of lost 
agricultural and industrial productivity, reduced amenity, and additional health care costs. ${ }^{139}$ The death and disease that could be avoided by reducing urban air pollution to one-fifth of current levels is equivalent to almost $1 \%$ of GDP, and the costs associated with indoor air pollution from the burning of biomass fuels are at least as high. Initial estimates of the disease burden associated with exposure to elevated levels of arsenic in water indicate economic costs equal to about $0.13 \%$ of GDP, approximately equal to the annual losses from the declining productivity of capture fisheries. The analysis presented in this report found no evidence for falling agricultural yields as a result of declining soil productivity, and while there is significant scope to strengthen institutional capacity for environmental management, no attempt was made to assign an economic cost to poor environmental governance.

258. The costs associated with the sources of environmental degradation analyzed in this report, and the fact that in all cases the poor are most severely affected, together form significant constraints to the achievement of Bangladesh's goals for growth and poverty reduction. The following sections of this chapter consider the extent to which adequate initiatives are underway to address these constraints, and identify priorities for additional action, including potential World Bank support. While this report estimates the economic losses associated with the environmental impacts considered, it does not provide a benefitcost or cost-effectiveness analysis of the proposed mitigating actions. It will be important to examine the costs of the proposed actions in more detail as an element of the follow-up work in each of the priority areas.

\section{Environmental Risks to Health: the Need to Better Address Air Quality}

259. This report estimates that initiatives to reduce exposure to environmental health risks could result in economic savings equivalent to as much as $3.5 \%$ of GDP. This would be achieved mainly by improving access to adequate sanitation and safe water supplies, and by reducing exposure to indoor and urban air pollution, which together account for about $97 \%$ of the environmental factors contributing to the burden of disease.

260. The wide range of initiatives underway to improve access to water supply and sanitation was reviewed in the World Bank's Country Water Resources Assistance Strategy, 2005. In addition to the Government's Total Sanitation Campaign, a variety of schemes are supported by a number of development partners including the Water and Sanitation Program for South Asia, ADB, UNDP, the Government of the Netherlands, DANIDA, WHO, JICA, WaterAid, UNICEF, and many national NGOs. The World Bank is also actively engaged in this sector, both through the Dhaka Chittagong Water Supply and Sanitation Project currently under preparation, and the ongoing Bangladesh Water Supply Program Project, which represents an important step towards the integration of arsenic mitigation into an overall vision for safe water supply.

261. While significant resources are committed to improving water supply and sanitation, air pollution attracts relatively little attention, although respiratory infections and disease

\footnotetext{
${ }^{139}$ To avoid double-counting, the economic costs associated with Dhaka's poor surface water quality are adjusted in Figure 7.1 to exclude (i) lost productivity as a result of water-borne disease, and (ii) reduced fisheries production. Health care costs are retained, as these are not included in the estimate of productivity lost due to poor access to water and sanitation. As a result of these adjustments, the estimated annual cost of poor surface water quality in Dhaka indicated in Figure 7.1 is about US $\$ 360$ million, compared with the total cost estimate of US\$400 million provided in Chapter 3.
} 
caused by poor air quality, both indoor and urban, may contribute up to $10 \%$ of the total burden of disease, equivalent to the diarrhoeal disease caused by inadequate access to safe water, lack of sanitation and poor hygiene. Indoor Air Pollution (IAP) in particular remains almost entirely ignored, and urban air quality continues to deteriorate, despite a temporary improvement following the 2003 ban on two-stroke three-wheelers in Dhaka. To help address IAP, the World Bank plans to provide technical assistance to explore sustainable delivery models for the information and technology necessary to reduce IAP exposure. The Bank is also supporting efforts to better control urban air quality through the on-going Air Quality Management Project, for which a follow-up operation is under consideration, focusing on gross diesel polluters, fuel quality, and the expansion of air quality monitoring both within the capital and to other major cities. While exposure to agro-industrial toxics represents a relatively small, but growing share of environmental health risks, the World Bank is also prepared to assist the DoE address this challenge, including through the use of global resources to identify and control the risks posed by Persistent Organic Pollutants (POPs).

\section{Protecting Environmental Quality in Dhaka: a Focus on Water Quality}

262. Environmental quality in the capital city faces the triple threat of air pollution, inadequate solid waste management, and contamination of surface water. While initiatives are underway to better manage air quality and solid waste with the support of the World Bank and JICA respectively, little has yet been done to improve water quality, identified as a priority for World Bank engagement in the Bangladesh Country Water Resources Assistance Strategy (2005). The total economic cost of the poor management of water resources in Dhaka is estimated at US\$670 million annually, including impacts on human health, as well as industrial and natural resource productivity. Given that economic activity in Dhaka contributes about one-fifth of GDP, environmental constraints to growth in the capital constitute a national priority.

263. Improving the quality of surface and groundwater in and around Dhaka will require significant public and private investment. The rehabilitation of the existing sewerage and drainage system is alone projected to cost about US\$100 million. In response to the Government's request, the World Bank is helping prepare a project to improve sewerage, sanitation and storm water drainage services in Dhaka. A proposed separate initiative to strengthen the management of environmental quality and water resources would supplement these investments with support for appropriate treatment technologies targeting industrial effluent. Environmental compliance initiatives will form components of both these projects, as well as planned support for private sector development.

\section{Natural Resources under Pressure: Protecting Capture Fisheries}

264. With population density among the highest in the world, pressure on natural resources in Bangladesh is necessarily high, and this report considers the impact of this pressure on capture fisheries and soil productivity. As a Forest Sector Review was recently completed, the pressure on forest resources was not considered, although the land area under forest cover is the second lowest in South Asia and most of the nation's natural forests are significantly degraded.

265. Agriculture accounts for some $21 \%$ of GDP, and the ability of soil to sustain agricultural production is an issue of national concern. Declines in rice yields in some areas 
of Bangladesh in the mid-1990's led to a decline in soil productivity being inferred. The analysis of more recent data presented in this report indicates, however, that yield trends are stable or increasing, and that earlier assessments were influenced by a period in which yields were below trend. Nevertheless, there remain causes for concern, including evidence that fertilizer inputs are imbalanced and nutrient mining is occurring, suggesting that greater attention to the monitoring of soil quality is warranted.

266. Bangladesh's fisheries are estimated to provide two-thirds of the country's animal protein needs, which is twice the regional average and the seventh highest in the world. Capture fisheries and associated wetlands play a particularly important role in the nutrition and welfare of the poor. There is general consensus, however, that inland and coastal $/$ marine capture fisheries are in decline. Threats include losses of floodplain habitat due to agriculture and urbanization, lost connections along critical fish migration pathways, significant reductions in dry season river flows, over-fishing, and rapidly increasing industrial, human and agricultural pollution. Almost $30 \%$ of all inland fish species are in some danger of extinction, and there is a fear that the inland major carps, Indian Salmon and other coastal inshore fisheries, may be in danger of collapse. The value of the production currently lost each year is estimated at about $\$ 60$ million, with the nutritional and livelihood consequences being felt most severely by the poor.

267. The remarkable recovery of Hilsa in 2004, most likely as a result of Government management activities, demonstrated that recovery of the capture fisheries is possible if political will combines with good management. The actions needed to reverse the decline of Bangladesh's capture fisheries are reasonably clear, and a framework for their implementation is provided by the Government's draft Inland Capture Fisheries Strategy. The Aquatic Biodiversity Conservation Project (closed in 2005) and the Fourth Fisheries Project (closing in 2006) were supported by the World Bank, and among other achievements led to the development of this strategy. The Bank is prepared to provide further assistance to support the implementation of the strategy and strengthen community management of fisheries, as well as regional collaboration for the management of marine and coastal resources in the Bay of Bengal.

\section{Environmental Governance: an Over-Arching Concern}

268. An over-arching theme that emerges from this report is the need to improve environmental governance to strengthen incentives for behaviour and investments that lead to better environmental quality. The most important governance elements to support such incentives are access to environmental information, transparency and consultation for accountable decision-making, adequate institutional capacity for credible enforcement, and economic policies that promote improved environmental performance.

269. Strengthening environmental management in Bangladesh will require action on a number of fronts, from enhanced inter-sectoral coordination by the National Environment Council, through mainstreaming of environmental management capacity in sectoral agencies, down to wider public consultation by Union Parishads. It is clear, however, that essential requirements for better environmental management in Bangladesh are additional resources for the DoE, and improvements in the transparency of its functioning. Despite its critical and wide-reaching mandate, the DoE currently receives less than $1 \%$ of MoEF's annual budget, which itself is less than $0.5 \%$ of the Government's total revenue and development budget. 
With the support of CIDA, DoE recently undertook an institutional assessment and developed a Strategic Plan to clarify its goals, expected results and major initiatives. Securing the financial support necessary to implement DoE's Strategic Plan will be challenging, and must be accompanied by improvements in transparency and accountability to enhance the credibility of the effort.

270. Given the continued availability of technical assistance resources for DoE, particularly from CIDA and UNDP, the most important role for the World Bank will be to help address the revenue budget implications of the Department's Strategic Plan through dialogue with the Ministry of Finance and the World Bank's ongoing program of development policy lending. Such efforts may be complemented by planned World Bank support for the strengthening of local government, which provides an avenue to increase consultation and accountability for environmental decision-making at this level.

\section{Priorities for Additional Action and World Bank Support}

271. Among the environmental challenges considered in this report, a number are being addressed through a range of initiatives that are already underway or planned, and a few pose risks that are relatively less pressing. The following three concerns emerge, however, as priorities currently receiving insufficient attention given their relative significance:

- the threat of air pollution to human health;

- the need to better control urban and industrial effluent in Dhaka; and

- the continuing decline of capture fisheries.

The economic losses associated with these three environmental challenges alone may amount to more than $2.7 \%$ of GDP, in each case with the poor suffering disproportionately as a result. In addition to these three sectoral priorities, an over-arching concern is the need to strengthen environmental governance.

272. To better address these challenges, this report recommends that the World Bank provide additional support for action in each of these three areas. Such support could take a variety of forms:

- to reduce exposure to IAP, it would be appropriate at the current stage of understanding for the World Bank to provide further technical assistance to explore sustainable delivery models for the necessary information and technology. As urban air quality continues to deteriorate, the Bank will maintain support for the on-going Air Quality Management Project, as well as a possible follow-on operation;

- in response to the Government's request for assistance in better managing effluent in Dhaka, the World Bank is helping prepare a project to improve water supply, sewerage, sanitation and storm water drainage services in Dhaka. In addition, the World Bank would be prepared to support a separate initiative targeting industrial effluent, drawing on proposed further analysis of industrial environmental compliance and pollution control in the city. Environmental compliance initiatives may also form a component of planned support for private sector development; 
- with the Fourth Fisheries Project closing in 2006, the Bank is prepared to provide further assistance to support the implementation of the Inland Capture Fisheries Strategy developed under this project, and to strengthen community management of fisheries. The Bank is also prepared to support the development of a strategic action plan for the management of marine and coastal resources in the Bay of Bengal, for which an ecosystem approach would be adopted to foster regional collaboration in addressing the transboundary issues.

To help strengthen environmental governance, the World Bank will use the ongoing program of development policy lending to help address the revenue budget implications of the DoE's Strategic Plan. The need to implement the DoE's Strategic Plan is reflected in the policy matrix for the series of Development Support Credits supported by the World Bank, and will continue to be incorporated in future development policy lending discussions. In addition, proposed support for the strengthening of local government provides an opportunity to increase consultation and accountability for environmental decision-making at the local level.

273. The technical assistance, investment and budget support operations discussed above are reflected in the World Bank's Country Assistance Strategy (CAS) for the period FY0609. Appendix III provides a summary of the relevant products, and indicates the principal environmental management outcomes associated with each. Such initiatives will complement the investment support and technical assistance being provided by other development partners to strengthen environmental management in Bangladesh.

274. The activities proposed above will help the Government fulfil its strong commitment to the MDGs as reflected in the National Strategy for Accelerated Poverty Reduction, in particular the Goals related to child mortality and environmental sustainability. Meeting the target for reduction in child mortality under Goal 4 will require efforts to reduce respiratory infections, which account for $18 \%$ of under-five deaths, up to half of which may be associated with IAP. Meeting the targets to ensure environmental sustainability under Goal 7 will require renewed efforts to reverse the degradation of urban environmental quality, particularly in Dhaka, better manage natural resources, including capture fisheries, and strengthen environmental governance. Initiatives to undertake the key actions summarized above will not only bring Bangladesh closer to achieving its targets under the MDGs, but will significantly contribute to the removal of environmental constraints to poverty-reducing growth. 


\section{Appendix I: Dhaka Environment Programme Prioritized Portfolio of Water Quality Solutions}

\#1 Improvement of Water Supply (Participants: all Dhaka residents and businesses; building developers; DWASA; Department of Public Health Engineering; Department of Environment; RAJUK; DCC).

- Complete repairs to the DWASA supply system.

- Control groundwater extraction; shift to increasing surface water supply; examine long-term supply options for Saidabad, including an intake on the Meghna River.

- Promote rainwater harvesting.

- Examine options for reservoir development in Madhupur Tract.

- Develop guidelines on rainwater percolation.

- Examine feasibility of borehole aquifer recharge.

\#2 Treatment and Disposal of Sewage (Participants: all Dhaka residents and businesses; building developers; boat and ship operators; DWASA; Department of Environment; RAJUK; DCC).

- Rehabilitate the sewage collection system and the Pagla sewage treatment plant.

- Construct four new sewage treatment plants.

- Ban hanging and pit latrines; use dry composting toilets.

- Constructed wetlands in smaller settlements.

- Treat ship-based sewage.

\#3 Treatment and Disposal of Industrial Waste (Participants: Department of Environment; industries; DWASA; DCC; Ministry of Industry; BSCIC; RAJUK).

- Moratorium on industrial development in Dhaka.

- Move tanneries to Savar; remediation of Hazaribagh.

- Constructed wetland for Tejgaon wastewater.

- Settling ponds and reed beds for textile industry clusters.

- Turn-key common effluent treatment plants.

- Flow control from proposed Madhupur Tract reservoirs.

- Fertilizer plant runoff diverted.

- Regulations to control discharge of cooling water.

\#4 Handling and Disposal of Solid Waste (Participants: all Dhaka residents and businesses; DCC; Department of Environment).

- Incineration of hospital waste.

- Three new landfill sites; remediation of Matuail.

- Solid waste management at source.

- Enforce ban on polythene bags.

- Ditch and drain management. 
\#5 Flood Management, Dredging, and Improving River Navigability (Participants: Joint River Commission; Water Development Board; villagers in upstream watersheds; brick kiln operators; Department of Forests; RAJUK; DCC; DWASA; BIWTA; Dhaka residents and businesses; building developers; private dredgers; Department of Environment).

- Rehabilitate the Dhaka canal system.

- Dredging guidelines and enforcement of encroachment guidelines.

- Reservoir and flood flow zone management.

- Land use controls; management of sediments during construction.

\#6 Management of Household Liquid Waste (Participants: all Dhaka residents and businesses; Department of Environment; DCC).

- Ban disposal of liquid hazardous materials.

- Domestic and restaurant grease traps.

- Recycling of grey water.

- Ban phosphate-based detergents.

\#7 Management of Ship Oily Waste (Participants: boat and ship operators; shipyards; Department of Environment; BIWTA; Ministry of Shipping).

- Regulate treatment and disposal of bilge water.

- Guidelines on ship fueling.

- Waste oil management programme at ship yards.

- River oil spill contingency plans.

\#8 Improving Aesthetics and Opportunities for Recreation (Participants: all Dhaka residents and businesses; building developers; RAJUK; DCC; DWASA; BIWTA; WDB).

- Enforce the 50-metre buffer zone.

- Local area river management committees.

- Improve ghat facilities for recreation.

- Recreational opportunities in proposed Madhupur Tract reservoirs.

\#9 Controlling Agricultural Runoff (Participants: farmers and village households; Plant Protection Wing - Department of Agricultural Extension; Department of Environment).

- Ban chemical pesticides within $30 \mathrm{~km}$ of Dhaka.

- Ban chemical fertilizers within $30 \mathrm{~km}$ of Dhaka.

- Encourage use of dung as a fertilizer or source of biogas. 


\section{Appendix II: Organogram of the Department of Environment}

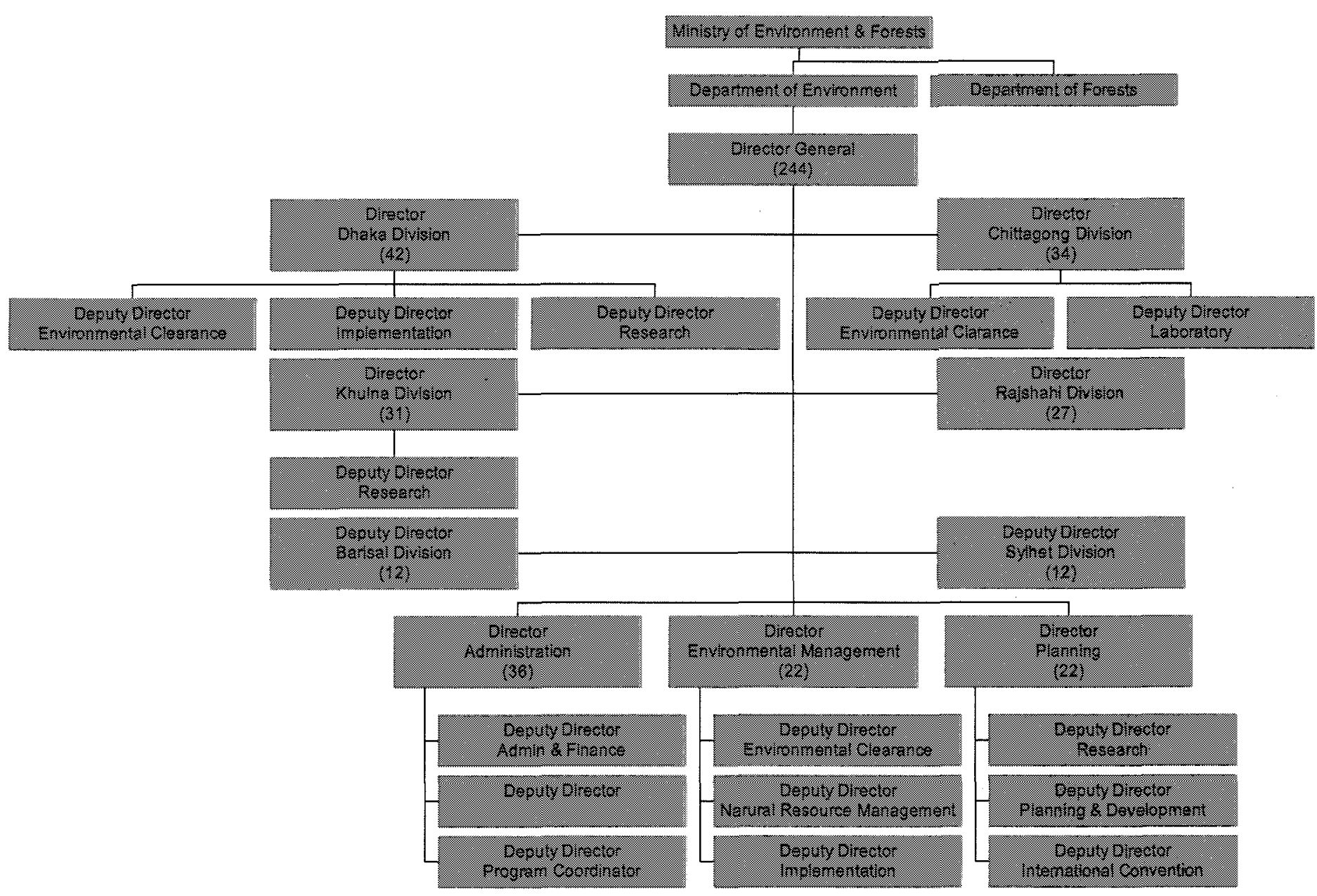




\section{Appendix III: World Bank Country Assistance Strategy for Bangladesh FY06-09}

\section{Selected Products and Key Environmental Management Outcomes}

\begin{tabular}{|c|c|c|c|}
\hline $\begin{array}{l}\text { Fiscal } \\
\text { Year }\end{array}$ & Product & $\begin{array}{c}\text { Product } \\
\text { Type }^{\mathrm{a}}\end{array}$ & Key Environmental Management Outcomes \\
\hline \multirow[t]{3}{*}{ Ongoing } & Municipal Services & SIL & $\begin{array}{l}\text { Improving environmental service delivery in } \\
\text { urban areas. }\end{array}$ \\
\hline & Water Supply Program & SIL & $\begin{array}{l}\text { Pilot innovative measures for the provision of } \\
\text { safe water in rural areas and small towns. }\end{array}$ \\
\hline & 7. & & N \\
\hline 2006 & Local Governance Support & SIL & $\begin{array}{l}\text { Strengthening of environmental management } \\
\text { processes in local government. }\end{array}$ \\
\hline & 52 & & W \\
\hline \multirow[t]{7}{*}{2007} & Development Support Credit IV & DPL & $\begin{array}{l}\text { Support for implementation of DoE's Strategic } \\
\text { Plan. }\end{array}$ \\
\hline & Dhaka Chittagong Sewerage and Drainage & SIL & $\begin{array}{l}\text { Investment in sanitation and drainage in Dhaka } \\
\text { and Chittagong. }\end{array}$ \\
\hline & Private Sector Development & SIL & $\begin{array}{l}\text { Institutional strengthening and investment for } \\
\text { environmental management in industrial estates. }\end{array}$ \\
\hline & National Agricultural Technology & $\overline{\text { SIL }}$ & $\begin{array}{l}\text { Integration of environmental considerations in } \\
\text { agricultural research, extension and value chain } \\
\text { development. }\end{array}$ \\
\hline & Bay of Bengal Large Marine Ecosystem & SIL & $\begin{array}{l}\text { Development of a regional action plan for } \\
\text { resource management in the Bay of Bengal. }\end{array}$ \\
\hline & Indoor Air Quality & NL-TA & $\begin{array}{l}\text { Development of approaches to mitigate indoor air } \\
\text { pollution. }\end{array}$ \\
\hline & 20 & & 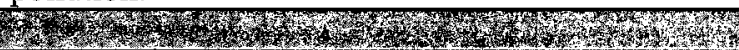 \\
\hline \multirow[t]{4}{*}{2008} & Poverty Reduction Support Credit I & DPL & $\begin{array}{l}\text { Support for implementation of DoE's Strategic } \\
\text { Plan. }\end{array}$ \\
\hline & Dhaka Environment & $\overline{\text { SIL }}$ & $\begin{array}{l}\text { Institutional strengthening and investment for } \\
\text { protection of water quality in the Dhaka area. }\end{array}$ \\
\hline & Urban Industrial Pollution & $\mathrm{PN}$ & $\begin{array}{l}\text { Policy analysis for the management of industrial } \\
\text { pollution. }\end{array}$ \\
\hline & 298 & 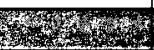 & Wher \\
\hline \multirow[t]{4}{*}{2009} & Poverty Reduction Support Credit II & DPL & $\begin{array}{l}\text { Support for implementation of DoE's Strategic } \\
\text { Plan. }\end{array}$ \\
\hline & Air Quality & SIL & $\begin{array}{l}\text { Institutional strengthening and investment for the } \\
\text { management of air quality. }\end{array}$ \\
\hline & Urban Development and Services & SIL & $\begin{array}{l}\text { Integrated assistance to management and } \\
\text { investment in the urban sector. }\end{array}$ \\
\hline & Community Fisheries & SIL* $^{*}$ & $\begin{array}{l}\text { Policies and investment for the protection and } \\
\text { sustainable management of capture fisheries. }\end{array}$ \\
\hline
\end{tabular}

a: DPL - Development Policy Loan; SIL - Specific Investment Loan; NL-TA - Non-Lending

Technical Assistance; PN - Policy Note.

* Reserve Project.

Source: World Bank, 2006. Country Assistance Strategy for the People's Republic of Bangladesh for the Period FY06-09. 


\section{Chapter 1: Context and Objectives}

\section{$\underline{\text { References }}$}

BCAS and DoE, 2001. "Bangladesh Climate Change Country Study: Assessment of Vulnerability and Adaptation to Climate Change." Bangladesh Centre for Advanced Studies and Department of Environment, Dhaka.

FAO, 2001. FAOSTAT on-line statistical service.

MoEF, 2005. "National Adaptation Programme of Action". Ministry of Environment and Forest, Government of the People's Republic of Bangladesh, November 2005.

World Bank, 2000. "Bangladesh: Climate Change and Sustainable Development. Report No. 21104BD”, Rural Development Unit, South Asia Region, The World Bank (WB), Dhaka,

World Bank, 2005. "Bangladesh: Country Water Resources Assistance Strategy."

\section{Chapter 2: Environmental Health}

M. Feroze Ahmed, Sk. A. J. Shamsuddin and Ryan Knox (2004). South Asian Conference on Sanitation. October 2003. Local Government Division. Ministry of Local Government Rural Development and Cooperation. Dhaka. Bangladesh

K. Ahmed, Y. Awe, D. Barnes, M. Cropper, M. Kojima (2005). Environmental Health and Traditional Fuel Use in Guatemala. The World Bank, Washington DC.

Arsenic Policy Support Unit. (2004) Risk Assessment of Arsenic Mitigation Options. RAAMO. ITN Bangladesh.

Argoss, DFID and WHO (2001). Guidelines for assessing the risk to groundwater from on-site sanitation.

Awal, Dr. Md. Abdul, 2001. "Determination of Pesticide Level in the Environmental Samples and Their Residual Effect on Animal Samples." Bangladesh Agricultural Research Council. Bangladesh.

Aziz KMA, Bilqis A. Hoque, Hasan KZ et al. (1990), Reduction in diarrhoeal diseases in children in rural Bangladesh by environmental and behavioural modifications, Trans. of the Royal Society of Trop. Med. and Hygiene, U.K., vol. 84 (3);433-438.

Bilqis AH, Sufia Khanam, S. Islam, Sanjoy Kumar Saha (2004). Completion Report of Arsenic Mitigation Continued Safe Water Option Under the 15 - Upazila Arsenic Mitigation Project, Kalia, Narail. UNICEF report

Bilqis AH. (2005). Assessment and Management of Risks in Supply of Safe Drinking Water Through Alternative Water Supply Options in Arsenic Affected Area ,DFID proposal

Bilqis AH, T. Ahmad, and Sack RB (2005). Development of Appropriate Household Drinking Water Management in Flood Prone Coastal Areas of Bangladesh. Submitted to Child Health Foundation. USA. 
Biswas, S.K., A.K.M. Sharif, M. Alamgir \& D.A. Chowdhury. 1998. "Mercury Level of Some Marine Fishes from the Bay of Bengal." The Journal of NOAMI, Vol.10. National Oceanographic and Maritime Institute, Dhaka, Bangladesh.

Das, Dr. H.K. 2005. Inventory of POPs Pesticides in Bangladesh. Paper presented in Priority Setting Workshop for Phase out of POPs in Bangladesh, April 3, 2005.

Dasgupta, Susmita, Benoit Laplante and Craig Meisner. 1998. "Accounting for Toxicity Risks in Pollution Control: Does it Matter?" Development Research Group, The World Bank.

Dasgupta, Susmita, Carig Meister \& David Wheeler. 2004. "Is Environmentally- Friendly Agriculture less Profitable for farmers?" An Evidence on Integrated Pest Management in Bangladesh. Development Research Group, World Bank.

S. Dasgupta, M. Huq, M. Khaliquzzaman, K. Pandey, D. Wheeler (2004). Indoor Air Quality for Poor Families: New Evidence from Bangladesh

DNV RN 590. 2000. Decommissioning of Ships - Environmental Standards. Ship-Breaking Practices/ on site Assessment. Report No. 2000-3158. Chittagong, Bangladesh.

ESCAP. 1988. Costal Environment and Management Program for Bangladesh, Vol. 2. Fisheries Research Institute, Chandpur, Bangladesh.

Fewtrell L, Colford JM. Water (2004). Water, Sanitation and Hygiene: Interventions and Diarrheoea. A Systematic Review and Meta-Analysis. World Bank.

Fewtrell, Kaufmann, et al (2005). Water, sanitation, and hygiene interventions to reduce diarrhea in less developed countries: a systematic review and meta-analysis. Lancet Infect Dis 2005:5:42-52

Fisher, Brandy E. 1999. "Most Unwanted: Persistant Organic Pollutants.” Environmental Health Perspectives Volume 107.

GHK (2003). Local Governance and Service Delivery to the Poor: Bangladesh Case Study.

Gorman, Steve \& Ellen Tynan. 2003. "Persistent Organic Pollutants: A legacy of Environmental Harm and Threats to Health." Environment Strategy Notes, Environment Department, The World Bank.

K. Gwilliam, M. Kojima, T. Johnson (2004). Reducing Air Pollution from Urban Transport. Washington, D.C.: World Bank

Hettige, M.,P. Martin, M.Singh and D. Wheeler. 1995. The Industrial Pollution Projection System, working paper series, No. 1431, Development Research Group, The World Bank, Washington. D.C.

Hoq, Dr. Md. Shamsul. 2001. Blood Ace tylcholinesterase enzyme level among the agricultural workers using organophosphorus (OP) pesticides of some selected area of Bangladesh, MPh (OEH) Course thesis, Session 2001 and 2002, NIPSOM, Mohakhali, Dhaka.

Bilqis A. Hoque,T. Juncker, R.B. Sack, Md. Ali and K.M.A. Aziz (1996), Sustainability of a water, sanitation and hygiene education project in rural Bangladesh: a five-year follow-up. Bulletin of the WHO: volume 74, No.4, 
Bilqis A.Hoque ,M.M. Hoque, Tofayel Ahmed, Shoriful Islam, Nahid Ali et. al (2003)

People's Demand Based Water Options for Arsenic Mitigation: An Experience from Rural Bangladesh. Journal of Public Health Medicine and Epidemiology., UK. 2004

Bilqis A. Hoque, S. Zeitlyn, N. Ali, F.S.M. Yahya N.M. Shaheed (1994), Promoting. Sanitation in Bangladesh,. (World Health Forum) Vol. 15.

Bilqis Amin Hoque, R. Bradley Sack, JTA Chowdhury and Nahid Ali (1997). Domestic Water and Sanitation in Cyclones and Floods: Research Agenda. Water International, USA Volume 22 No. 4.

Enamul Hoque (2005). Public Expenditures on the Environment in Bangladesh (draft). World Bank.

Hossain, Kbd Quazi Tafazzal, 2004. Executive summary of Inventory of POPs Pesticides in Bangladesh. Paper presented in Priority Setting Workshop for Phase out of POPs in Bangladesh, April 3, 2005.

Hossain, M. Monowar, Md. Rashedul Islam \& Sara Ferdousi. 2003. "Pollution and Sediment Flux in the Coastal Water of Bangladesh." The Journal of NOAMI, Vol.20. National Oceanographic and Maritime Institute, Dhaka, Bangladesh.

Hayat. 2000. The Report of Pesticide Association.

Islam, Faisal, Rumi Sharmin \& Juhaina Junaid. "Industrial Pollution in Bangladesh." The Department of Environment Studies, North South University, Dhaka, Bangladesh. Available: http://www.worldbank.org/nipr/InfoPol/Industrial\%20Pollution-003-full.htm\# Toc2700573

IPEN. International PoPs Elimination Network Background Statement Platform. Available: http://www.psr.org/ipen/platform.htm.

Khan, ASY \& MAA Khan.1998. "Study on the Use of DDT as Preservative Practiced in Stored Dried Fishes of Bangladesh." Pollution Research, 17(4): 363-365

M. Khaliquzzaman (2004). Health Impact of Air and water pollution in Bangladesh. World Bank. December 2004

Kamalini M. Lokuge, Wayne Smith, Bruce Caldwell, Keith Dear and Abul Milton (2004). The Effect of Arsenic Mitigation Interventions on Disease Burden in Bangladesh. Environmental Health Perspectives, Volume 112, Number 11, August 2004.

Malek, Dr. M. A.2005. Executive summary of Inventory of

Polychlorinated biphenyls (PCBs), Paper presented in Priority Setting Workshop for Phase out of POPs in Bangladesh, April 3, 2005.

Debendra N. Guha Mazumder, Reina Haque, Nilima Ghosh, Binay D. De, Amal Santra, Dipankar Chakraborti, and Allam H. Smith (2000). Arsenic in drinking water and the prevalence of respiratory effects in West Bangal, India. International Journal of Epidemiology, 2000:29:1047-1052.

Mecon. 2001. Mecon Limited 2001. Assessment of Pollution potential from ship breaking activities. Mecon Limited, Ranchi. Project Commissioned by Central Pollution Control Board (CPCB). 
Meisner, Craig.2004. "Report of Pesticide Hotspots in Bangladesh." Development Economics Research Group, Infrastructure and Environment Department, The World Bank.

Nahar, Nilufar. 2004. Organochlorine and modern pesticides in fish, vegetables and water sample. Paper presented at Annual Conference of Bangladesh Chemical Society.

Omar, K.A. Rahman, K. and Ahamed, N.1985. Study of effluent management for pollution control. Report on KPM and KRC, BCIC, BUET, Dhaka.

Orris, Peter, Lin Kaatz Chary, Keren Perry \& Joe Asbury. 2000. "Persistent Organic Pollutants and Human Health." A Publication of the World Federation of Public Health Associations' Persistent Organic Pollutants Project.

Ramaswamy. 1992. Pest control and Environment notes for discussion at a seminar on environment and agriculture. Agriculture Association of Bangladesh, Dhaka. P. 19

Rathore, Minakshi, Bhatnagar, Pradeep, Mathur, D., and Saxena G.N. 2002. "Burden of Organochlorine Pesticides in Blood and its Effect on Thyroid Hormones in Women." The Science of the Total Environment. 295: 207 -215.

Siddiqui, M.K.J., Srivastava, S., Srivastava, S.P. Mehrotra, P.K., Mathur, N., and Tandon, I.. 2003. "Persistent Chlorinated Pesticides and Intra-Uterine Foetal Growth Retardation: A Possible Association." International Archives of Occupational and Environmental Health. 76: 75 - 80

Smith, K.R. (2000). National Burden of Disease in India from Indoor Air Pollution. Proceedings of the National Academy of Sciences 97(24):13286-93.

SOS-arsenic.net.2004. "Agrochemicals: Imported Pollutants in Bangladesh." Available: http://www.sos-arsenic.net/index.html.

Srivastava, A.K., Gupta, B.N., Birari, V., Mathur, N., Pangtey, B.S., and Godbole, M.N.1995. "Organochlorine Pesticide Exposure and Thyroid Functions: A study in Human Subjects." Journal of Environmental Pathology, Toxicology and Oncology. 14(2): 107-110.

Streatfild PK, Persson LA, Chowdhury HR, Saha KK. (2001)Disease Patterns in Bangladesh; present and future health needs. International Center for Diarrhoeal Disease Control - Bangladesh. Dhaka.

Streatfield PK, Mercer A., Siddique AB, Khan ZUB, Ashraf ( 2003). A. Status of Performance Indicators 2002. Health and Population Sector Programme 1998-2003, Bangladesh. ICDDR,B.

SUNS. 1998. "Pesticide Overuse Takes Serious Turn in Bangladesh." Monday, Jan 24, Dhaka, Jan 23 IPS/ Tabibul Islam.

Sutherland D, Swash PM, Macqueen AC, McWilliam LE, Ross DJ, Wood SC. 2002. A field based evaluation of household arsenic removal technologies for the treatment of drinking water. Environ Technol 23(12):1385-1403.

Tardiff, R.G. (ed). 1992. Methods to Assess Adverse Effects of Pesticides on Non-Target Organisms. New York: John Wiley and Sons. 
Toxic Link, 2004. PoPs in South Asia. Status and environmental health impacts, A Report for the World Bank, New Delhi, India.

UBINIG. 1999. "Sparrows Massacred by Pesticide in Bangladesh." Available: http://www.ubinig.cjb.net

UNDP-GEF. "PoPs Resource Kit." Available: www.undp.org/gef

UNDP. 2003. "Bangladesh moves to eliminate dangerous chemicals." A Media Release.

World Bank. 2004. "Issues and Options in Addressing the Objectives of the Stockholm Convention on Persistent Organic Pollutants in India and the South Asia Region." A Final Draft of the Discussion Paper.

World Bank (2005). Attaining the Millennium Development Goals in Bangladesh: How Likely and What Will It Take To Reduce Poverty, Child Mortality and Malnutrition, Gender Disparities, and to Increase School Enrollment and Completion?

World Bank (2005b). Bangladesh: Country Water Resources Assistance Strategy.

World Bank (2005c). Arsenic Contamination of Groundwater in South and East Asian Countries: Towards a More Effective Operational Response.

World Bank (2002). India: Household Energy, Indoor Air Pollution, and Health. ESMAP Report 261/02. Washington, D.C.: World Bank.

World Bank, Proshika and SSR. (2002) Bangladesh: Urban Service Delivery. A Score Card. May 2002

World Bank (1999). Fuel for Thought: Environmental Strategy for the Energy Sector. Washington, DC: World Bank.

World Health Organization (1997) . Health and Environment in Sustainable Development. Five years after the Earth Summit. WHO.

World Health Organization (2002). The World Health Report, 2002: Reducing Risks, Promoting Healthy Life.

Xiliang and Smith (2004). An assessment of Programs to Promote Improved Household Stoves in China.

Zahm, S.H., M.H. Ward and A. Blair. 1997. Pesticides and Cancer in Occupational Medicine: State of the Art Reviews. Vol 12. Pesticides (Kaifer, M. ed). Philadelphia, Hanley and Belfus Inc. P $269-289$.

\section{Chapter 3: Management of Water Ouality in Dhaka}

Alam, M. Khorshed and Dora Marinova (2002), "Valuing Benefits of Environmental Improvement: The Case of the Buriganga River in Bangladesh", Institute for Sustainability and Technology Policy, Murdoch U. Australia. 
Bangladesh Centre for Advanced Studies (BCAS). 2004. Dhaka City State of Environment: 2003. Report for Department of Environment, Ministry of Environment and Forests.

Bangladesh Environmental Management Project (BEMP). 2003. Review and Assessment of Current GoB Proposals Relating to Water Use and Rehabilitation of the River System Around Dhaka. Report for Ministry of Environment and Forests and CIDA.

Bangladesh Environmental Management Project (BEMP). 2004a. Socio-Economic Survey for Assessment of Impacts of River Pollution in the Project Area. Report for Ministry of Environment and Forests and CIDA.

Bangladesh Environmental Management Project (BEMP). 2004b. Problem Analysis and Portfolio of Solutions (Technical Interventions for the Dhaka Environment Programme). Report for Ministry of Environment and Forests and CIDA.

Bangladesh Environmental Management Project (BEMP). 2004c. Strategic Benefit-Cost Framework. Report for Department of Environment

Bangladesh Environmental Management Project (BEMP). 2005a. The Dhaka Environment Programme: A One-Generation Strategy to Save the City from Environmental Catastrophe. Report for Ministry of Environment and Forests and CIDA.

Bangladesh Environmental Management Project (BEMP). 2005b. Demonstration of Innovative Waste Management Technology for the Textile Industry in Bangladesh. Final Report: Surveys, Consultations, and Experiments in the Madhobdi Area, Narsingdi District. Report for Ministry of Environment and Forests and CIDA.

World Bank (2005). Background Paper on Dhaka Water Quality Management.

World Bank (2005b). Bangladesh: Country Water Resources Assistance Strategy.

\section{Chapter 4: Management of Capture Fisheries}

Ahmed, M. 2003. (draft) Valuation of Wetlands in Sherpur District of Northern Bangladesh. Support for University Education and Research (SUFER)

Colavito, L. et al. 2000. Resource Valuation of Hail Haor.

Colavito, L, W.J. Collis, et al, 2001. Valuation of the Hail Haor Wetlands.

DANIDA, 2003. Environmental Study of the GNAEP Program.

Fourth Fisheries Project, 2004. Presentation- Coastal Fisheries of Bangladesh

FSRFD, 2003. Summary Document - Draft Fisheries Sector Review and Future Development. MoFL - Fisheries LCG

Gertjan de Graaf et al. Floods, fish, and fishermen

Islam, M.N., 1999. Fishery rights, government revenue and community management. Paper presented at the national workshop on community based fisheries management and future strategies for inland fisheries in Bangladesh, 1999, Dhaka, Bangladesh. 
IUCN, 2000. Red List of Threatened Animals of Bangladesh.

Badre Alam Khan et al. Report of the National Workshop on Fisheries Resources Development and management in Bangladesh, 29 October-1 November, 1995, Dhaka, Bangladesh

Land Economics (U.S.): Institutions and externalities in the inland fisheries of Bangladesh. 74:409-21, August 1998

Hans A.J. Middendorp, Paul M. Thompson, Robert S. Pomeroy: Sustainable inland fisheries management in Bangladesh

Munir, A. 2004. SUFR Project

World Bank, 2003. Fourth Fisheries Review Mission, November 2003.

World Bank, 2005. Bangladesh: Country Water Resources Assistance Strategy.

Williams, T. 1996. What good is a wetland ? Audubon November-December 1996.

Winrock. 2003. Environmental and Social Impact Assessment of GNAEP Prawn Farming Activities.

World Development (U.K.); 25:457-67, March 1997: Some observations on power and property rights in the inland fisheries of Bangladesh.

\section{Chapter 5: Sustaining Soil Quality}

Abu Abdullah (Editor) et al. Bangladesh economy 2000: selected issues

Mohammad Alauddin and Mosharaff Hossain. Environment and agriculture in a developing economy: problems and prospects for Bangladesh

Michael Mastaller, Roger D. Montgomery, Joseph A. Weinstock: Bangladesh: toward an environment strategy

M. A. Wadud Mian et al. Agricultural research in Bangladesh in the 20th century, crops, forestry, livestock, fisheries

Stefano Pagiola, 1995. Environmental and natural resource degradation in intensive agriculture in Bangladesh

Riaz Hussain Qureshi. Impact of agricultural practices on environmental sustainability in Asia

Golam Rasul and Gopal B. Thapa, World Development Vol. 31, No. 10, pp. 1721-1741, 2003. Sustainability Analysis of Ecological and Conventional Agricultural Systems in Bangladesh

Kazi Ali Toufique, World Development, Vol. 25, No. 3, pp. 457-467, 1997. Some Observations on Power and Property Rights in the Inland Fisheries of Bangladesh

Abu Muhammad Shajaat Ali, Agriculture, Ecosystems and Environment 55 (1995) 95-109. Population Pressure, environmental constraints and agricultural change in Bangladesh: examples from three agroecosystems. 
R. Lal and B.A. Stewart, 1995. Sustainable Management of Soils, Chelsea: CRC Press.

World Bank, 2005. Arsenic Contamination of Groundwater in South and East Asian Countries: Towards a More Effective Operational Response - Volume II: Technical Report

\section{Chapter 6: Institutions for Environmental Management}

ADB, UNDCF et al. (2003). Local Governance and Service Delivery to the Poor: A Bangladesh Case study.

Ahammed, R \& Harvey, N. (2003). EIA in Bangladesh: Evaluation of environmental impact assessment procedures and practice in Bangladesh. Impact Assessment and Project Appraisal. Vol. 22, No.1, 63-78.http://www.elaw.org/resources/text.asp?ID=2016

Bangladesh Enterprise Institute (2006). Survey of Intermediaries and Businesses to Measure Administrative Barriers to Private Sector Development in Bangladesh.

Grindle, M. (1997). Divergent Cultures? When Public Organizations Perform Well in Developing Countries. World Development, Vol. 25, No. 4, pp. 481-485.

Ipe, C. V. (1995). Issues in the Management of Environment and Natural Resources in Bangladesh. Journal of Environmental Management. 45, 319-332.

Lam, K. C. \& Brown, A. L. (1997). EIA in Hong Kong: Effective but Limited. Asian Journal of Environmental Management. 5(1), pp. 51-65.

Matin, M. A. (1995). Environmental Pollution and its Control in Bangladesh. Trends in Analytical Chemistry. Vol. 14, No. 10, pp. 468-473.

Momtaz S. (2002). Environmental impact assessment in Bangladesh: A critical review, Environmental Impact Assessment Review. 22:163-79

Rahman \& Aina. (2005). Inadequacy of Environmental Impact Assessment (EIA) in Bangladesh. http://www.eco-web.com/cgi- local/sfc?a=/editorial/index.html\&b=/editorial/050307.html

Transparency International (TI). (2000). Transparency International Bangladesh News Scan Database, Jan -June 2000. http://www.ti-bangladesh.org/olddocs/newsscan/

Transparency International (2005). Global Corruption Report. http://www.globalcorruptionreport.org/gcr2005/download/english/country_reports_a _.p.pdf

Westergaard, K. \& Mustafa Alam, M. (1995). Local government in Bangladesh: Past experiences and yet another try. World Development, Volume 23, Issue 4: 679-690

Wilson, J. Q. (1989). Bureaucracy: What Government Agencies do and why they do it. Basic Books.

World Bank. (2002). Taming Leviathan: Reforming Governance in Bangladesh. An Institutional Review. The World Bank: Washington D. C. 



